\title{
Method to Monitor Nuclear Power Plant Risk from Transmission Grid Conditions
}

This report describes research sponsored by EPRI and the U.S. Department of Energy (Award No. DE-FC07-03IDI4536). 



\section{Method to Monitor Nuclear Power Plant Risk from Transmission Grid Conditions}

1009662

Final Report, October 2004

Cosponsor

U.S. Department of Energy

Washington, DC

EPRI Project Manager

K. Canavan 


\section{DISCLAIMER OF WARRANTIES AND LIMITATION OF LIABILITIES}

THIS DOCUMENT WAS PREPARED BY THE ORGANIZATION(S) NAMED BELOW AS AN ACCOUNT OF WORK SPONSORED OR COSPONSORED BY THE ELECTRIC POWER RESEARCH INSTITUTE, INC. (EPRI). NEITHER EPRI, ANY MEMBER OF EPRI, ANY COSPONSOR, THE ORGANIZATION(S) BELOW, NOR ANY PERSON ACTING ON BEHALF OF ANY OF THEM:

(A) MAKES ANY WARRANTY OR REPRESENTATION WHATSOEVER, EXPRESS OR IMPLIED, (I) WITH RESPECT TO THE USE OF ANY INFORMATION, APPARATUS, METHOD, PROCESS, OR SIMILAR ITEM DISCLOSED IN THIS DOCUMENT, INCLUDING MERCHANTABILITY AND FITNESS FOR A PARTICULAR PURPOSE, OR (II) THAT SUCH USE DOES NOT INFRINGE ON OR INTERFERE WITH PRIVATELY OWNED RIGHTS, INCLUDING ANY PARTY'S INTELLECTUAL PROPERTY, OR (III) THAT THIS DOCUMENT IS SUITABLE TO ANY PARTICULAR USER'S CIRCUMSTANCE; OR

(B) ASSUMES RESPONSIBILITY FOR ANY DAMAGES OR OTHER LIABILITY WHATSOEVER (INCLUDING ANY CONSEQUENTIAL DAMAGES, EVEN IF EPRI OR ANY EPRI REPRESENTATIVE HAS BEEN ADVISED OF THE POSSIBILITY OF SUCH DAMAGES) RESULTING FROM YOUR SELECTION OR USE OF THIS DOCUMENT OR ANY INFORMATION, APPARATUS, METHOD, PROCESS, OR SIMILAR ITEM DISCLOSED IN THIS DOCUMENT.

ORGANIZATION THAT PREPARED THIS DOCUMENT

Data Systems and Solutions

\section{ORDERING INFORMATION}

Requests for copies of this report should be directed to EPRI Orders and Conferences, 1355 Willow Way, Suite 278, Concord, CA 94520, (800) 313-3774, press 2 or internally x5379, (925) 609-9169, (925) 609-1310 (fax).

Electric Power Research Institute and EPRI are registered service marks of the Electric Power Research Institute, Inc. EPRI. ELECTRIFY THE WORLD is a service mark of the Electric Power Research Institute, Inc.

Copyright (C) 2004 Electric Power Research Institute, Inc. All rights reserved. 


\section{CITATIONS}

This report was prepared by

Data Systems and Solutions

4920 El Camino Real

Los Altos, California 94022

Principal Investigator

B. Gregg

This report describes research sponsored by EPRI and the U.S. Department of Energy (Award No. DE-FC07-03ID14536. Task FY03-11).

Any opinions, findings, and conclusions or recommendations expressed in this material are those of the authors(s) and do not necessarily reflect the views of the Department of Energy.

The report is a corporate document that should be cited in the literature in the following manner:

Method to Monitor Nuclear Power Plant Risk from Transmission Grid Conditions, EPRI, Palo Alto, CA, and U.S. Department of Energy, Washington, DC: 2004. 1009662. 



\section{REPORT SUMMARY}

This report examines a method to monitor and trend the transmission grid in the local vicinity of a nuclear or other generating station. In particular, the method addresses the potential for a conditional loss of off-site power (LOOP) following a plant trip or a loss-of-coolant accident (LOCA). Degraded grid conditions are a Nuclear Regulatory Commission (NRC) safety concern, impeding progress on risk-informed regulations such as those related to emergency diesel operation and loss of off-site power given a LOCA. The purpose of this study is to use existing transmission grid analysis tools such as contingency-analysis programs and state estimators to monitor and trend the condition of the local transmission grid and trend the risk of a loss of off-site power.

\section{Background}

In recent years, deregulation of the electric industry has resulted in changes to the approach to generation and distribution of power. Previously, one power company would both generate and distribute power. Now these functions are often performed by separate entities. The market has resulted in changes to the way that electric grids are being operated other than those for which they were originally designed, including various configurations and load levels. In addition, a desire to risk-inform regulatory practices at nuclear plants has also provided impetus to pursue a more complete understanding of the factors that contribute to the loss of off-site power events. Lastly, a perceived trend in terms of an increasing frequency and duration of loss of off-site power provides another basis for pursuing a tool that can provide an instantaneous picture of the risk for loss of off-site power and, more importantly, an ability to trend this metric over time.

\section{Objectives}

- To produce a tool that is capable of assessing the potential for a conditional loss of off-site power event given a plant trip or LOCA based on current grid conditions

- To produce a tool that is capable of trending the potential for a conditional loss of off-site power for the spectrum of grid conditions and over long periods

\section{Approach}

The management of the risk associated with a concurrent LOCA and a loss of off-site power involves the development of a probabilistic model of the local electrical grid in the vicinity of the nuclear plant. This probabilistic model uses fault tree logic to assess the likelihood of a loss of off-site power as a result of the random failure of grid transmission and distribution equipment or as a result of the transient caused by a plant trip. This model is used as the basis for the gridreliability monitor. The grid monitor is developed in several steps. 
First, a detailed fault tree model of the switchyard is developed. The fault tree identifies and models the electrical transmission lines supplying power to the plant as well as to the switchyard. Next, the desired input from the state estimator is determined. The input consists of results from contingency runs (that is, a transmission line being removed from service) being performed by the program. The results from the contingency runs is a voltage at the plant should the contingency occur. Contingencies that result in reduced voltage (that is, voltage near or below the safety bus set point) are input to the grid monitor. A list of grid-monitor contingencies is identified based on the loss of grid components significant to the plant. These contingencies are added to the state estimator's program to be evaluated periodically.

The fault trees developed for the switchyard and grid are combined into an expanded tree that incorporates the significant contingencies identified. Probabilities are assigned to the specific contingencies, and the combined fault tree determines an overall probability for the loss of offsite power at the nuclear unit's safety buses.

The grid monitor is a software program that provides an interface for the user to easily provide input to the fault tree, calculate the risk of the grid condition and configuration, and evaluate changes in the risk based on switchyard and line configurations or additional contingencies.

\section{Results}

A fully functional grid monitor based on an operating nuclear power plant was constructed. Contingencies of the more significant grid components were identified. A method for identifying additional low-probability contingencies for use in trending was also proposed. A technique was developed for using the output from the state estimator to evaluate risk.

\section{EPRI Perspective}

This study presents a method for a generating station to monitor the conditional probability of a loss of off-site power given a plant trip or LOCA. The method uses existing grid condition monitoring as well as proven risk-monitoring technologies to provide the user with the conditional probability of the loss of off-site power. The grid-reliability monitor is easily developed and deployed, and can be as detailed and plant-specific as the user desires.

The combination of these technologies results in a powerful tool for the monitoring and potential improvement of the local area grid and off-site power reliability. However, given the innovative nature of the work presented, several caveats need to be noted. The first is the fact that the monitor is limited in its assessment to the local area grid. Disturbances wider than the local area, such as grid-wide disturbances, are not reflected in the risk result, and therefore the risk picture remains incomplete. Second, while the grid monitor can be used in an instantaneous manner, this mode of operation is not currently recommended, given the current state of the art of this technology. Decisions reached through the use of the grid monitor should be verified through additional detailed analysis. The primary use of this tool remains the long-term trending of the conditional loss of off-site power probability given a plant trip or LOCA.

\section{Keywords}

Transmission grid

Loss of off-site power

Risk monitor

Probabilistic risk assessment 


\section{CONTENTS}

1 INTRODUCTION

1.1 Grid-Risk Monitoring Concept................................................................ $1-1$

1.2 Description of Phase I................................................................................

1.2.1 Selection and Description of the Phase I Pilot Plant .................................... 1-3

1.2.2 Development of a Hypothetical Plant for Phase I....................................... 1-4

1.2.3 Operation of Contingency-Analysis Program ......................................... 1-4

1.2.4 Development of Risk Model ........................................................... 1-5

1.2.5 Quantification and Evaluation of the Model........................................... 1-6

1.2.6 Conclusions from Phase I ............................................................... 1-6

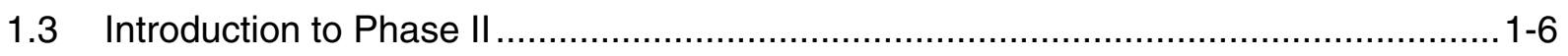

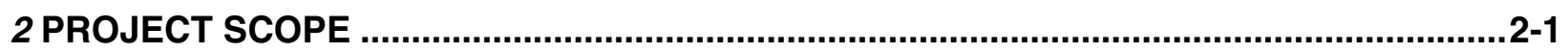

3 ANALYSIS APPROACH .........................................................................................

3.1 Select Site and Establish Project Team ...................................................... 3

3.2 Develop Switchyard Model ................................................................ $3-5$

3.3 Evaluate Performance of the Grid in Relation to Plant .......................................... 3-7

3.4 Evaluate and Quantify the Risk ................................................................ $3-11$

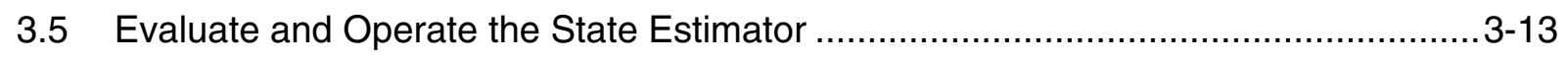

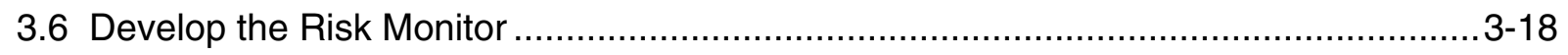

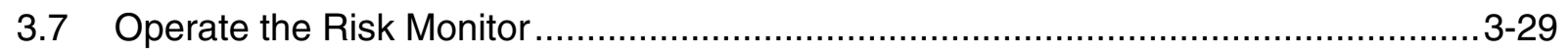

4 GRID MONITOR RESULTS ...........................................................................................

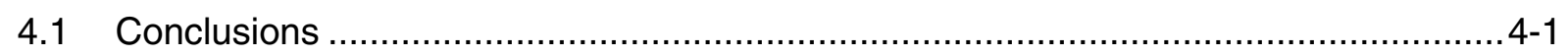

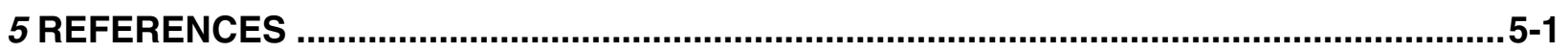


A DETAILED DEVELOPMENT OF SWITCHYARD FAULT TREE ....................................... A-1

A.1 Development of Switchyard Model ............................................................ A 1

A.2 Review and Quantification of the Switchyard Model......................................... A-4

A.3 Development of the Grid Performance Model........................................... A-10

B TRANSMISSION LINE FAILURE RATES ................................................................ B-1 


\section{LIST OF FIGURES}

Figure 1-1 Concept of the Risk Monitor $1-2$

Figure 3-1 Grid Monitor Development Process Diagram ................................................. 3

Figure 3-2 Simplified One-Line Diagram of Pilot Plant Electrical Power.................................. 3-6

Figure 3-3 Grid Near the Nuclear Pilot Plant ........................................................... $3-8$

Figure 3-4 Pilot Plant Operator's Screen ....................................................................

Figure 3-5 Tour of the Grid Monitor .................................................................... $3-21$

Figure 3-6 Tour of the Grid Monitor (Continued) ...................................................... $3-22$

Figure 3-7 Tour of the Grid Monitor (Continued) ........................................................... $3-22$

Figure 3-8 Tour of the Grid Monitor (Continued) ...................................................... $3-23$

Figure 3-9 Tour of the Grid Monitor (Continued) ......................................................... $3-23$

Figure 3-10 Tour of the Grid Monitor (Continued) ........................................................ $3-24$

Figure 3-11 Tour of the Grid Monitor (Continued) ............................................................. 3-24

Figure 3-12 Tour of the Grid Monitor (Continued) .................................................... $3-25$

Figure 3-13 Tour of the Grid Monitor (Continued) ....................................................... $3-25$

Figure 3-14 Tour of the Grid Monitor (Continued) .......................................................... $3-26$

Figure 3-15 Tour of the Grid Monitor (Continued) ..................................................... $3-26$

Figure 3-16 Tour of the Grid Monitor (Continued) ...................................................... $3-27$

Figure 3-17 Tour of the Grid Monitor (Continued) .................................................. $3-27$

Figure 3-18 Tour of the Grid Monitor (Continued) ..................................................... $3-28$

Figure 3-19 Tour of the Grid Monitor (Continued) ........................................................ $3-28$

Figure A-1 Switchyard Fault Tree for Accident Mitigation ................................................. A-2

Figure A-2 Fault Tree for 161-kV Power to SSST .......................................................... A-3

Figure A-3 Fault Tree for 345-kV Power to SSST ....................................................... A-3

Figure A-4 Expansion of Basic Event into Fault Tree for Transmission Line Fault ................ A-10

Figure A-5 Modified Switchyard Fault Tree for Accident Mitigation .................................. A-12

Figure A-6 Modified Fault Tree for 161-kV Power to SSST ............................................. A-13

Figure A-7 Fault Tree for Availability of 345-kV Power ..................................................... A-13

Figure A-8 New Fault Tree for Availability of $69-k V$ Power ............................................ A-14

Figure A-9 Voltage Non-Recovery Probabilities ....................................................... A-15

Figure A-10 Voltage Failure per State Estimator ................................................... A-16

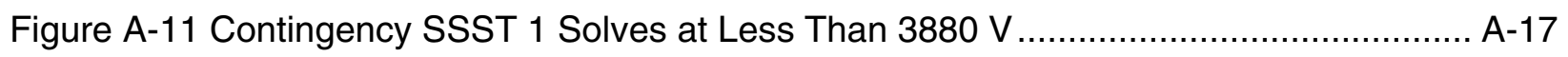

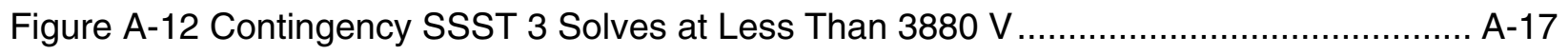


Figure A-13 No Power from Monroeville Line ........................................................ A-18

Figure A-14 Reduced Voltage per State Estimator ................................................. A-18 


\section{LIST OF TABLES}

Table 3-1 List of Transmission Grid Contingencies for Pilot Plant Local Grid.........................3-9

Table 3-2 Final List of Contingencies Used in Pilot Plant Model ......................................... 3-18

Table A-1 Switchyard Fault Tree Model Cutsets ............................................................ A-6

Table A-2 Loss of Off-Site Power to the Switchyard (Sorted by Risk Achievement Worth)...... A-7

Table A-3 Loss of Power to the Switchyard (Sorted by Risk Reduction Worth)..................... A-9

Table B-1 Generic Line Failure Probabilities for 69-kV Lines ........................................... B-2

Table B-2 Generic Line Failure Probabilities for 110-kV to 138-kV Lines ............................. B-3

Table B-3 Generic Line Failure Probabilities for 220-kV to 230-kV Lines ................................ B-4

Table B-4 Generic Line Failure Probabilities for 440-kV to 500-kV Lines ............................. B-5

Table B-5 Grouped Generic Line Failure Probabilities for 69-kV Lines ................................ B-6

Table B-6 Grouped Generic Line Failure Probabilities for 110-kV to 138-kV Lines ................. B-6

Table B-7 Grouped Generic Line Failure Probabilities for 220-kV to 230-kV Lines .................. B-7

Table B-8 Grouped Generic Line Failure Probabilities for 440-kV to 500-kV Lines ................. B-7 



\section{1 \\ INTRODUCTION}

In the 1980s many nuclear plants in the United States began to prepare plant-specific probabilistic risk assessments (PRAs) to evaluate the performance of the plants during accidents. The Nuclear Regulatory Commission (NRC) eventually required all existing plants to perform a systematic examination of their plants to identify any plant-specific vulnerabilities to severe accidents. This process was named an individual plant examination (IPE) [1], and the use of a PRA was the accepted method for its performance.

The PRAs developed during this process have proved extremely useful in many ways. Design weaknesses and low-cost methods to reduce risk were identified. They enabled the plants to quantify risks and thereby place relative values on improvements. This provided a structured method to prioritize projects and determine cost-effective approaches to risk reduction. The use of these PRAs has greatly expanded over the subsequent years.

Originally, the PRA was a static model that used average plant configurations to quantify an annual risk of core damage. For instance, if a pump were determined to be unavailable for an average of six days out of the year, this value would be used in the PRA to calculate the probability of it being unavailable for use during an accident. This was an appropriate method to determine average risk. This view changed with the implementation of the NRC's Maintenance Rule [2]. The Maintenance Rule requires evaluation of plant risk prior to performing maintenance while the plant is operating. The PRA is the natural tool to provide this evaluation. The original PRA models were modified to remove the average maintenance configurations and are now quantified for the actual plant configuration prior to planned maintenance. Emergent conditions are also evaluated for new configurations as they occur. Software tools that used the PRA in this manner are termed "risk monitors." The purpose of this project is to develop a similar tool for use in evaluating risk from the current conditions on the electrical grid connected to the nuclear power plant.

\subsection{Grid-Risk Monitoring Concept}

The general concept of monitoring for the risk of loss of off-site power is to use a combination of the existing grid condition monitoring technologies, such as state estimators and contingencyanalysis programs, and the current risk-monitor software in use at nuclear power stations for compliance with the Maintenance Rule.

State estimators are computer software tools that use data, such as voltage and current measurements, obtained from monitoring equipment, which is physically located on strategic portions of the transmission grid, to extrapolate the conditions throughout the grid. 
Contingency-analysis programs are software tools that allow for an extrapolated or simulated evaluation of the grid performance after some change in grid configuration. For example, the contingency-analysis program provides the projected state of the grid following the loss of an individual line or generating station (a contingency). The program uses the information on current grid conditions from the state estimator to perform this evaluation. A contingency is simply a possible new configuration of the grid based on planned maintenance or a failure of equipment.

In this report, the term state estimator is used to describe the use of both the state estimator and the contingency-analysis program to provide input to the risk monitor. The grid monitor contains logic models (fault trees) of equipment failures and provides an estimate of the average probability for a loss of off-site power due to random failures. The information on the state of the grid generated from the state estimator is used by the risk monitor to estimate the increased risk of the loss of off-site power due to grid conditions. The state estimator can identify contingencies that can create a low-voltage condition at the safety buses of the nuclear unit. The grid monitor uses the probability of occurrence of these contingencies to monitor current risk. This concept is illustrated in Figure 1-1.

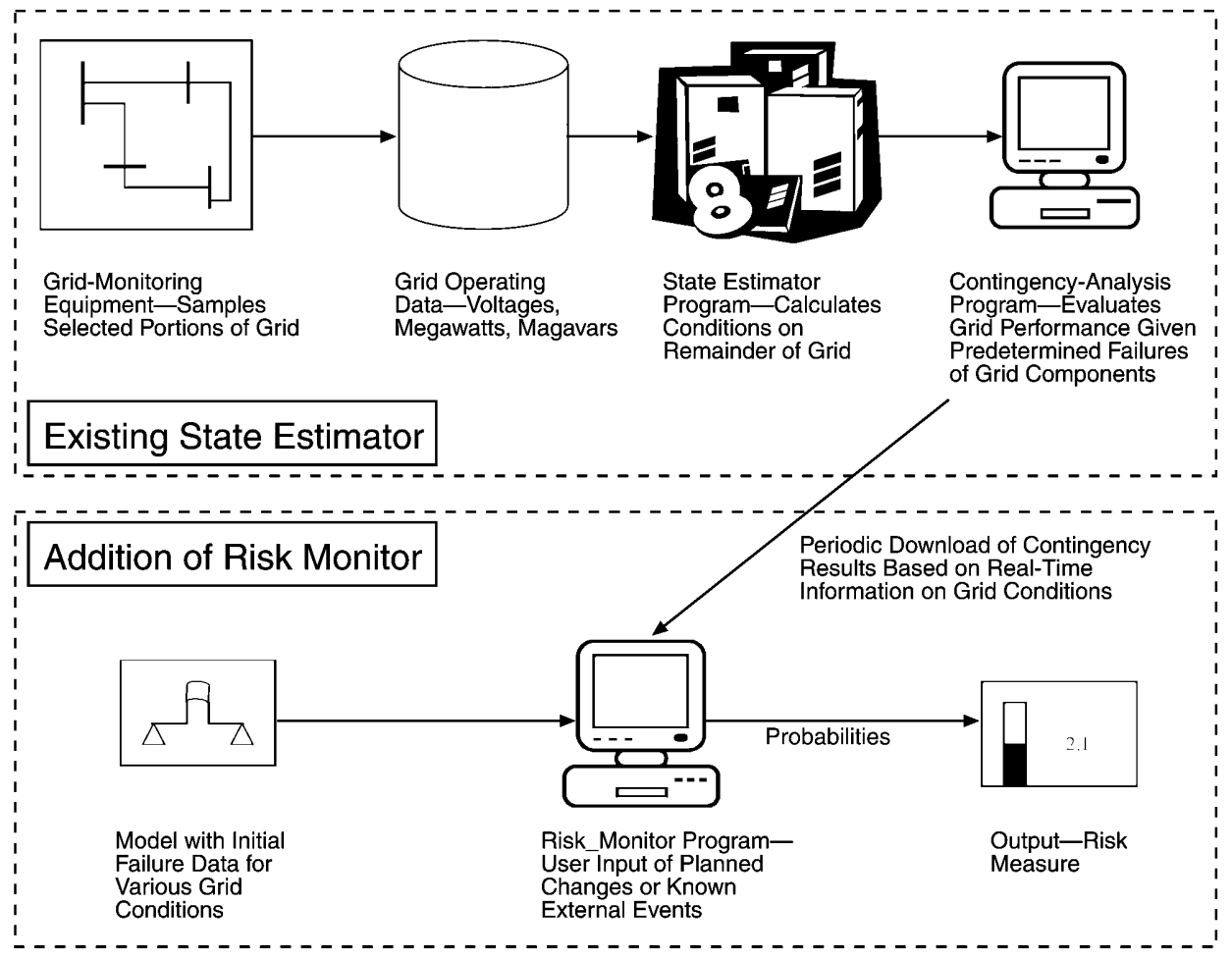

Presently, the state estimator receives current data on the grid conditions from equipment that monitors selected points on the grid. The program takes the current data and calculates overall grid conditions. A contingencyanalysis program can then be used to determine what changes would occur given various known contingencies or grid configurations. The program thus enables the grid operator to make informed decisions regarding removal of equipment or possible problems of which to be aware.

The concept of the grid-reliability or risk monitor is to periodically take this information and evaluate it in relation to the nuclear power plant. By concentrating on the conditions at substations and nearby generating facilities, an estimate is made of the potential to lose offsite power given that the nuclear plant trips and requires offsite power for emergency equipment.

Figure 1-1

Concept of the Risk Monitor 
The objective of this process is to demonstrate the ability to achieve cost and safety benefits for nuclear plant operators from the increasing use of state estimators, contingency analyzers, and related risk-management methods of power grid operators.

The grid-risk monitoring concept was introduced in a proof-of principles study to demonstrate the principles required for a full-scope project. This project was phase I of the more comprehensive study and was performed to determine the optimal path for this development and to reduce uncertainty in the estimation of resources required for the full-scope study. The results of this study are documented in an EPRI report [3]. A brief description of the study is included in the introduction to this report. The important conclusions of that study are:

- The contingency-analysis program is capable of providing the information required by the risk monitor to produce a conditional probability of a loss of off-site power. Of interest to note is that the resulting safety bus voltage is generally no more sensitive to post LOCA loads as compared with normal post-trip transient loads.

- Dynamic evaluations of the short-term voltage transients, as a result of a plant's loss of electrical production (plant trip) as well as short-term transients as a result of other contingencies, demonstrate that the static evaluations of local grid voltage are sufficient surrogates for the determination of a loss of off-site power. This is a result of the fact that the voltage transients are of extremely short duration and do not cause safety bus separation on low voltage.

- The grid configuration and condition prior to the trip were of greater significance than potential electrical transients caused by the loss of electrical production of the pilot plant.

- This study is the second phase of this project and is based on an actual operating nuclear power and the plant's interface with the grid.

\subsection{Description of Phase I}

Phase I is a proof-of-principles study performed to evaluate the capability of existing grid analysis tools and determine the feasibility of using those tools to develop an operating grid-risk monitor. The objectives of the phase I study was to investigate the use of a contingency-analysis program's output for use in risk modeling, determine success criteria for off-site power, and develop a risk monitor based on the output and criteria.

\subsubsection{Selection and Description of the Phase I Pilot Plant}

In the phase I study, a pilot nuclear plant was selected that is located on a $500-\mathrm{kV}$ grid. The site is a dual-unit site with five lines from the grid connected to the plant's switchyard. One of the units is selected as the primary plant, while the other units are considered only for its generation contribution to the grid. The pilot plant utility does not have a state estimator. To determine grid performance, the utility uses an engineering contingency-analysis program, "Power System Simulator for Engineering (PSS/E)," developed by Power Technologies, Inc. This program requires that the user specify power load conditions prior to performing any contingency evaluations. 
Prior to performing grid maintenance, engineering uses the PSS/E program to evaluate power availability. Appropriate load conditions are used along with the expected maintenance configuration. Contingencies are then evaluated. The contingencies used meet the $\mathrm{N}-1$ criteria. The $\mathrm{N}-1$ criteria specify that one additional failure is assumed in addition to the given configuration. Contingencies are evaluated for each major transmission line or generating station to demonstrate that satisfactory voltage conditions would be maintained if the nuclear plant tripped and immediately required power sufficient to meet accident-loading conditions.

\subsubsection{Development of a Hypothetical Plant for Phase I}

For this study, it was necessary to determine the voltages to be expected with more than one additional failure. With five 500-kV lines, it was anticipated that multiple failures would be required before voltage requirements at the nuclear unit's safety buses would not be met. Due to the large number of transmission lines to the plant's switchyard, the potential combinations of off-site power are extensive. Therefore, instead of modeling the actual plant, a hypothetical plant with fewer sources of off-site power is modeled. Two lines were removed from service (not considered in the model) prior to performing contingency evaluations on the remainder of the lines and generating stations. In addition, only one power load (summer peak) configuration was used.

\subsubsection{Operation of Contingency-Analysis Program}

Numerous evaluations were performed to determine final voltages at the plant with multiple line or generating station failures. These evaluations provided information on the combinations of transmission lines that would be successful at supplying the required voltage. Normal grid voltage was $525 \mathrm{kV}$. Low voltage was $490 \mathrm{kV}$, which was used as the failure point. The PSS/E software is capable of performing both "static" final state calculations and "dynamic" evaluations that show conditions as a function of time. Because time was a possible factor in low voltage (a time delay relay of several seconds prevents bus separation on momentary low voltage), several evaluations were performed using both methods. A static evaluation was performed first, followed by an identical dynamic evaluation. The dynamic evaluations show a rapid large voltage drop concurrent with the transient and a rapid recovery to above the final static voltage level within less than one-half second. The final static voltage is achieved a few seconds later after minor oscillations. It was thereby determined that the static evaluations were acceptable to establish the success criteria.

All possible combinations of component failures were evaluated until the failure point was reached. First, all single failures of transmission lines or generating stations were performed; then, combinations of two and three were performed until the evaluations showed unacceptable voltage. These evaluations identify all the combinations of transmission line and generating station failures that result in acceptable conditions. These combinations were used to establish the success criteria for the logic (risk) model. 


\subsubsection{Development of Risk Model}

Using the criteria established previously, a fault tree model was developed to reflect the various combinations of failures that would result in a loss of off-site power to the plant. The primary focus of the fault tree is on the combinations of line and generating station failures from the contingency evaluations. The fault tree also includes a rudimentary model of the switchyard, but this is not developed to any significant degree of detail because it was considered outside the scope of the project.

Transmission line and generating station failure probabilities were assigned based on generic industry data. Various types of line failures are used. Failures due to lightning, high winds, line contamination, and maintenance, as well as random failures such as inadvertent breaker operation, are used. This treatment allows for later adjustment in the grid monitor to actual conditions. For example, during a thunderstorm, the probability of loss due to lightning is greater than the annual average. Probabilities for generating station failures are assigned based on plant trip frequencies. In this manner, a fault tree was constructed using the combinations previously identified.

It is recognized that the fault tree is very limited because the contingencies that were evaluated were based on only a summer peak load at normal voltage levels; therefore, consideration was given as to how to include other conditions. Although the summer peak might initially appear to be a limiting power condition, it is very possible that a low-load condition may be more limiting because there is less power production reserve available. However, at normal voltage, considerable margin exists before an unacceptable low voltage would occur. The exception is during periods when grids are operated at reduced voltage due to high power demands. A method is needed to incorporate these other power loadings and grid voltage conditions.

It was decided to use multiple fault trees for various conditions. In that way, fault tree gates can set to use the tree that is most applicable to current conditions. All of the trees are combined into a single top event for the loss of off-site power, but only the selected tree would be evaluated. To accomplish this, however, requires many more evaluations of the contingency-analysis program. For this initial project, it was decided to limit the development. Only the original evaluations are used, and only a summer peak model is developed.

Various starting voltage conditions are further developed. The original contingency evaluations were used, and proportionate decreases in voltage from various levels were calculated. Starting voltage is modeled in $5-\mathrm{kV}$ increments from the normal $525 \mathrm{kV}$ to a low of $500 \mathrm{kV}$. A new set of success criteria for each incremental voltage decrease was determined in this manner. Separate fault trees were then created for each voltage based on the calculated success criteria. Each fault tree is combined with a basic event for the starting voltage using an "AND" gate. The probability of the starting voltage basic event is based on the portion of the year that that voltage was expected to occur from historical voltage data.

Finally, consideration was given to the possibility of a cascading effect from the failures. The trip of the nuclear unit and its subsequent demand for power creates an initial stress on the grid. If a second failure occurs, the grid is further challenged and subsequent failures are more likely. 
The random failures are low-probability events, and during the short duration of an accident, random failures are highly unlikely to occur. Combinations of random failures are even less probable. Therefore, to model the possible cascading failures, the probability of subsequent failures is increased, based on the occurrence of the first. Because the degree of challenge depends on the first failure, the order of failures is also significant. Each combination of failures is therefore modeled for each possible order of the failures. Probabilities were assigned based on the order. Details of this development are provided in the phase I report [3].

\subsubsection{Quantification and Evaluation of the Model}

After the above development was completed, the fault tree model was ready for quantification. The absolute values of this quantification are not considered of importance because it is only a partial model. Relative contributions of the various events were examined to determine the significant contributors. The primary finding is that the grid configuration prior to the trip was of greater significance than events caused by the trip. This finding is a major factor when designing the model for phase II of this project.

\subsubsection{Conclusions from Phase I}

Based on the above development and evaluation, it was concluded that a contingency-analysis program can provide useful information for calculating the conditional probability of a loss of off-site power. The static voltage evaluations performed using the state estimator and contingency programs are suitable for providing the necessary grid condition information required by the grid-risk monitor. A finding that grid configuration prior to the start of the transient is of the greatest significance gives credence that the use of a state estimator provides a valuable addition to risk monitoring because it provides real-time information that is updated frequently. The phase I pilot recommends that a detailed switchyard model be developed because much of the base risk of a loss of off-site power involves failures in the switchyard and its interface with the nuclear unit and the local area transmission grid.

\subsection{Introduction to Phase II}

Phase II of this project is performed to develop a risk monitor for an operating nuclear plant. Since the completion of the original proof-of-principles study, a major blackout in the Northeast United States caused nine nuclear power plants to trip, with eight of the nine plants losing offsite power. This event increases the concern about the availability of off-site power to the plants. The NRC has recently issued a temporary instruction [4] to the NRC inspection manual to evaluate off-site power system operational readiness. One of the key issues raised by the inspection requirements is the frequency of calculating post-trip voltages. It is intended that this monitor will help address these concerns. Although it is not intended to predict a grid event of the magnitude that occurred in August of 2003, it is believed that the monitor, using current information from a state estimator, will prove of considerable value to maintain awareness of possible undesirable conditions that can lead to a loss of off-site power. 


\section{2 \\ PROJECT SCOPE}

Phase II is designed to demonstrate the ability to achieve cost and safety benefits for nuclear plant operators from the increasing use of electrical grid state estimators and power grid operator risk-management methods. The original proof-of-principles study (phase I) provided evidence that the existing analysis tools are capable of determining increased risk of a conditional loss of off-site power due to changing conditions on the grid. This purpose of this project is to develop a grid monitor for an actual operating plant. Specifically, the following items were included:

- The project is based on a pilot that is an actual operating nuclear power plant and that plant's interface with the grid.

- Site-specific information, where available, is used in the development of the model.

- Modeling of the grid is more extensive to include power sources that are significant to the area grid.

- A detailed switchyard model is developed to provide more accurate modeling of the potential power losses from within the switchyard.

- The fault tree model developed in Computer Aided Fault Tree Analysis (CAFTA) software module of the Risk and Reliability Workstation is capable of supplying probabilistic results for the loss of off-site power to the plant similar to the plant's probabilistic risk assessment model used to calculation core damage frequency.

- The identified contributors and uncertainty information are reviewed to provide specific information to the pilot plant and grid provider as to possible vulnerability and potential improvements.

- A risk monitor is developed to provide relative risk increase due to line configuration, load conditions, and weather. The EPRI Equipment Out Of Service (EOOS) software is used for the construction of this monitor.

- The risk monitor is capable of long-term trending of the probability of a conditional loss of off-site power. 



\section{3 \\ ANALYSIS APPROACH}

The management of the risk associated with a concurrent LOCA and a loss of off-site power involves the development of a probabilistic model of the local electrical grid in the vicinity of the nuclear plant. This probabilistic model uses fault tree logic to assess the likelihood of a loss of off-site power as a result of the random failure of grid transmission and distribution equipment or as a result of the transient caused by a plant trip.

It is essential to differentiate between the modeling of a loss of off-site power due to random events on the grid and the modeling of a conditional loss of off-site power due to the plant trip. The first is beneficial in evaluating the grid design and identifying areas in need of improvement to prevent a loss of power due to outside events. The second is the purpose of the grid monitor. It is intended to assess current grid conditions and identify potential problems caused by the plant trip and subsequent demand for power. This report discusses both but is mainly concerned with the latter.

The general approach described can be used for any power plant with access to the grid provider's state estimator and contingency-analysis programs. The current section of this report discusses this general approach. The approach is then applied to the specific pilot plant of this project. The pilot plant is used for general discussion purposes in the current section of the report, but, to improve readability, some of the details are included as appendices. The selected pilot plant is not identified in this report, and some information has been changed to reflect a hypothetical plant; however, the modeling is based on the actual plant. For the purposes of this report, the analyzed plant is referred to simply as the pilot plant.

The approach used in phase II of this project is similar to that used in the first phase. The primary difference is that the cascading approach used in phase I is not used in this phase. Modeling using the cascading approach results in a complex fault tree that depends on system voltage. The cascading approach was necessary in phase I because the pilot did not have a state estimator that would evaluate predetermined contingencies based on the current grid conditions. In addition, the quantification of the phase I model showed little contribution to the risk from the cascading basic events. Conditions on the grid prior to the trip resulted in the greatest changes in the quantification. Because phase II uses a state estimator, the current grid conditions are provided as an input as well as the grid conditions following any evaluated contingency. Although cascading failures are often observed when the problem originates from a failure on the grid, this model is primarily concerned with the impact on the grid that occurs from the trip of the nuclear unit. This occurrence is not a fault but only a loss of generation combined with the demand for power from the plant. This is the primary contingency that is run on the state estimator. Therefore, including cascading failures within the model would serve to complicate the model without providing useful information to the monitor user. 
The resulting grid-risk monitor development is divided into several steps as discussed below and illustrated in Figure 3-1. Figure 3-1 demonstrates that some of the steps can be performed in parallel and may require iterations in their development. Each of these steps is described in more detail in the subsequent subsections. The steps are:

1. Select the site and establish the project team:

- Plant's system operator uses a state estimator.

- Site PRA personnel develops switchyard model.

- System operating personnel use state estimator and evaluate the grid.

2. Develop a switchyard model:

- Develop detailed model of the plant switchyard.

- Model is to be based on source of power after a plant trip.

- Model is developed to be used as basis for grid monitor.

3. Evaluate performance of the grid in relation to the plant:

- Identify all lines supplying power to the plant.

- Identify other major power supplies on the grid.

- Determine the degree of modeling of grid components.

- Establish a preliminary list of contingencies to be evaluated to reflect the current grid capability to supply power to the plant.

- Include random line failures of power lines connected to the switchyard based on best available information.

4. Evaluate and quantify the risk:

- Quantify the switchyard model to determine sources of risk.

- Expand switchyard model as required to more completely model sources of risk.

5. Evaluate and operate the state estimator:

- Determine the plant's present use of a state estimator.

- Determine the capability of the state estimator in relation to the plant.

- Perform calculations as necessary to determine vulnerabilities.

- Review contingencies and calculations to develop a final list.

6. Develop a risk monitor:

- Determine appropriate modifications to the fault tree to add input from the stateestimator contingencies.

- Insert the developed fault tree into the EOOS computer program. 
- Determine and add the appropriate indicators of risk.

- Provide the necessary input interfaces for operators.

7. Operate risk monitor:

- Risk values obtained from modeling will not include values from the state estimator until actual operation.

- Determine frequency of grid vulnerabilities in the short term.

- Evaluate use to support maintenance decisions.

- $\quad$ Trend to track possible decline in grid capability in the long term.

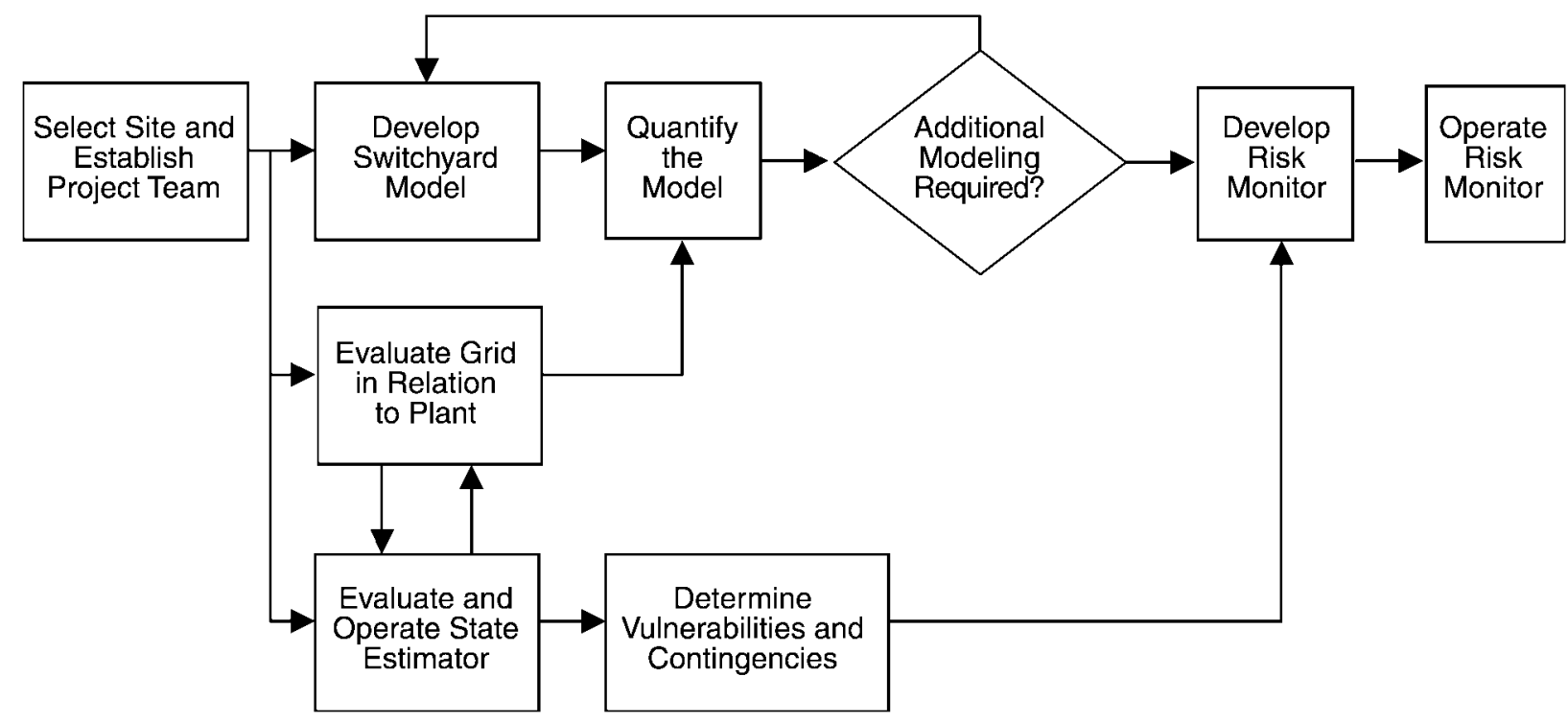

Figure 3-1

Grid Monitor Development Process Diagram

\subsection{Select Site and Establish Project Team}

The first step is the selection of a suitable site. The selected plant must have a grid operator that uses state-estimator and contingency-analysis programs to continuously evaluate the condition of the grid. The grid operator must be willing to participate in the development of the monitor by providing technical information about the grid during the project and agreeing to use the state estimator to provide input to the monitor once development is complete.

The grid operator must be willing to work with the PRA staff by providing information, including but not limited to protective logic of switchyards, information on failure rates of system components, and probability of transmission line faults from various causes. Most utilities collect this type of information to evaluate system reliability, but the degree of detail varies. The more specific the data as to the cause and frequency, the more useful the data in gridmonitor development. 
The grid operator must be also willing to provide the results of the output of the state estimator to the plant when the monitor is in place. Electronic access to this information is highly desirable but not essential. The method of providing this information can range from a system operator providing it verbally to the plant to a fully automated computer interface. Obviously, the more automatic the interface, the more acceptable it will be to both the grid and plant personnel. Most likely, a semiautomatic method will be chosen to expedite the use of the monitor. The nature of the present interface capabilities and plans for the final desired interface should be discussed early in the project.

The plant should have developed or be ready to develop a detailed fault tree model of the switchyard to evaluate the plant-centered loss of off-site power risk and identify the interface with the grid. The switchyard fault tree model is beneficial to the plant regardless of the use of a grid monitor because it can identify the more risk-significant components within the switchyard. This also supplements the plant internal events PRA by completing the plant-centered modeling of a loss of off-site power. The plant PRA staff will be required to develop this model with help from the plant engineers and operators.

Although a switchyard model is not required to use the state estimator information, it is the basis for the grid monitor. The switchyard fault tree provides a base probability for a loss of off-site power from the switchyard. The switchyard fault tree is modified to add the random line faults on the grid. This modified fault tree will provide the base probability for any loss of power.

For the grid-risk monitor, input from the state estimator will also be incorporated into the fault tree. This input has a zero probability of occurrence assigned until the state estimator predicts a potential problem. When this occurs, the input will show an increase in the risk over the base probability. This increase provides a measure of the risk due to grid conditions as opposed to random failures.

The monitor provides a method for non-PRA personnel to input both the state estimator output and other information such as components out of service or weather conditions. The monitor uses the input and recalculates the probability to show the increase in risk due to the current conditions or configuration.

To accomplish the above, a project team consisting of both grid operator and plant personnel is required. The plant PRA staff will be the lead on the project but will need considerable assistance from the grid operator to provide both the information discussed above and knowledge of grid operations. Management support for both will be required to commit the necessary resources.

The pilot plant for this project developed and provided a switchyard fault tree model. The grid operator provided the required support and assistance to build the grid monitor. The state estimator used by the grid operator is already used to evaluate some limited contingencies to assess the power supply to the plant after a plant trip. The state estimator is located solely at the grid operator's system control center. System operators are required to notify the plant if the contingencies indicate possible grid problem on a potential plant trip. There was no capability for an automated interface. 


\subsection{Develop Switchyard Model}

For the most part, development of the switchyard model differs little from the development of a system fault tree for the plant PRA. The switchyard is simply an electrical system with inputs from other systems, the grid, and outputs to the plant transformers. The PRA staff and the electrical system engineers determine the components requiring modeling and potential failure modes. There are, however, some special considerations that differ from most internal plant systems.

Switchyards are designed to both supply and receive power from the grid. The buses are often configured in a ring that provides multiple paths for electrical flow. This creates a problem with the fault tree in that the same power path can circle back on itself, creating a circular logic. Thus a breaker could be seen as supplying power to itself. The fault-tree developer must provide a method to break that logic in his model. In general, the path can be developed up to the point of the originating breaker and stopping at that point.

Another concern based on the same configuration is the isolation of a line fault. If a fault occurs on any of the lines connected to the ring bus and is not isolated, the fault will be sensed on all of the lines. This will result in multiple breakers opening and could easily cause a complete loss of power in the switchyard. In plants using only a single bus tie to connect switchyard buses, this effect may not be as great. This can be conservatively modeled by requiring only one un-isolated line fault to cause this effect. If a less conservative method is used to model the effects of line faults, the protective logic must be well developed in the fault tree. The conservative approach works adequately for the grid monitor because it is evaluating only a conditional loss of off-site power for a short time period. Detailed modeling of the protective logic may be desired, however, if the purpose is to determine vulnerabilities to line faults.

The pilot plant is a single unit nuclear site with a boiling water reactor (BWR) and is located on a major 345-kV transmission path. The pilot plant developed a fault tree model of the plant switchyard that is used in this study as the interface between the plant site and the transmission grid. The fault tree model of the switchyard includes all the components and details required to support the grid-reliability monitor. The conservative method of dealing with line faults is used in this model.

A simplified one-line diagram of the switchyard and plant power is shown in Figure 3-2. The plant is connected to the grid through five $345-\mathrm{kV}$ transmission lines that are joined in the plant's $345-\mathrm{kV}$ switchyard through a ring bus. An autotransformer, located in the switchyard, provides power to a $161-\mathrm{kV}$ switchyard. The $161-\mathrm{kV}$ switchyard is connected to the $161-\mathrm{kV}$ grid by one transmission line. This line is normally used to transmit power to the $161-\mathrm{kV}$ grid but can supply power to the plant if necessary. Finally, there is one $69-\mathrm{kV}$ line that originates from a substation several miles from the plant. This line provides a source of emergency power to the plant's critical buses and also supplies some site non-essential loads. 


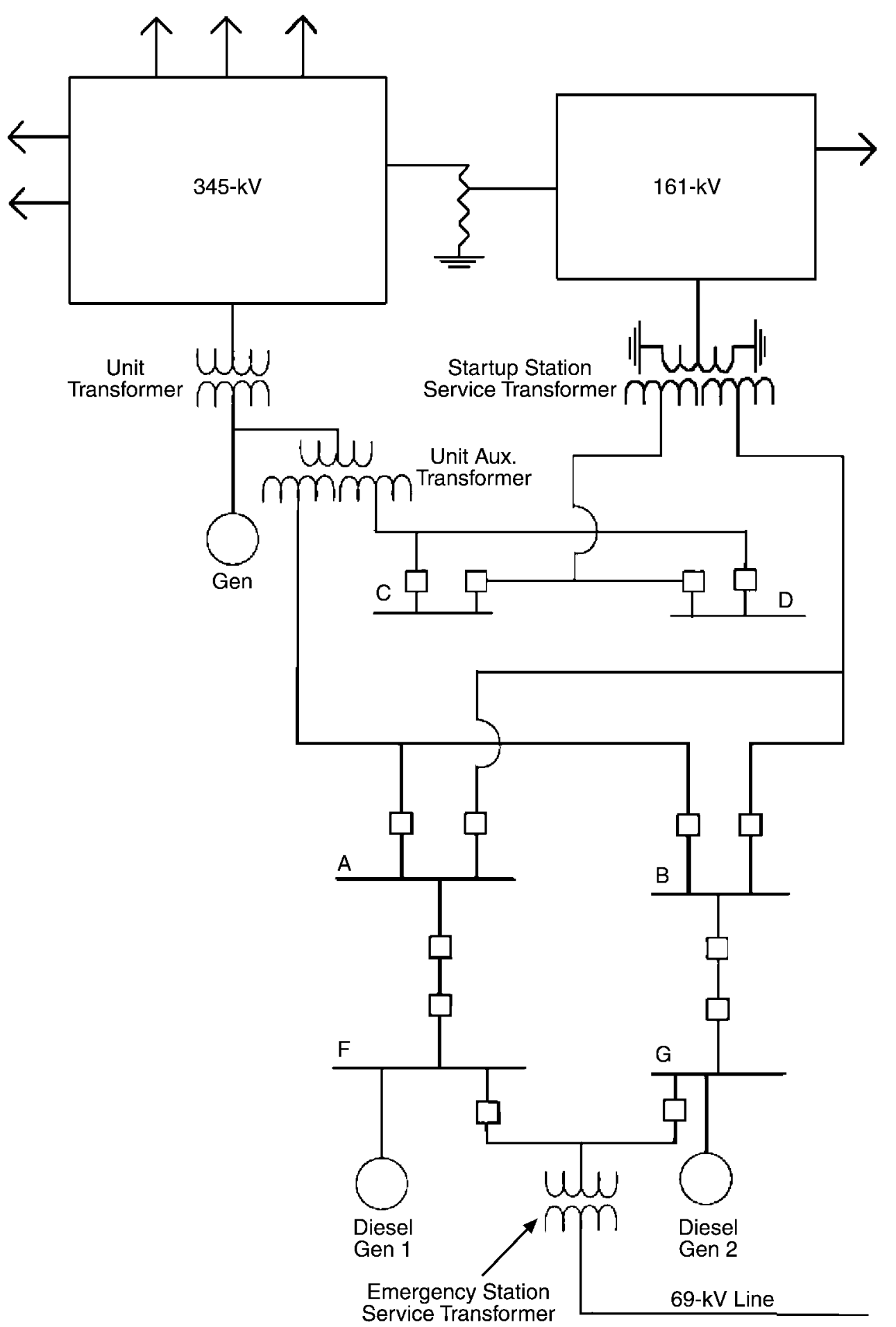

Figure 3-2

Simplified One-Line Diagram of Pilot Plant Electrical Power

Per the pilot plant personnel, any one of the five 345-kV lines is capable of supplying power to the plant that is sufficient to support the LOCA loads. The $161-\mathrm{kV}$ line is also capable of supplying the required power but is not one of the 10CFR50 Appendix A, General Design Criteria (GDC) 17 lines. This line is modeled and credited in the plant PRA. 
Power is provided during normal operation from an auxiliary transformer powered from the main generator. On a plant trip, the auxiliary transformer is isolated along with the main generator. When the auxiliary transformer is not available, a single startup station service transformer (SSST) provides off-site power to all buses. The SSST receives power from the $161-\mathrm{kV}$ switchyard.

When the normal station service transformer is lost, the SSST, which is normally energized, automatically energizes 4160 -volt buses $\mathrm{A}$ and $\mathrm{B}$, as well as their connected loads, including the critical buses. If the SSST fails to energize the critical buses, the emergency station service transformer (ESST), which is normally energized, will automatically energize both critical buses. If the emergency station service transformer were also to fail, the emergency diesel generators (EDGs) automatically energize their respective buses.

The pilot plant provided a detailed fault tree model of the switchyard and its connections to the grid before the start of this project. This model was taken as the basis for further evaluation. The model consists of two fault trees. One is used to determine the initiation of a plant trip based on a loss of off-site power. The second is used as an accident-mitigation fault tree to determine the availability of off-site power for 24 hours after a trip. The second fault tree is used for this study. This fault tree models only the power from the SSST. The ESST is not included. For this project, power to the ESST is added as a separate fault tree.

In addition to switchyard component failures, the fault tree models unavailability of power, unisolated line faults, failure of the SSST during the accident sequence, failure of the power path to the SSST, and maintenance errors within the two switchyards. The tree consists of all significant switchyard components and provides for both fault and power availability inputs from the transmission lines. These inputs provide a point to link the grid faults into the switchyard model. Additional details are presented in Appendix A, Section A.1.

\subsection{Evaluate Performance of the Grid in Relation to Plant}

This step can be performed in parallel with the development of the switchyard model and in conjunction with the next step: Evaluate and operate the state estimator. The grid-operating engineers and the plant electrical engineers have the primary responsibility for these steps. The lines, substations, and generating stations most significant to the nuclear plant need to be identified based on their knowledge and experience of the grid. The layout of the grid is, of course, readily available to them, but it must be determined how much should be modeled.

There are two main objectives to this step. First is to develop a preliminary list of contingencies to be run on the state estimator. Second is to determine the degree of detailed modeling of the grid to be done. In support of the first objective, some investigation of the grid and plant interaction may have already been accomplished. Studies have usually been performed to determine the grid response to a plant trip given various grid configurations. These studies are a good starting point and may be of sufficient depth to identify the important grid configuration and components to be evaluated. If such studies have not already been accomplished, the plant and grid operator engineers must confer on the plant's requirements and the grid's capabilities. The list can be developed based on their judgment and then passed on to the group performing 
the next step: Evaluate and operate the state estimator. With an iterative process between the two groups, a final list can be developed. This process is discussed further in the next section of this report.

A simplified sketch depicting the grid in the area of the pilot plant is shown in Figure 3-3. The pilot plant had previously performed a load-flow study to evaluate the impacts of a pilot plant load rejection and LOCA emergency event on the plant area bus voltages. Two base cases were used for this study: a summer peak 100\% load base case and a summer off-peak $70 \%$ with heavy transfers. Each base case was evaluated with the grid system intact. Then a series of N-1 (a contingency with one additional component out of service) evaluations were performed. The components removed from service for these evaluations were major components in the plant's power supply. They included the autotransformer, each of the five 345-kV lines, and each of the four major generating stations nearby in the grid.

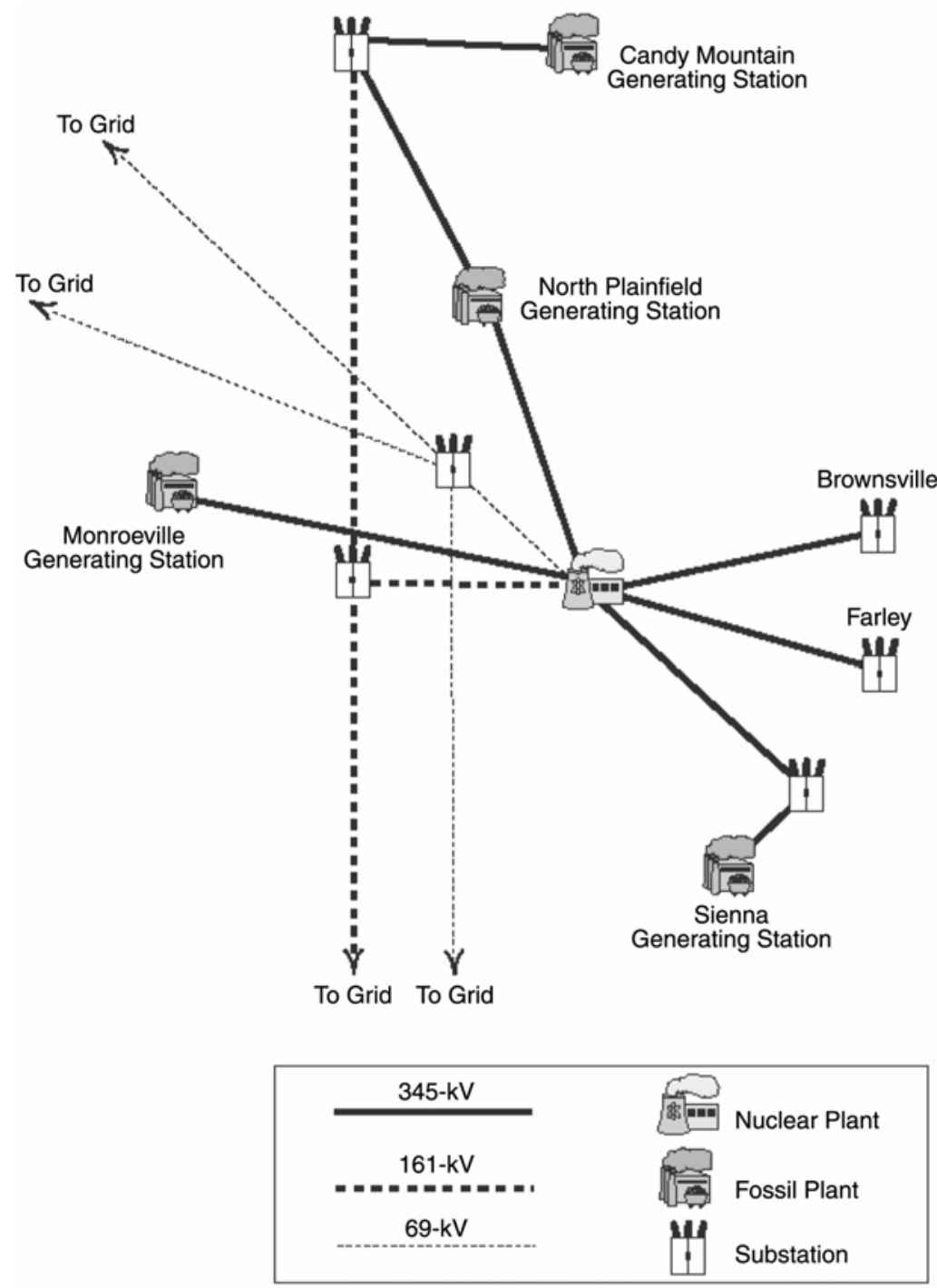

Figure 3-3

Grid Near the Nuclear Pilot Plant 
The base cases coupled with the other outages were determined to be the most limiting conditions with respect to the plant area voltages. The simulations evaluated the time period immediately after the plant load rejection and did not include any reactive switching for voltage control. Post-disturbance voltages were determined for both the SSST and the ESST. The study showed satisfactory voltages for all contingencies. The contingencies consisted of 11 configurations:

- $\quad$ System intact (1)

- Autotransformer unavailable (1)

- $\quad$ Each of the five 345-kV lines unavailable (5)

- $\quad$ Each of the four nearby generating stations out of service (4)

Because these configurations were evaluated for both the SSST and the ESST, there were a total of 22 contingencies.

The N-1 evaluations performed above were chosen for the basic contingencies to be evaluated by the state estimator for input to the grid monitor. Except for the configuration with the system intact, these evaluations are actually N-2 evaluations because they also assume a trip of the pilot plant. During the course of a year, as these contingencies are being evaluated based on actual grid conditions, the contingencies can reflect N-3 or greater because some additional components could be out of service. Each contingency was assigned a simple name for identification in the grid monitor. The contingency names and the components out of service for each are listed in Table 3-1.

Table 3-1

List of Transmission Grid Contingencies for Pilot Plant Local Grid

\begin{tabular}{|l|l|}
\hline Contingency & \multicolumn{1}{|c|}{ Components Out of Service } \\
\hline SSST 1 & System intact \\
\hline SSST 2 & Pilot 345/161-kV autotransformer \\
\hline SSST 3 & Pilot - Monroeville 345-kV line \\
\hline SSST 4 & Pilot - Brownsville 345-kV line \\
\hline SSST 5 & Pilot - North Plainfield 345-kV line \\
\hline SSST 6 & Pilot - Farley 345-kV line \\
\hline SSST 7 & Pilot - Sienna 345-kV line \\
\hline SSST 8 & Monroeville unit off-line \\
\hline SSST 9 & North Plainfield unit off-line \\
\hline SSST 10 & Candy Mountain unit \#3 off-line \\
\hline
\end{tabular}


Table 3-1 (cont.)

List of Transmission Grid Contingencies for Pilot Plant Local Grid

\begin{tabular}{|l|l|}
\hline Contingency & \multicolumn{1}{|c|}{ Components Out of Service } \\
\hline SSST 11 & Sienna unit off-line \\
\hline ESST 1 & System intact \\
\hline ESST 2 & Pilot 345/161-kV autotransformer \\
\hline ESST 3 & Pilot - Monroeville 345-kV line \\
\hline ESST 4 & Pilot - Brownsville 345-kV line \\
\hline ESST 5 & Pilot - North Plainfield 345-kV line \\
\hline ESST 6 & Pilot - Farley 345-kV line \\
\hline ESST 7 & Pilot - Sienna 345-kV line \\
\hline ESST 8 & Monroeville unit off-line \\
\hline ESST 9 & North Plainfield unit off-line \\
\hline ESST 10 & Candy Mountain unit \#3 off-line \\
\hline ESST 11 & Sienna unit off-line \\
\hline
\end{tabular}

The second objective is to make a preliminary determination of the degree of modeling of the grid to be accomplished. As mentioned in the introduction, the purpose of the grid monitor is to evaluate current grid conditions to determine the potential for a conditional loss of off-site power. The actual configuration of the transmission lines and the availability of other generation are used by the state estimator for evaluations. While general modeling of the significant components is sufficient for the grid monitor fault tree, detailed fault trees provide greater degree of information about the grid. A greater resolution within the results can be used to determine more detailed insights concerning the conditional loss of off-site power.

Detailed fault tree development of the grid can be resource-intensive, so the degree of modeling should be based on the expected return on the modeling. The greater the concern over the grid vulnerabilities, the more likely detailed modeling will be beneficial. The number and the independence of the transmission lines supplying power should be a primary consideration. For example, a plant with multiple transmission lines going to independent sections of the grid may decide that generic line failures may be satisfactory. A plant with limited ties to the transmission system or with lines concentrated in a small section of the grid should perform additional grid modeling to determine possible common-cause failures beyond the plant switchyard.

Unless there is a definite need for detailed modeling, the decision can be postponed until the switchyard model is completed and quantified. The quantification of the fault tree can provide additional indication of the value of additional details in the model. The minimal amount of 
modeling required for input into the switchyard model is the lines supplying power to the switchyard and some failure probability for those lines.

Once the degree of modeling has been determined, data should be gathered for input to the switchyard model. Grid providers generally gather this type of data for use in grid reliability. The data should be as grid-specific as possible because each grid will have varying degrees of concern over different causes of line faults. Some grids may be vulnerable to tornados, and others may be more concerned with hurricanes. If more detailed modeling is warranted, the above data are still required, but additional information must also be obtained. A detailed fault tree for a generating station switchyard or a substation will require the modeling of the protective logic for that station. The PRA staff will be required to work with the grid operator engineers to determine the type and amount of information that will be modeled.

Because of limited resources, the pilot plant elected to do general modeling of the grid unless the quantification proved that more modeling was warranted. It was originally intended to use the pilot grid-specific transmission line reliability data for the basic events in these trees. However, the pilot did not have ready access to these data. The pilot intends to obtain and use the plantspecific data at a later time if necessary. Therefore, for this project, generic data were used. If the modeling will be limited to generic data, an acceptable source of that data needs to be identified. The data used in this study were developed from a transmission power quality project study performed by Electrotek Concepts [5]. This is the same source used for phase I of the project and is discussed in the phase I report [3]. This phase required additional transmission voltages. Both the original information from phase I and the further development of these data are included in Appendix B.

\subsection{Evaluate and Quantify the Risk}

Once all of the inputs into the switchyard model have been added, the fault tree should be quantified to determine sources of risk. Quantification identifies sets of components whose combined failure results in failure of the overall event or loss of power to the switchyard. These sets of components are called cutsets. Cutsets show minimal combinations of components required to cause failure. A first-order cutset is a single component that results in failure, second order, combinations of two, and so forth. A report can be generated that ranks them in order of contribution to risk.

Other measures of importance can also be identified after quantification. Two of these are the risk achievement worth (RAW) and the risk reduction worth (RRW). Reports can also be generated for these importance measures and sorted in order of decreasing values of the measures.

Risk achievement worth is a multiplier of the basic risk that indicates how much risk increases if that component's failure probability is increased to one or certain failure. For example, with a basic risk of 1E-06, a component with a RAW of 10 would increase the overall risk to $1 \mathrm{E}-5$ if it were out of service or its failure probability increased to one. Risk achievement worth is a good measure for decisions on performing maintenance. 
Risk reduction worth is a divider of the basic risk that indicates how much the risk is reduced when the component never fails. Using the same example basic risk, a RRW of 2 would result in a reduction of risk to 5E-07 if the component were infallible. Risk reduction worth is a good measure for determining when increasing the reliability of a component is warranted.

The purpose of examining the cutset and importance reports is to determine where improvements or design changes can best improve grid reliability. In addition, examination of the cutsets and importance reports can also be used to determine where additional refinement of the model is required. For the purposes of developing a grid monitor, the latter is of most interest.

Assuming that the switchyard components are modeled in sufficient detail, the cutset and importance reports provide information regarding the relative importance of the grid connections to the switchyard model. Even if the grid connections are developed only as simple basic events, with a realistic failure value, the reports can provide indication that additional modeling may be required. For example, if one transmission line shows a high value in any of the reports, additional modeling of details on that line and its off-site components may be warranted. This could both identify additional areas for improvements and more accurately determine the actual failure probability. If none of the lines show a high significance, the switchyard model is of sufficient detail to establish a reasonable base risk value for use with the grid monitor.

The quantification is performed for the pilot plant, and it was determined that, with the exception of the SSST itself, all of the components shown of high importance are located in the 161-kV switchyard. The only transmission line in the importance measures is the $161-\mathrm{kV}$ line. The unavailability of this line contributes to the risk, although not significantly. This line appears in many of the second-order cutsets in combination with components that fail the 345-kV path (such as the autotransformer). Failure of the autotransformer increases the significance of this line substantially. Therefore, it was determined that additional modeling of the line was warranted.

A breaker failure in the substation where the $161-\mathrm{kV}$ transmission line terminates would have an equivalent effect on availability but was not included in the switchyard model. Therefore, additional components were added to reflect possible additional failures at the substation. At the substation there are two breakers supplying this line, so an additional common cause failure would be required. For this reason, modeling was not extended beyond this point.

The quantification used a truncation limit of $1 \mathrm{E}-16$. That is, any cutsets with lower values were not evaluated. The 345-kV lines do not show up in any cutsets until the E-15 probability level is reached. These cutsets are a $345-\mathrm{kV}$ line fault combined with multiple failures of switchyard breakers to isolate the fault. The $345-\mathrm{kV}$ lines did not appear at all as a single-order cutset. From these results it was determined that detailed modeling of the $345-\mathrm{kV}$ off-site transmission components would not contribute to the model. 
The final modifications to the original model were performed for completeness for use in a risk monitor. The original switchyard model did not include any modeling of the ESST line. This is because it does not connect through the plant's switchyards but directly to the plant's ESST from a substation several miles away. A simple model for this line was developed for inclusion in the risk monitor.

Additional details regarding the quantification and fault tree changes are included in Appendix A, Section A.2.

\subsection{Evaluate and Operate the State Estimator}

The next step is the evaluation of the pilot plant's state estimator and its contingency-analysis program. This consists of reviewing the capabilities of the state estimator and how it is presently being used. All that is required is a meeting with the grid operator's personnel in charge of the state estimator. The project team presents the grid-monitoring concept and the type of output required from the state estimator and then discusses how this can be accomplished. Following are some types of information that would be useful to discuss in this meeting:

- Present use

- Monitoring and evaluating current conditions only

- Short-term outage planning

- Long-term outage planning

- Types of contingencies presently run:

- N-1 only

- Special contingencies based on experience

- Frequency of runs:

- Frequency of grid data update

- Frequency of contingency runs

- Burden on the computer from additional contingencies:

- Quantity of contingencies presently run

- Increase in running time due to additional contingencies

- Difficulty of adding contingencies

- Type of output from the program:

- Simple success or failure output

- Details on failed contingencies 
- Use of the output from the program:

- Grid system operator use only

- Communication to generating plants

- Communication to other grid operators

- Capability of data savings from runs:

- What data are saved, if any

- Automatic data saving

- Manual data saving

- Archiving of data

- Ability to access the program output remotely:

- Physical location of state estimator computer

- Network access to state estimator or its output

- Reliability of the program:

- Unavailability of program

- Frequency of failure to solve

- Actions on unavailability and failure to solve

- Any concerns regarding capabilities in plant grid proximity:

- Availability of grid data from adjacent grid operators

- Adequate instrumentation for real data

- Static inputs used for some interfaces

The second purpose of this task is to identify the level of failures required to cause low-voltage conditions. Once it is determined that the state estimator is capable of supplying the required information for the monitor, it should be decided whether the program is the proper one to be used to identify additional contingencies for the grid monitor.

State estimators generally have a "what if" capability used to determine the impact of discretionary maintenance prior to entering that condition. This can also be used to evaluate hypothetical conditions for long-term planning but may not be best suited for this purpose.

In phase I of this project, an engineering contingency-analysis program was used to evaluate contingencies. This program requires that a grid loading condition be loaded to evaluate the contingencies. It is a common tool used for planning outages and to evaluate the grid performance given projected changes in power demands over time. In phase I, a summer loading case was used to determine the contingencies that could cause a loss of off-site power. This type of tool can also be used to identify the additional contingencies to be run on the state estimator. The engineers who normally use this tool can provide a great deal of insight into what power loads and which contingencies are of interest. 
Based on the capabilities of both programs, one should be selected to identify the additional contingencies. Contingencies that always fail would provide only nuisance information. The goal is to identify contingencies that will usually be satisfactory but that solve at reduced voltage under some circumstances. These may be highly unlikely events requiring the failure of multiple components. The purpose of identifying these types of failures is to provide a trending capability for the grid monitor. This is discussed in more detail below in the pilot plant.

The grid operator for the pilot plant uses a state estimator that models current grid conditions. The contingency-analysis program models the impact of a defined set of contingencies on the model. The grid operators are satisfied that the two programs provide a reliable assessment of the grid performance. The contingency-analysis program operates every 10 minutes and following system configuration changes. The program is somewhat limited, however, in its reporting capabilities. Contingencies that have predicted loading or voltage violations are reported to the system operator via a violation summary display. Only contingencies that fail (that is, result in voltages lower than the pilot plant safety bus undervoltage setpoint) are reported, and this output goes to a system operator's computer screen. The data are not saved, and hard copies are available only if the operator chooses to print the results. The system operator must notify the pilot plant if a contingency affecting the plant has failed. The pilot plant has no direct method of obtaining information from these programs.

The pilot plant has an emergency procedure that uses results from the state estimator program to determine when there is a potential for low voltage due to grid conditions. This procedure is based on three of the contingencies that are evaluated by the state estimator. Each of these contingencies specifies a pilot plant trip and accident loading of the associated transformers. System operators are required to monitor the contingency program at least once per hour and notify the pilot plant control room if a violation occurs. The three contingencies are:

- Pilot plant off-line: Resultant voltage from the SSST <95\% of $4160 \mathrm{~V}$ with post-trip station service load on SSST

- Pilot plant off-line: Resultant voltage from the ESST $<95 \%$ of $4160 \mathrm{~V}$ with post-trip station service load on ESST

- Pilot plant off-line and autotransformer open: Resultant voltage from the ESST $<95 \%$ of $4160 \mathrm{~V}$ with post-trip station service load on ESST

The contingencies report out when the solved voltage is $3950 \mathrm{~V}$ or less. The actual low-voltage setpoint is $3880 \mathrm{~V}$, leaving a substantial margin for reporting. No action is taken unless actual voltage is decreasing, but if the contingencies solve at $3920 \mathrm{~V}$ or less, the corresponding transformer is declared inoperable, and the appropriate limiting condition of operation (LCO) is entered. None of the plant personnel can remember an occurrence of these contingencies being reported.

To provide meaningful input to the grid monitor, it is necessary to identify marginal configurations that could result in unacceptable voltage, depending on the grid conditions. The above contingencies provide a good basis for ensuring that the grid is capable of responding to a plant trip but will normally provide no information on degrading grid conditions. It is desirable 
that the grid monitor be capable of indicating small increments of risk increase. Therefore, it is necessary to evaluate various configurations to determine how many failures would challenge the grid's capabilities.

The original approach planned to do evaluations using the state estimator and its contingencyanalysis program. The grid operator, however, believed that their engineering contingencyanalysis program was more appropriate for the task. Evaluations performed by the state estimator are based on the grid conditions presently existing. These would not provide significant information. During normal grid conditions, even multiple failures may result in acceptable voltage. The purpose of this project is to identify minimum combinations of failures that may impact the grid, even if only under unusual conditions. Once these configurations are identified, they can be used as additional contingencies that are evaluated by the programs.

Based on the proof-of principles study, an engineering contingency-analysis program can provide the information required and can be evaluated simulating high demand loads or other configurations of interest. It was therefore decided that the grid operator's engineering analysis program could be used for any required evaluations of the grid performance.

For this project, it would be desirable to identify additional contingencies greater than the N-2 evaluations in the preliminary list. Although these evaluations would provide sufficient input to detect higher-risk configurations, it is expected that the contingencies would not report out frequently. This is desirable to the pilot plant because its state estimator programs require action by system operators when they receive a report. The system operators should not be burdened with reporting failed contingencies of very low probability. Infrequent failures, however, do not provide a very good basis for trending.

It is advantageous to get failures on very low probability events because they will provide trending information about the grid. A pattern of failures will identify seasons, loading conditions, and other variables that are influencing grid performance. After a normal pattern of these failures is established, deviations from that pattern could indicate that the grid performance, although still robust, is weakening over time or is just vulnerable under certain conditions. New load conditions, changes in demand, actual equipment failures due to age, or other negative changes could be occurring without being readily apparent. If these could be trended automatically by the computer program, this information could be gathered and evaluated periodically.

The pilot plant agreed that the information would be of value and would be worth saving, if it could be done without excessive human effort. Although its present program could not perform this trending, it is planning an upgrade and would consider doing this if it is possible. At the time of this report, however, other priorities by the grid operator prevented doing additional evaluations. For future use, an approach was proposed to accomplish this task using the engineering contingency-analysis program.

The purpose of these evaluations is to determine the number of failures that would be required to threaten the power availability at the plant during an accident. It is not to identify configurations 
where the contingency program would fail to solve but rather where it solves at a reduced voltage. A total failure to solve may just be a result of the program's capability.

First, evaluations based on combinations of the same set of components used in the previous load-flow study were considered. Again, these should be evaluated at both the SSST and the ESST. Using possible combinations of all ten components, however, would result in a prohibitive number of evaluations. Therefore, the evaluations were proposed to be limited using the following basis:

- Because the autotransformer being out of service effectively removes five 345-kV lines, no other combinations with this component were deemed to be necessary.

- To prove the capability of each of the $345-\mathrm{kV}$ lines, five cases are required, one for each line being the only one available. It is to be expected that these evaluations would all show success. If this is the result, it would be determined that no combination of these lines would be worth evaluating. The probability of losing all five lines even with a common cause is negligible in the short period following an accident. Common-cause failures of multiple lines would usually be a result of an un-isolated line fault, not a plant scram.

- Finally, the four generating stations were considered. To determine the effects of the loss of these stations, only the following 11 cases would have to be evaluated, because all of the singles had already been done:

- Six groups of two:

o Generating Station A and Generating Station B

o Generating Station A and Generating Station C

o Generating Station A and Generating Station D

o Generating Station B and Generating Station C

o Generating Station B and Generating Station D

o Generating Station C and Generating Station D

- Four groups of three:

o Generating Station A, Generating Station B, and Generating Station C

o Generating Station A, Generating Station B, and Generating Station D

o Generating Station A, Generating Station C, and Generating Station D

o Generating Station B, Generating Station C, and Generating Station D

- One group of four:

o Generating Station A, Generating Station B, Generating Station C, and Generating Station D 
In addition to the above evaluations, the pilot plant suggested that it would be worthwhile to consider the grid supplying the $161-\mathrm{kV}$ line. Although this power source is not a general design criteria (GDC 17) source of power, it does supply a backup to the auto transformer. Although this line is not a high contributor to the risk, contingencies affecting this line could also be useful for trending.

Once the additional contingencies are identified, they can be added to the fault tree developed for the risk monitor. Even when these report out of the state estimator as failed, these will not cause any significant increase in the overall risk because of the multiple additional failures that would be required. In these cases, however, common-cause failure should be considered for inclusion when appropriate.

\subsection{Develop the Risk Monitor}

The risk monitor uses both the switchyard/grid fault tree and the contingencies developed in the previous steps. It is now necessary to provide a method for input of the state estimator information. This requires another modification to the fault tree.

The contingencies were listed in Table 3-1. This table is repeated here as Table 3-2 for the convenience of the reader. Details about the fault tree model are again presented in Appendix A, Section A.3. This section provides a limited, general discussion.

Table 3-2

Final List of Contingencies Used in Pilot Plant Model

\begin{tabular}{|l|l|}
\hline Contingency & \multicolumn{1}{|c|}{ Components Out of Service } \\
\hline SSST 1 & System intact \\
\hline SSST 2 & Pilot 345/161-kV autotransformer \\
\hline SSST 3 & Pilot - Monroeville 345-kV line \\
\hline SSST 4 & Pilot - Brownsville 345-kV line \\
\hline SSST 5 & Pilot - North Plainfield 345-kV line \\
\hline SSST 6 & Pilot - Farley 345-kV line \\
\hline SSST 7 & Pilot - Sienna 345-kV line \\
\hline SSST 8 & Monroeville unit off-line \\
\hline SSST 9 & North Plainfield unit off-line \\
\hline SSST 10 & Candy Mountain unit \#3 off-line \\
\hline
\end{tabular}


Table 3-2 (cont.)

Final List of Contingencies Used in Pilot Plant Model

\begin{tabular}{|l|l|}
\hline SSST 11 & Sienna unit off-line \\
\hline ESST 1 & System intact \\
\hline ESST 2 & Pilot 345/161-kV autotransformer \\
\hline ESST 3 & Pilot - Monroeville 345-kV line \\
\hline ESST 4 & Pilot - Brownsville 345-kV line \\
\hline ESST 5 & Pilot - North Plainfield 345-kV line \\
\hline ESST 6 & Pilot - Farley 345-kV line \\
\hline ESST 7 & Pilot - Sienna 345-kV line \\
\hline ESST 8 & Monroeville unit off-line \\
\hline ESST 9 & North Plainfield unit off-line \\
\hline ESST 10 & Candy Mountain unit \#3 off-line \\
\hline ESST 11 & Sienna unit off-line \\
\hline
\end{tabular}

The contingencies are arranged in two basic groups, voltage at the SSST and voltage at the ESST. All of the ESST contingencies address only the availability of the 69-kV line. Of the SSST contingencies, one is unique. SSST 2 is based on the autotransformer being out of service. It is therefore evaluating only the availability of the $161-\mathrm{kV}$ line. All of the other SSST contingencies evaluate the availability of both the $345-\mathrm{kV}$ and the $161-\mathrm{kV}$ lines. This results in one group for the 69-kV line, one group for the 345/161-kV lines, and a single contingency for the $161-\mathrm{kV}$ line. Each of these is added to the fault tree in the appropriate position to model failure of those respective lines.

All of the contingencies except the SSST 1 and the ESST 2 require a failure of an additional component, line, or generating station. The probability of these failures is added as a basic event and combined with its respective contingency.

Each contingency is set to be false or zero probability. Therefore, the fault tree will receive no failure probability from this combined input until the contingency is set to true (input from the grid monitor operator) or a probability of one. The combined probability will then have the value of the component basic event failure.

Finally, the grid monitor must take the resultant voltage predicted by the state estimator into consideration. When the state estimator solves at voltages at $3880 \mathrm{~V}$ or less, it is predicting that voltage at the transformer will be inadequate and a loss of off-site power will occur. When it solves at voltages from $3880 \mathrm{~V}$ to $3950 \mathrm{~V}$, it is not predicting a failure. It is, however, indicating grid degradation. Although voltage recovery is likely under this condition, there is still increased 
probability that further degradation and loss of off-site power could occur. When this occurs, the monitor must predict the increase in its probability. A second fault tree provides a probability of voltage recovery from the reduced voltage. This is combined with the contingency information to provide the new failure probability.

After the above changes to the fault tree are accomplished, the tree is ready to be used in the grid monitor. The fault tree has the base failure probability from the switchyard and grid components. It can now have additional failure probability added from the use of the state estimator. This is accomplished by using the grid-risk monitor.

The grid-risk monitor is developed using the EPRI EOOS software. EOOS is one of EPRI's Risk and Reliability Analysis Workstation products and is a computer program for monitoring safety. It uses a CAFTA fault tree model but provides an interface that makes the fault tree usable by non-PRA experts. An operator panel, which can be readily adapted to an individual utility's requirements, allows easy user input to the fault tree.

The fault tree discussed above was used as the basis for this monitor. The operator's panel developed for the pilot station is shown in Figure 3-4. The fault tree is invisible to the operator but provides the results that will be displayed on this screen. The fault tree will recalculate the risk based on the operator's input. This screen can be customized for any utility, depending on the information and operability desired.

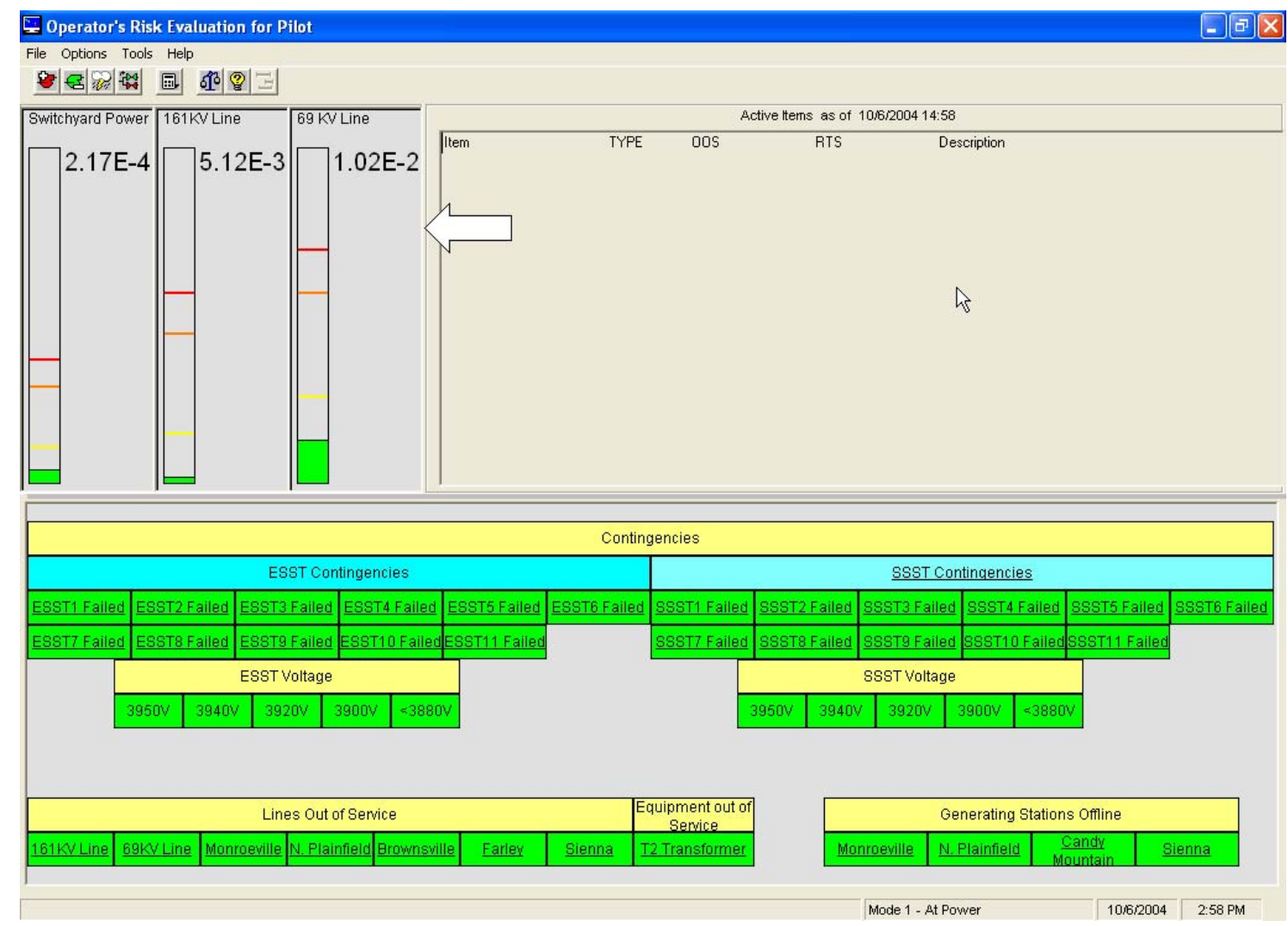

Figure 3-4

Pilot Plant Operator's Screen 
The section of the screen, indicated by the white arrow, is the risk meter. The pilot plant's meter is designed around the three sources of power to the plant. The meter to the far left shows the probability of a loss of power to the SSST during the 24-hour mission time. It includes both $345-\mathrm{kV}$ and $161-\mathrm{kV}$ power sources. The meter immediately to the right shows the probability for loss of the $161-\mathrm{kV}$ line and the left most line, the probability for loss of the $69-\mathrm{kV}$ line. These are conditional probabilities given that a plant trip occurs. The probabilities shown are the base values and include only the risk from the switchyard and random line failures. Grid performance is not included because the contingencies are all set to false and do not contribute to the risk.

The risk meter can be easily changed to provide other indicators. A plant with only one voltage level of off-site power may desire only a single meter. With additional modeling, indicators could be divided to show risk from the grid, weather, and plant centered. The information displayed is determined by the user and can be modified later if desired.

The bottom of the screen contains buttons that can change the input and indicator windows that will display status as changes are entered. The lighter color sections are simply labels. The contingencies, lines-out of service, equipment-out of service, and the generating stations off-line are all buttons. These can be clicked to change the status of those items. The ESST and the SSST contingency voltages are status windows. The correct voltage must be selected through the alignment function of the monitor. Figures 3-5 through 3-19 provide a general tour of the monitor's operation.

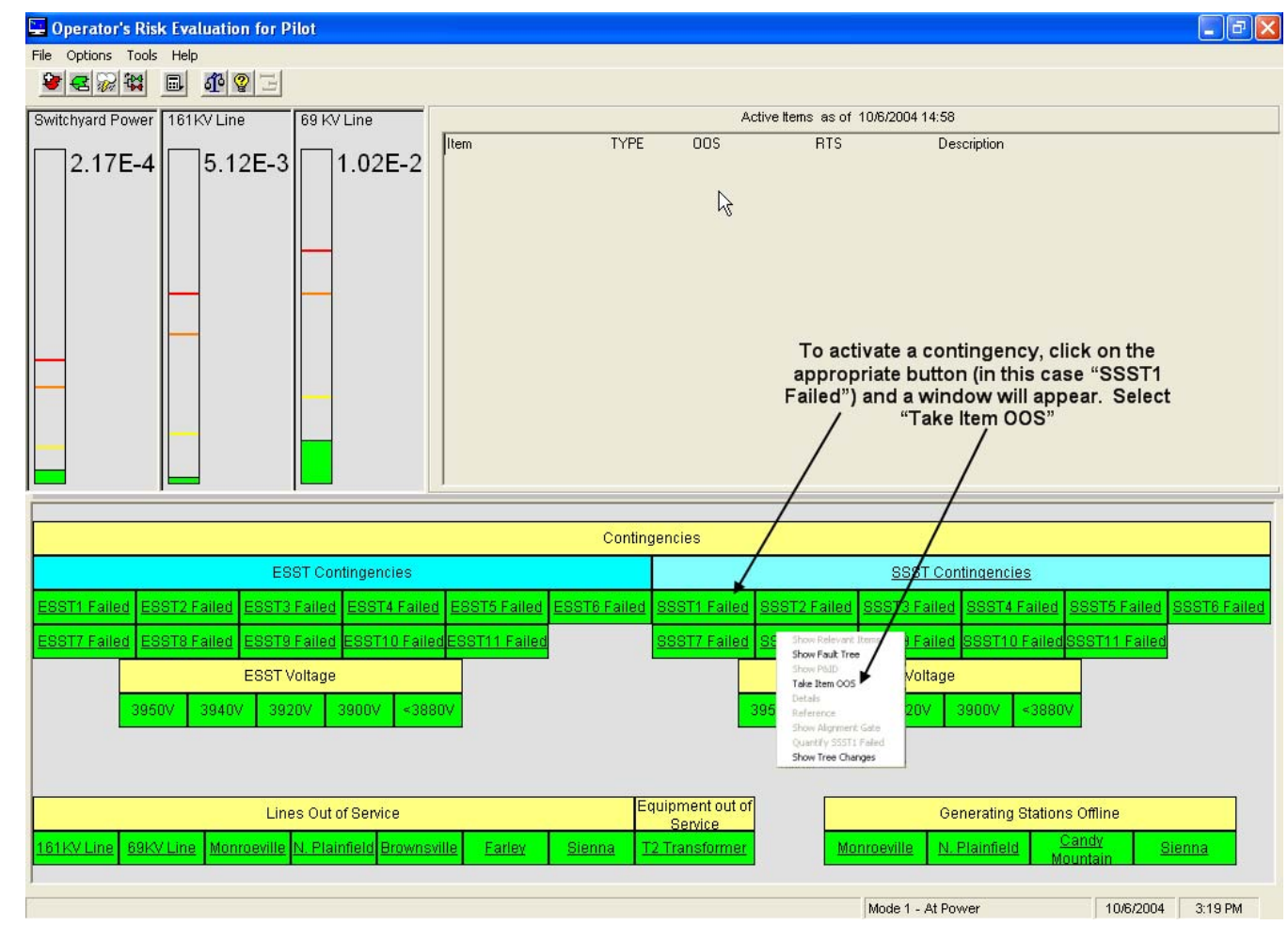

Figure 3-5

Tour of the Grid Monitor 
Analysis Approach

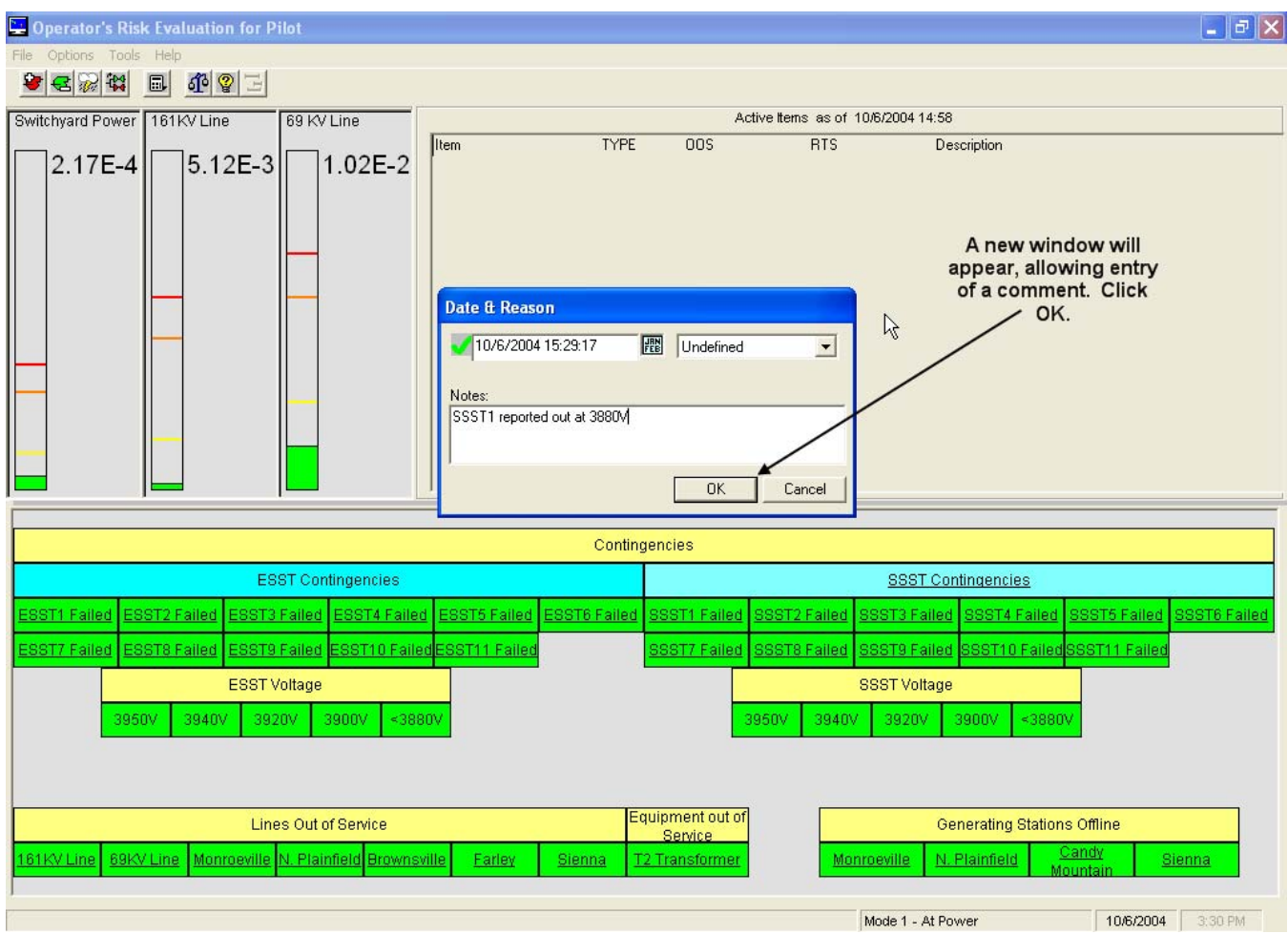

Figure 3-6

Tour of the Grid Monitor (Continued)

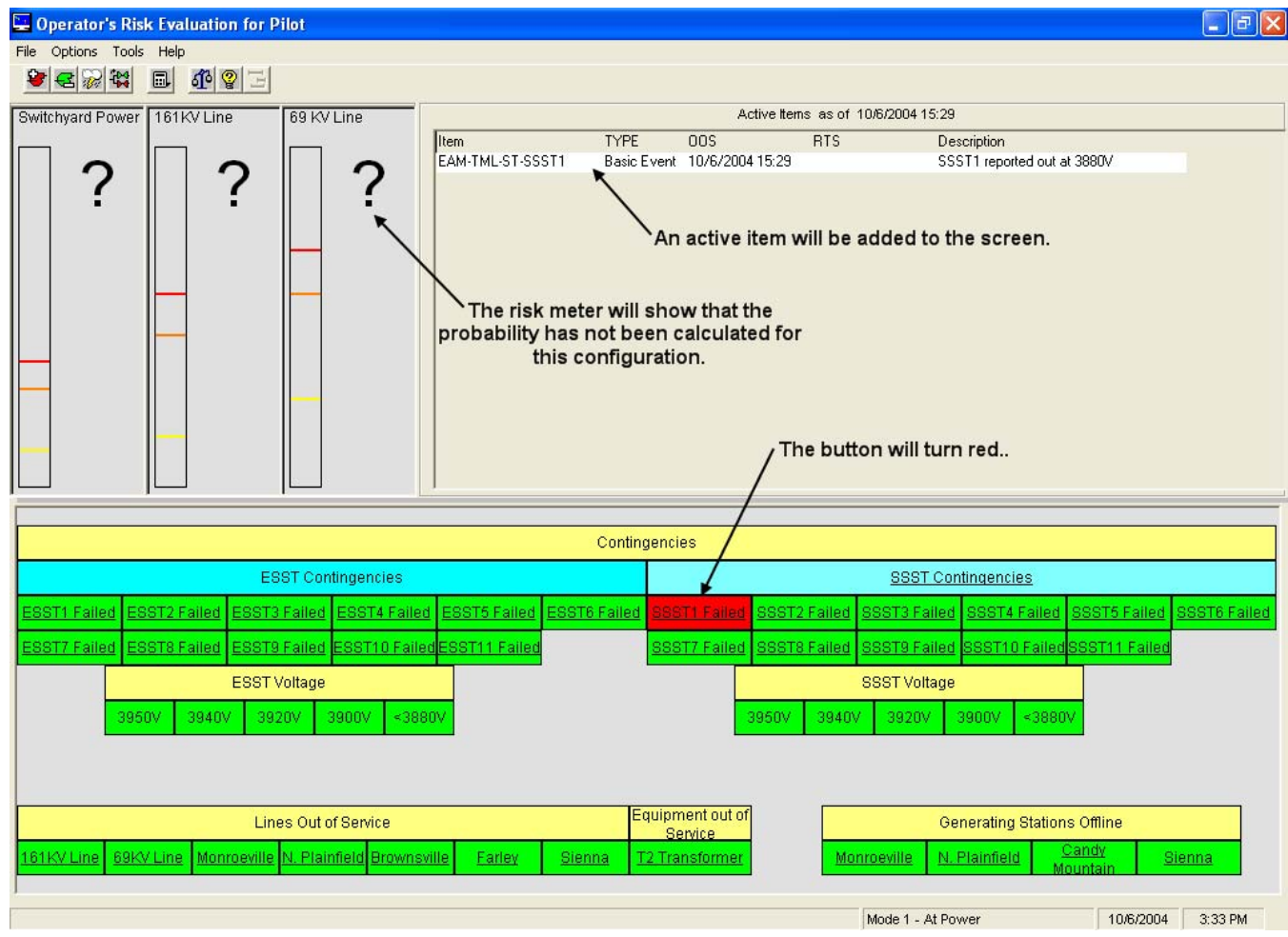

Figure 3-7

Tour of the Grid Monitor (Continued) 


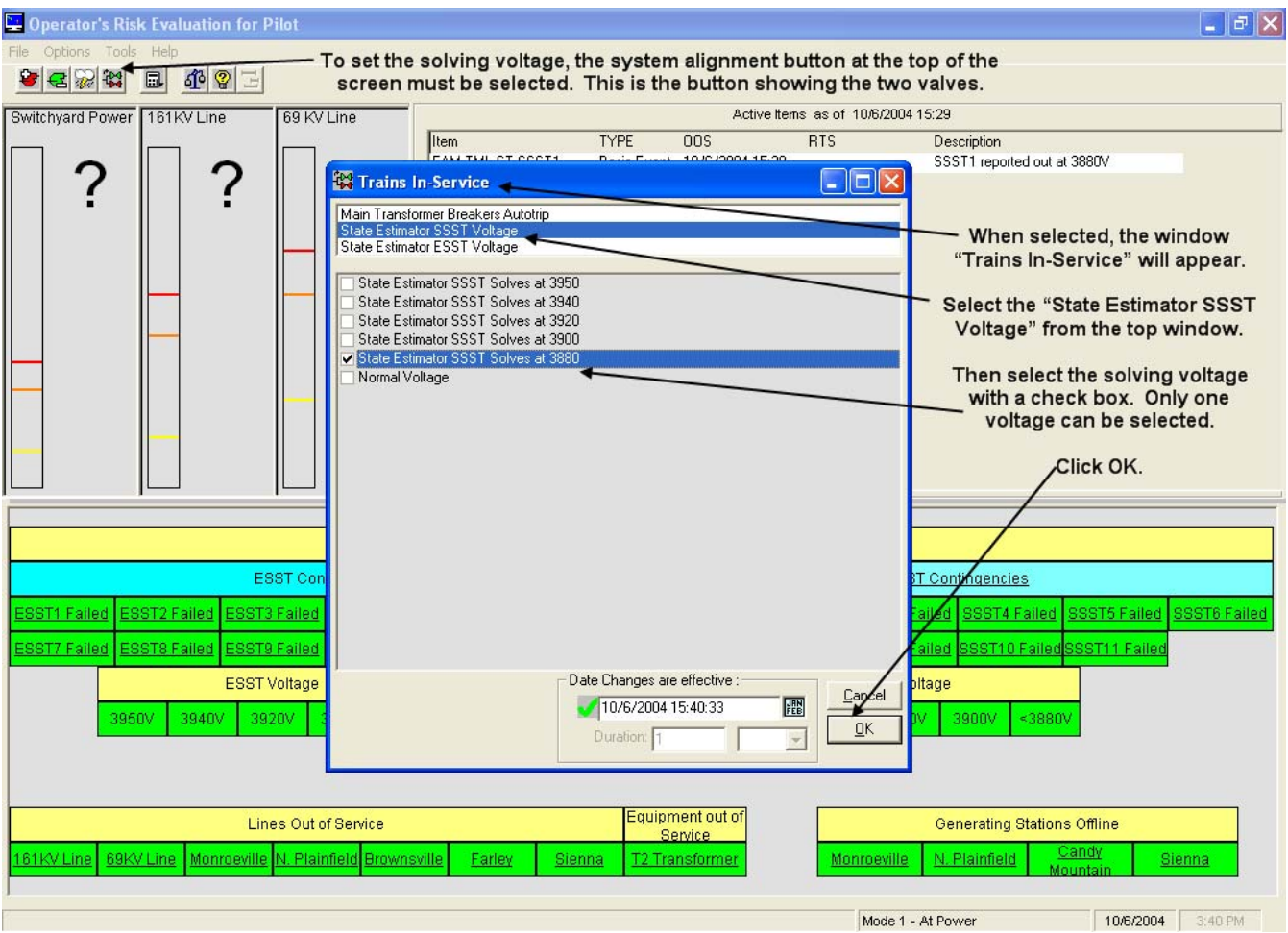

\section{Figure 3-8}

\section{Tour of the Grid Monitor (Continued)}

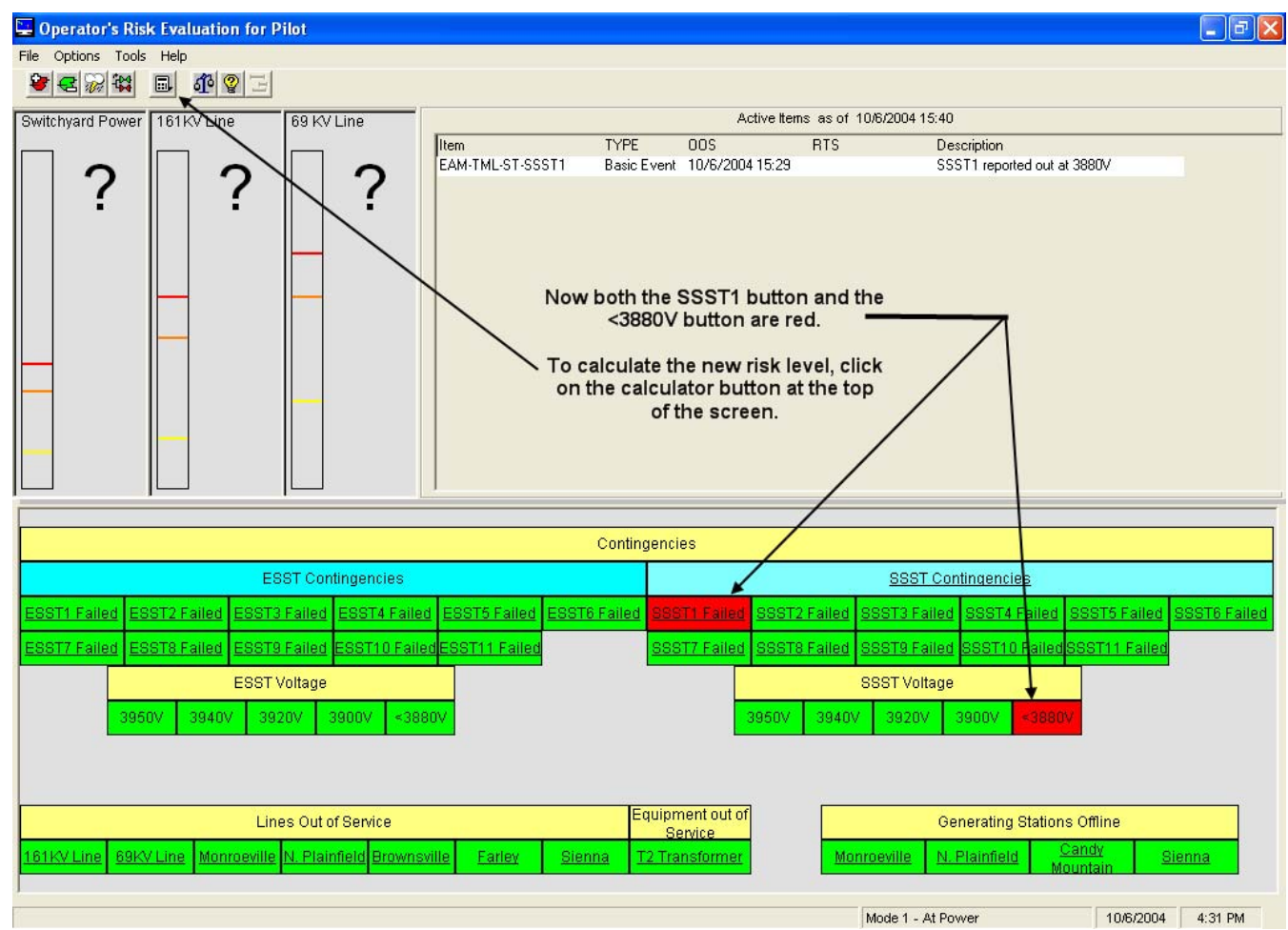

Figure 3-9

Tour of the Grid Monitor (Continued) 
File Options Tools Help

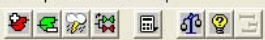

Switchyard Power $161 \mathrm{KV}$ Line $69 \mathrm{KV}$ Line Active ttems as of 10,6/2004 15:40

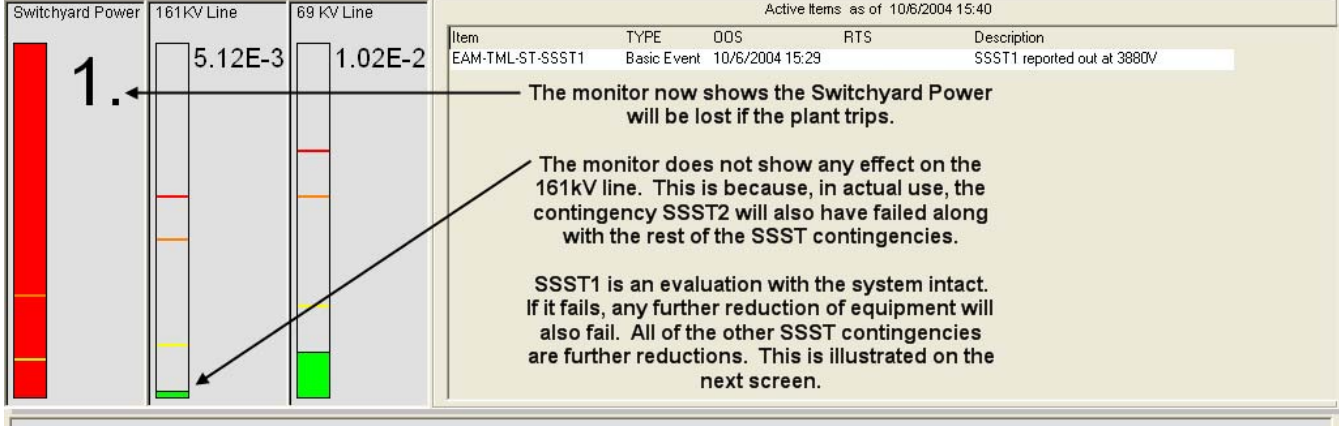

\begin{tabular}{|c|c|c|c|c|c|c|c|c|c|c|c|c|c|c|}
\hline \multicolumn{15}{|c|}{ Contingencies } \\
\hline \multicolumn{8}{|c|}{ ESST Contingencies } & \multicolumn{7}{|c|}{ SSST Contingencies } \\
\hline ESST1 Failed & \multicolumn{2}{|c|}{ ESST2 Failed } & ESST3 Failed & \multicolumn{2}{|c|}{ ESST4 Failed } & ESST5 Failed & ESST6 Failed & SSTI Failed & \multicolumn{2}{|c|}{ SSST2 Failed } & SSST3 Failed & SSST4 Failed & SSST5 Failed & SSST6 Failed \\
\hline ESST7 Failed & \multicolumn{2}{|c|}{ ESST8 Failed } & ESSTg Failed & \multicolumn{2}{|c|}{ ESST10 Failed E } & ESST11 Failed & & SSST7 Failed & \multicolumn{2}{|c|}{ SSST8 Failed } & SSsTg Failed & SSST10 Failed & SSST11 Failed & \\
\hline & \multicolumn{5}{|c|}{ ESST Voltage } & & & & \multicolumn{4}{|c|}{ SSST Voltage } & & \\
\hline & $3950 \mathrm{~V}$ & $3940 \mathrm{~V}$ & \begin{tabular}{l|l} 
& $3920 \mathrm{~V}$
\end{tabular} & $3900 \mathrm{~V}$ & $<3880 \mathrm{~V}$ & & & & $3950 \mathrm{~V}$ & $3940 \mathrm{~V}$ & \begin{tabular}{l|l}
$\mathrm{V}$ & $3920 \mathrm{~V}$
\end{tabular} & $3900 \mathrm{~V}$ & & \\
\hline
\end{tabular}

\begin{tabular}{|c|c|c|c|c|c|c|c|}
\hline \multicolumn{7}{|c|}{ Lines Out of Service } & Equipment out of \\
\hline $161 \mathrm{kV}$ Line & 69kV Line & Monroeville & N. Plainfield & Brownsville & Farley & Sienna & T2 Transformer \\
\hline
\end{tabular}

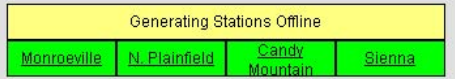

Finished

Mode 1 - At Power

Figure 3-10

Tour of the Grid Monitor (Continued)

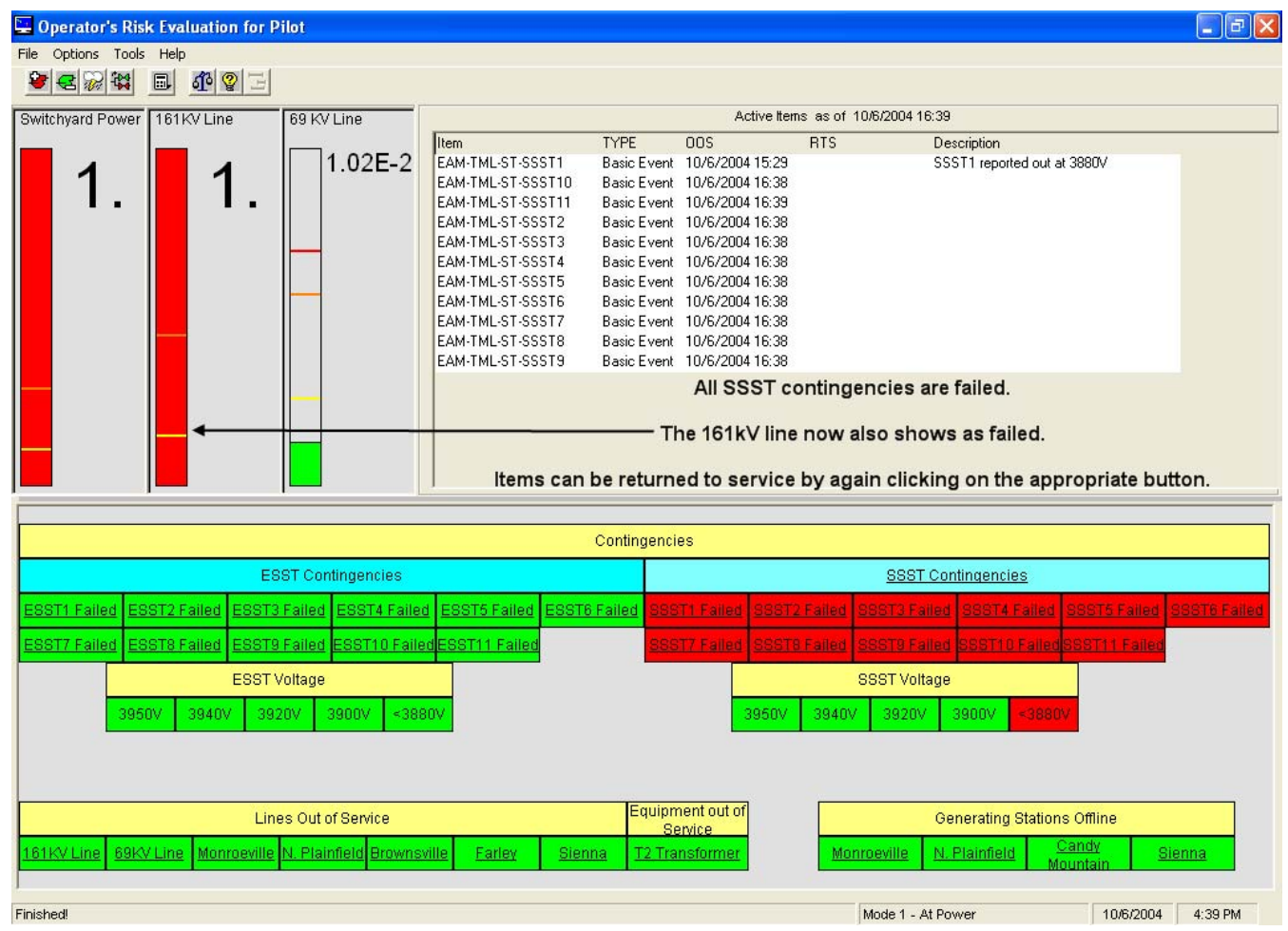

Figure 3-11

Tour of the Grid Monitor (Continued) 


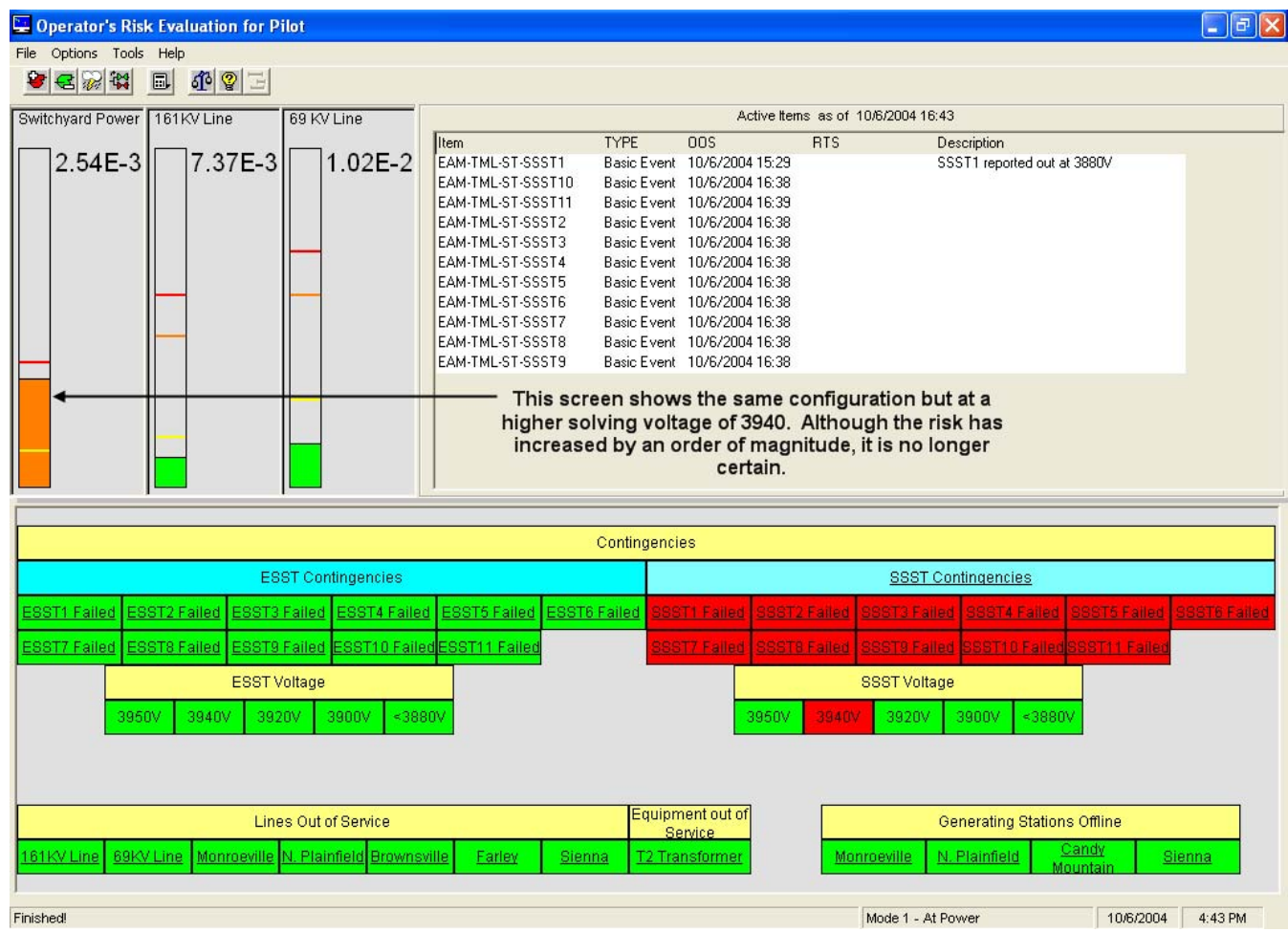

Figure 3-12

Tour of the Grid Monitor (Continued)

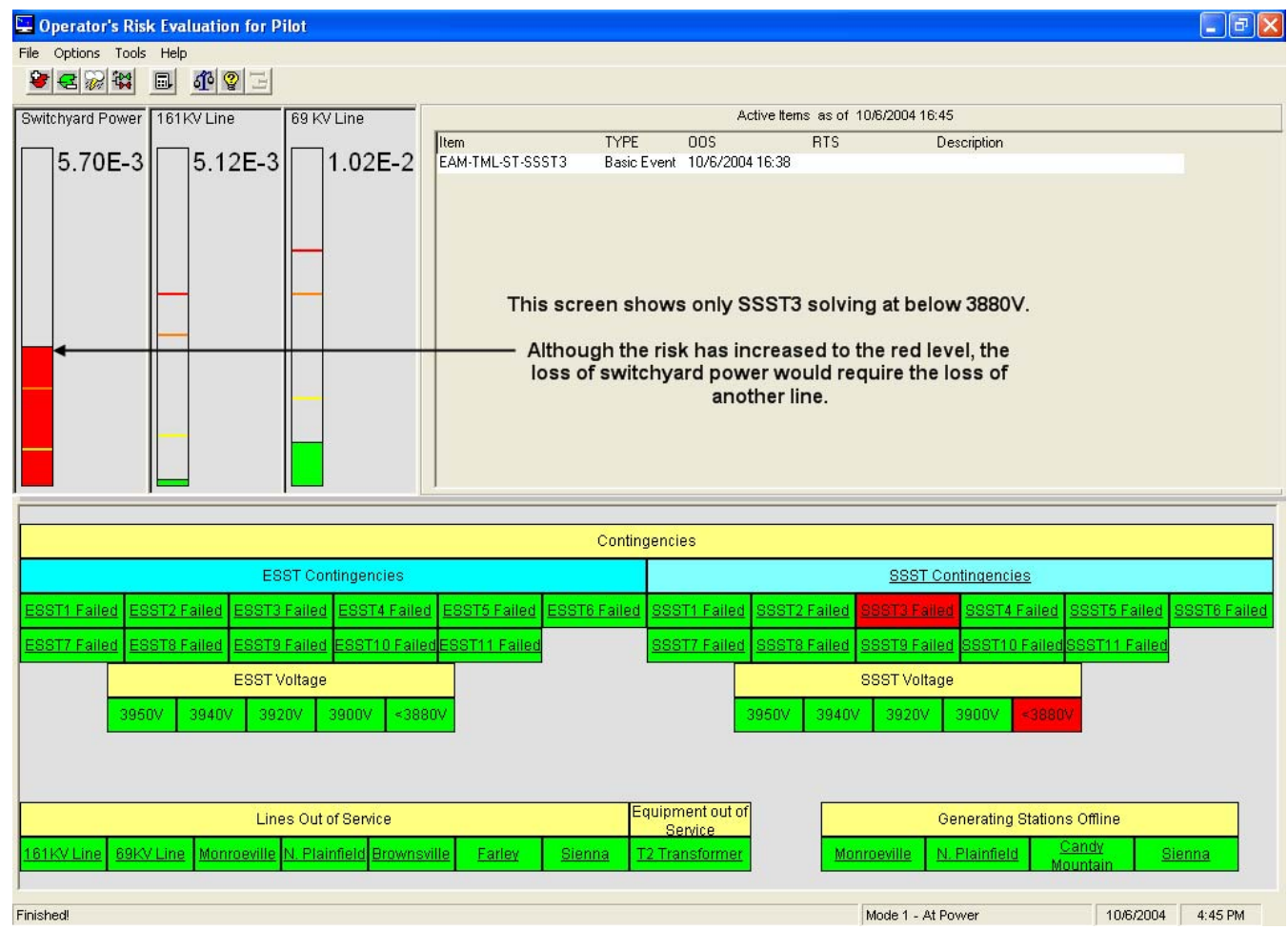

Figure 3-13

Tour of the Grid Monitor (Continued) 


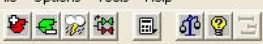

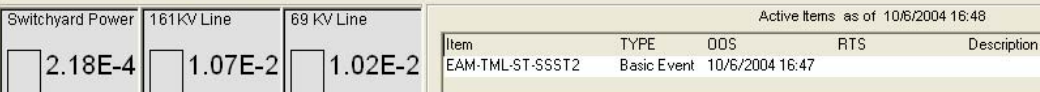

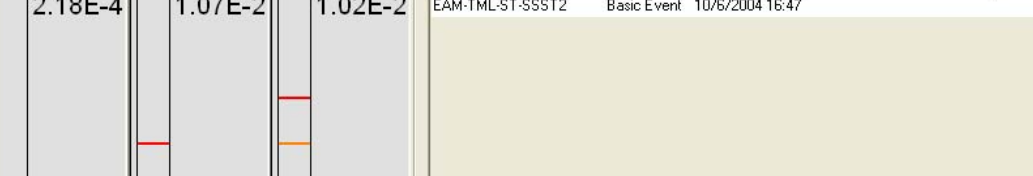

\begin{tabular}{||c|c|}
$\begin{array}{c}\text { This screen shows SSST2, the } \\
\text { contingency that evaluates only the } \\
\text { line capability, solving at 3900 }\end{array}$ &
\end{tabular}

\begin{tabular}{||c|c}
$\begin{array}{c}\text { This screen shows SSST2, the } \\
\text { contingency that evaluates only the } 161 \mathrm{kV} \\
\text { line capability, solving at } 3900 \mathrm{~V}\end{array}$ &
\end{tabular}

$\square$
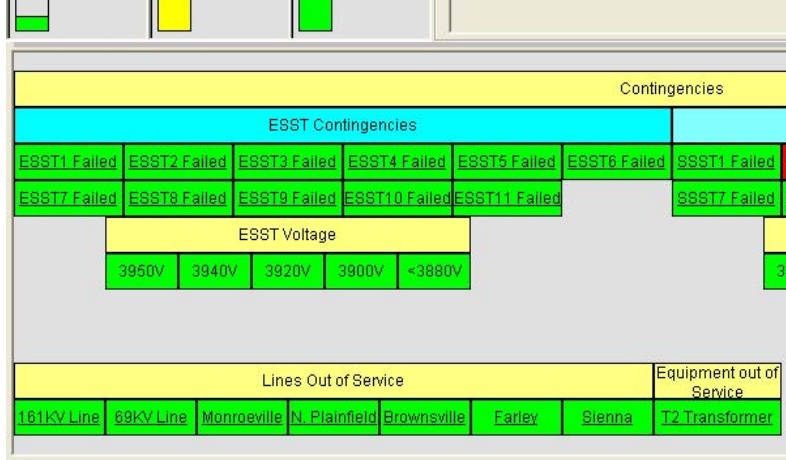

SSST Contingencies

\begin{tabular}{|l|l|l|l|l|}
\multicolumn{5}{c}{ SSST Contingencies } \\
SSST2 Failed & SSST3 Failed & SSST4 Failed & SSST5 Failed & SSST6 Failed \\
\hline SS
\end{tabular}

Finished!

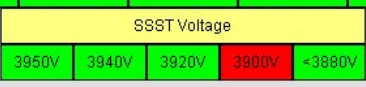

\section{Figure 3-14}

\section{Tour of the Grid Monitor (Continued)}

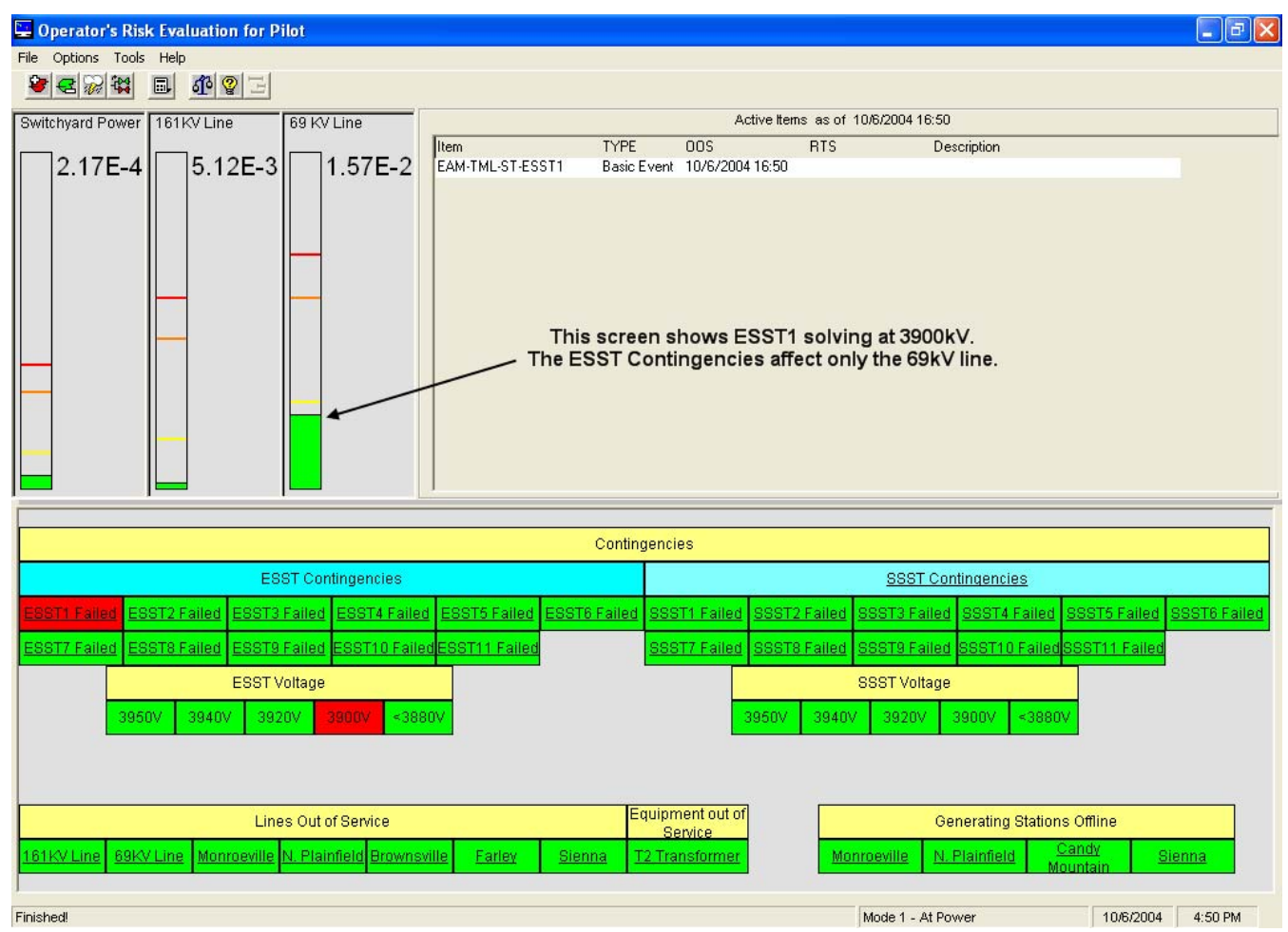

Figure 3-15

Tour of the Grid Monitor (Continued) 


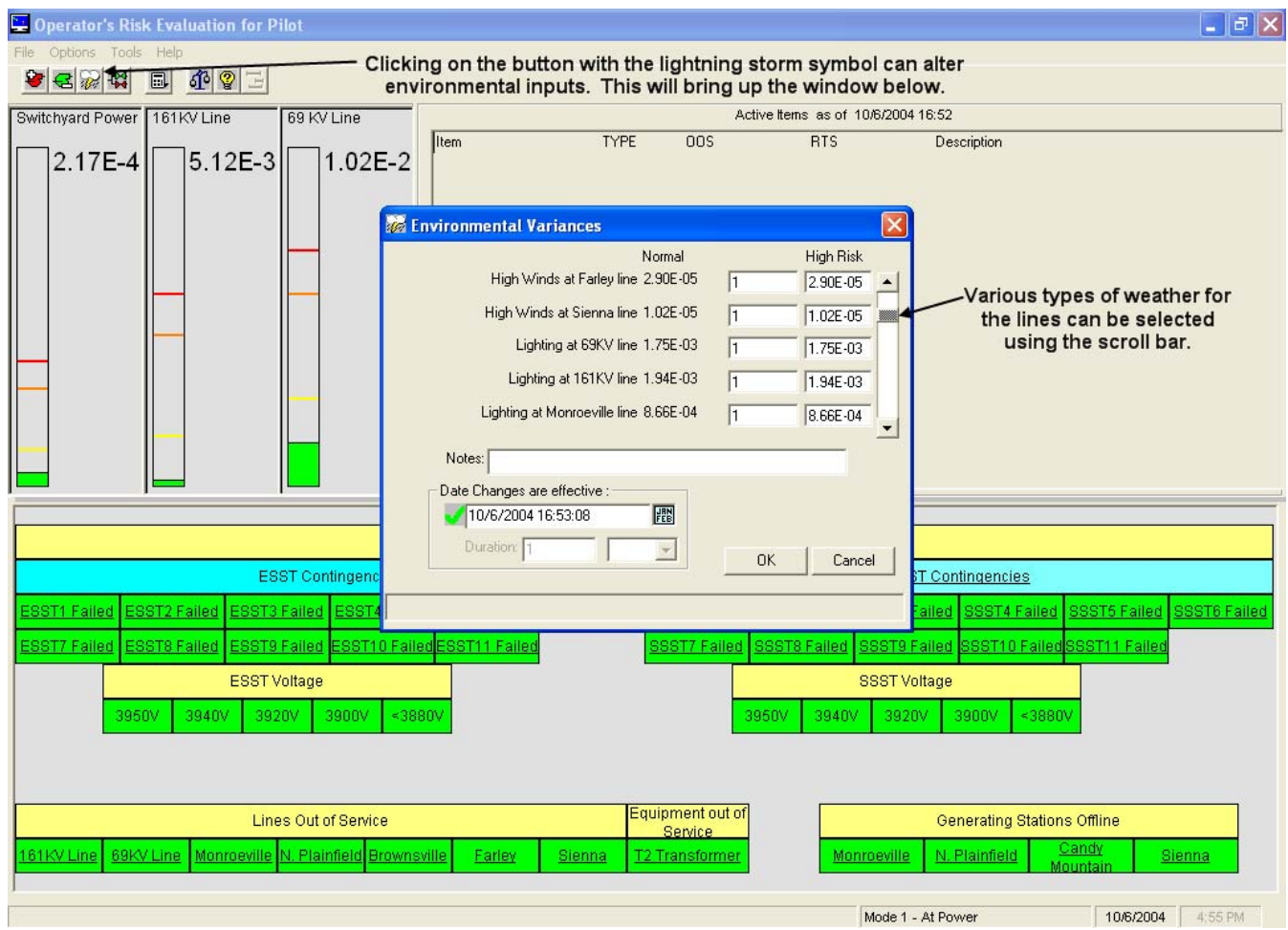

\section{Figure 3-16}

\section{Tour of the Grid Monitor (Continued)}

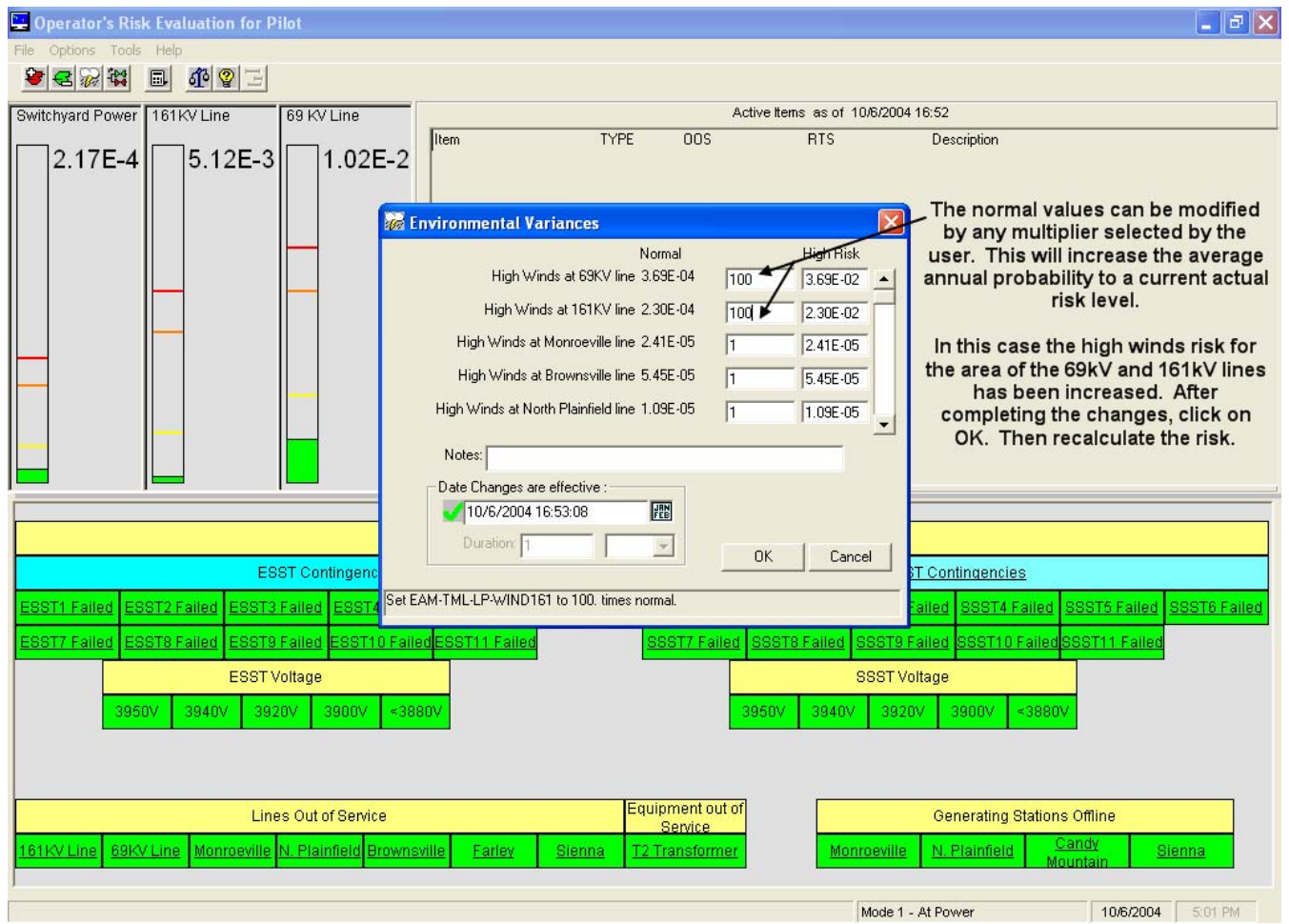

Figure 3-17

Tour of the Grid Monitor (Continued) 
He Options Tools Help

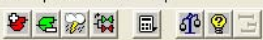
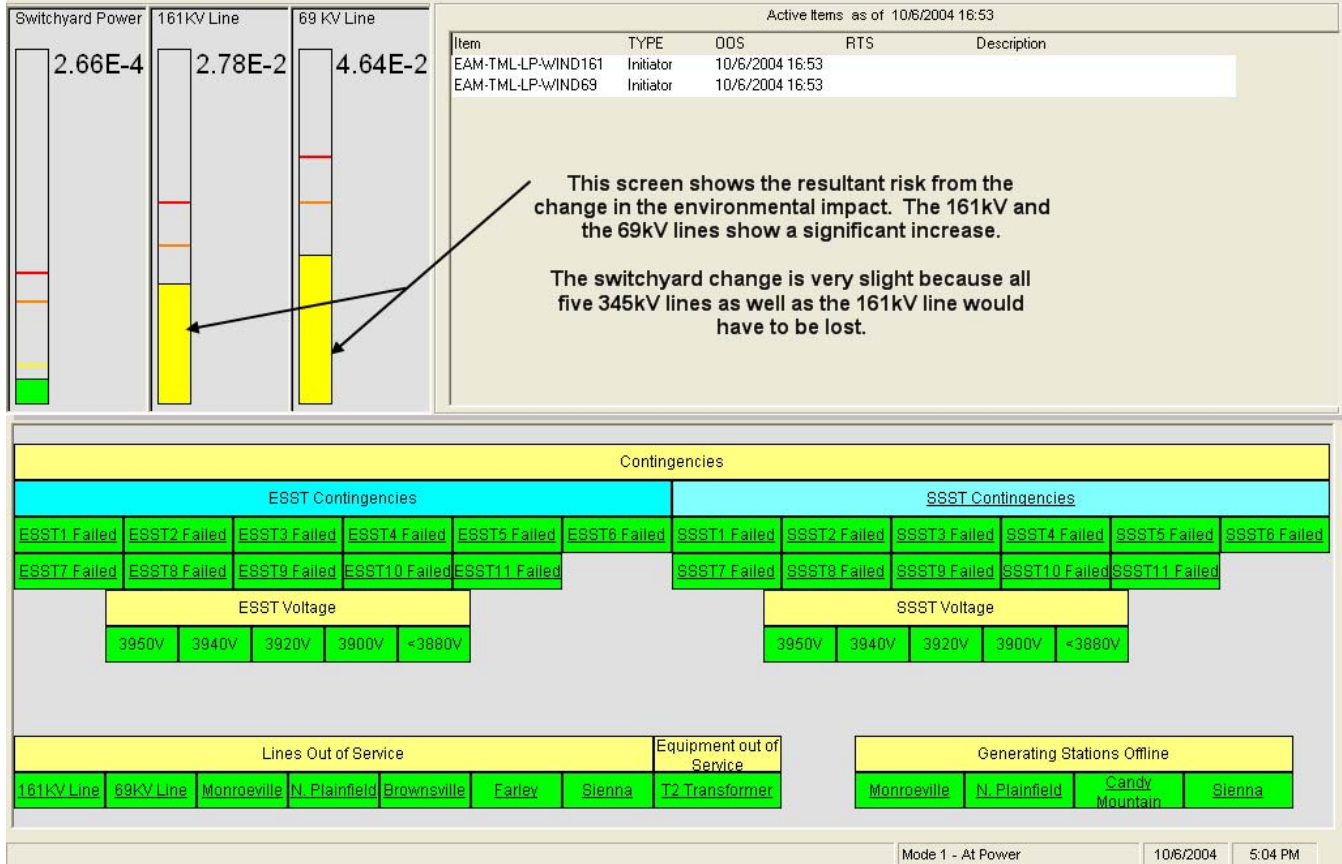

\section{Figure 3-18}

\section{Tour of the Grid Monitor (Continued)}

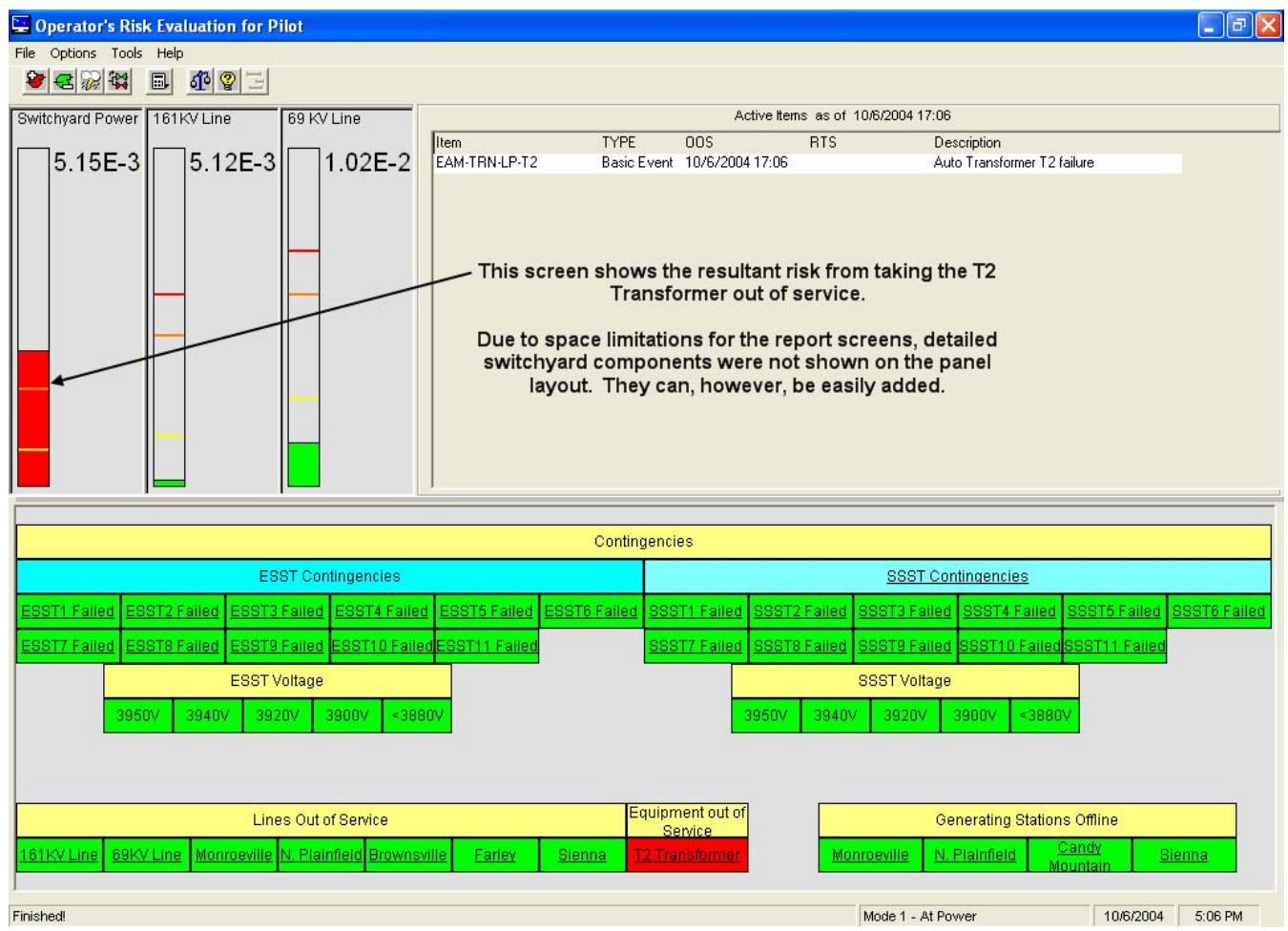

Figure 3-19

Tour of the Grid Monitor (Continued) 


\subsection{Operate the Risk Monitor}

After design and development of the monitor are completed, it is still necessary to operate it and evaluate it. In the case of the pilot plant, the output of the state estimator must be manually entered into the grid monitor. (Automatic state estimator output to the risk monitor is possible and desirable.) An evaluation period should be planned to work out problems with coordination and allow possible revision to the fault tree models and monitor. Results should be reviewed to determine whether the monitor would be best suited as a planning or operating tool. Members of the project team should be chosen to operate the monitor during this period.

Prior to operating the monitor, it is first necessary to incorporate the contingencies identified during development into the state estimator program. A method of reporting failures of these contingencies to the monitor operator must also be determined. The grid operators, who will be identifying the contingencies when they solve at reduce voltage, must be able to recognize these as special contingencies. These contingencies, developed for the monitor, require no action on their part except to report them to the monitor operator. It would be preferable if the contingencies could be reported directly to the monitor operator without the grid operator's involvement. The details will depend on the state estimator capabilities. This step can be accomplished while the monitor is still being developed once the contingency list is finalized.

During the evaluation period, the need for changes to the fault tree model, the monitor interface screen, or to the list of contingencies may become evident. These can be easily incorporated into the monitor. The frequency of the contingencies solving at low voltage needs to be analyzed. If the contingencies are showing problems regularly, does the monitor show an appropriate increase in risk for those contingencies? Are these contingencies the lower probability items? Is there a problem on the grid that needs attention? If the contingencies are solving only rarely, is the contingency list correct or should additional contingencies be considered? If the contingency list is determined to be correct, then a degree of assurance that the grid is normally in a stable condition has been established. Only periodic trending of the contingency results may be desired. The frequent running of the state estimator with the new contingencies solving successfully will establish a level of confidence that the plant will be able to maintain the off-site power from the grid.

The risk monitor also contains the switchyard and weather information that can be used for planning maintenance. This portion of the monitor should also be evaluated during this phase. The pilot plant monitor screen had only limited development for the switchyard components. A more detailed interface screen should be developed for switchyard maintenance during operation. In the previous section, an example of the risk increase from taking the autotransformer out of service was presented. This is a major component and results in a significant increase in risk. It is unlikely it would be removed from service for planned maintenance during operation. It does, however, demonstrate the capability of using the monitor for also evaluating the risk in the switchyard. 
The pilot plant had not yet operated the risk monitor developed under this project at the writing of this report. Then intend to incorporate it into a different risk-monitoring software program that is not yet in place at their plant. Further, they are planning upgrades to the switchyard based on the preliminary results from their model. 


\section{4 \\ GRID MONITOR RESULTS}

The result of this project is a fully functional grid monitor based on an operating nuclear power plant. Contingencies of the more significant grid components were identified. Combinations of these components will result in frequent periodic contingency evaluations at an N-2 level and greater during plant operation. A method for identifying additional low-probability contingencies for use in trending was also proposed. A technique was developed for incorporating the output from the state estimator into the grid monitor fault tree. Although the monitor was developed in the EPRI EOOS software, other risk-monitoring programs compatible with CAFTA or other fault tree software can be used.

Further refinement for the pilot plant model is desirable in several ways:

- Operate the monitor for evaluation and improvement.

- Identify and incorporate the low-probability events for trending.

- Investigate an automatic method to provide information from the state estimator.

- Use more grid-specific information for line failure rates.

- Consider using more detailed models of the substation protection logic to supplement the monitor and further develop the loss of power grid initiating fault tree.

\subsection{Conclusions}

The state estimator and contingency-analysis programs are versatile and useful tools for investigating and trending grid operation after a plant trip. A grid-reliability monitor based on input from these programs provides an interesting and useful assessment of the risk of a loss of off-site power at the plant.

The construction and operation of the grid-reliability monitor is very simple:

- The development of the grid-reliability monitor input and output screens is easily accomplished by risk-analysis personnel who are familiar with the software from experience with on-line maintenance risk monitoring per the Maintenance Rule (10 CFR 50.65) [2].

- The monitor uses relatively small fault trees that can be constructed in short timeframes.

- The data for the basic events (grid equipment failures) can be either generic or plant-specific. 
- The contingency evaluations that are required to provide the input to the grid-reliability monitor can be developed relatively quickly by inspection and discussion with the grid operators.

- The additional contingency analysis computer runtime is small.

The monitor can be operated in either an online or offline mode. In the online mode, the gridreliability monitor would be exercised each time the state estimator and contingency-analysis programs were run. This can be as often as every ten minutes. This mode of operation was not evaluated in the pilot project. In the offline mode, assuming archival capability, historical data from the state estimator are used to evaluate and trend the potential for off-site power loss. In this mode of operation, the grid operators do not have an increased workload because the additional contingencies have been added to the contingency-analysis program earlier. If reporting can be automated, this is also true of the first mode. Given the ease of operation of the monitor, work planners, schedulers, or risk-analysis personnel can operate the monitor.

Current risk-management practices associated with the management of the potential for a loss of off-site power call for the evaluation of the grid stability by the grid operators. In general, grid operations personnel will assess the stability of the grid by assessing current state estimator and contingency analysis results. As discussed in this report, the contingencies evaluated are generally limited to a single contingency $(\mathrm{N}-1)$, such as the failure of a line or loss of a single generating station. One contingency would likely be the loss of the electrical production of the nuclear unit. While the assessment of a single contingency is adequate for most purposes, the grid-reliability monitor assesses the potential for multiple contingencies. In addition, the probability of the contingencies allows for an additional risk-management perspective because not all contingencies are as probable. It should be noted that a grid-reliability monitor is not required to assess the additional contingencies that are the most significant contributors to the potential for loss of off-site power at the plant. The current contingency-analysis program can be augmented with the additional contingencies. These contingencies can be evaluated as a riskmanagement practice when the plant is concerned about grid conditions, such as during maintenance of an emergency diesel generator.

In addition to providing a framework to assess the potential for a conditional loss of off-site power (both the contingencies and their probability of occurrence), the grid monitor provides a method for the long-term trending of this probability. The long-term trending of the potential for a conditional loss of off-site power can provide many insights. These include insights into grid operation such as vulnerable periods of operation (for example, power transfers) and simple yet cost-effective improvements for the grid operator or the plant (for example, minor grid configuration changes or maintenance schedules). 
There are other conclusions that can be drawn from both the phase I and II pilot studies. These include:

- As the number and voltage rating of transmission lines into the pilot plant switchyard increase, the likelihood of a conditional loss of off-site power decreases. For example, five $500-\mathrm{kV}$ transmission lines into a plant's switchyard decreases the conditional loss of off-site power significantly over, for example, five $235-\mathrm{kV}$ lines or three $500-\mathrm{kV}$ lines.

- The basis for the sensitivity to the voltage of the transmission lines is simply that the voltage of the transmission lines is being reduced to the typical safety bus loads of $4-\mathrm{kV}$ (4160 VAC). The higher the voltage of the transmission line, the more significant the loss must be to have the same resultant loss of voltage on the safety bus. For example, if a 500-kV line voltage drops to $475 \mathrm{kV}$, this loss of $25 \mathrm{kV}$ represents only a $5 \%$ loss and a 3950 VAC final voltage at the safety bus, whereas a $25-\mathrm{kV}$ loss on a $235-\mathrm{kV}$ line represents a loss of $11 \%$ reduction in the voltage and a final voltage on the safety bus of 3700 VAC.

- The basis for the sensitivity of the probability of the conditional loss of off-site power on the number of transmission lines is strictly related to the number of lines required to support the voltage at the safety buses versus the number of lines available. The more lines, the lower the probability that sufficient power will not be available.

- For plants with significant numbers of higher voltage transmission lines, the probability of the conditional loss of off-site power is a function of the common-mode failure of the transmission lines, nearby generating stations or other grid transmission equipment, an offsite fault that is propagated into the plant switchyard, or the failure of the grid as a whole.

- In this case, the conditional loss of off-site power probability is relatively low and dominated by the mechanisms listed above for most configurations of the grid. However, rare grid configurations related to large power transfers, high loading, low generation, or reactive power conditions can result in higher potentials for loss of offsite power.

- These higher probability periods can occur several times a year and have various durations, depending on the cause.

- For some plants, the design-basis LOCA may not be the limiting condition for assessment of post-trip safety bus voltage. This is a result of the fact that some plants generate a LOCA signal that trips non-essential loads. These non-essential loads represent more significant electrical power demands than the safety loads. The most limiting condition should be identified for use as the success criteria in the contingency evaluations. 



\section{5 \\ REFERENCES}

1. Generic Letter 88-20, "Individual Plant Examination for Severe Accident Vulnerabilities," U.S. Nuclear Regulatory Commission, November 23, 1988.

2. Nuclear Regulatory Commission, Regulatory Guide 1.160, Monitoring the Effectiveness of Maintenance at Nuclear Power Plants, 10CFR50.65, June 1993.

3. Method to Monitor Nuclear Power Risk from Transmission Grid Conditions: Proof-ofPrinciple Study, EPRI, Palo Alto, CA: 2003. 1008050.

4. Operating Experience Assessment-Effects of Grid Events on Nuclear Power Plant Performance, U.S. Nuclear Regulatory Commission, April 29, 2003.

5. Transmission System Reliability and Power Quality Benchmarking, Electrotek Concepts, http://www.transmissionpq.com/summary.htm.

6. Losses of Off-Site Power at U.S. Nuclear Power Plants Through 2001, EPRI, Palo Alto, CA: 2002. TR-100298.

7. Data System (GADS) pc-GAR Version 2.04 v11 User's Guide, North American Electric Reliability Council (NERC) Generating Availability. 



\section{$\boldsymbol{A}$ \\ DETAILED DEVELOPMENT OF SWITCHYARD FAULT TREE}

This appendix contains details of the development of the pilot plant fault tree for use in the grid monitor. It is divided into three sections: the development of the switchyard model, quantification of the model, and converting the fault tree to a grid performance model for use in the grid monitor. This appendix is intended to provide information that might not be of interest to the general reader but useful for someone interested in the development of a similar fault tree. Only sufficient information to explain the development is discussed.

\section{A.1 Development of Switchyard Model}

In order to evaluate and quantify the risk due to a loss of off-site power, it is necessary to develop a model that reflects the plant interaction with the grid.

The pilot plant for this project developed and provided a switchyard fault tree model. This model was taken as the basis for further evaluation. The model consisted of two fault trees. One was to determine the initiation of a plant trip based on a loss of off-site power. The second was an accident-mitigation fault tree to determine the availability of off-site power for 24 hours after a trip. The second fault tree was used for this study. This fault tree modeled only the power from the single startup station service transformer (SSST). The emergency station service transformer (ESST) was not included. Figure A-1 shows the top event of this accident sequence fault tree. The tree models unavailability of power, unisolated line faults, failure of the SSST during the accident sequence, failure of the power path to the SSST, and maintenance errors within the two switchyards.

The basic events, displayed with circles at the bottom, are events that represent immediate failure of power to the SSST. The unisolated line faults are developed further in a lower part of the fault tree to include fault location and breaker operation to isolate the faults. The details of this development are not shown in this report. The availability of power is the main interest for further development in this project.

Figures A-2 and A-3 show the further development of the power availability. Figure A-2 models the availability of the $161-\mathrm{kV}$ line as well as faults on the line. Also in Figure A-2, there is a basic event entitled “161-kV Line Inadequate to Provide Loads per State Estimator.” The pilot plant included this event in anticipation of using the state estimator to determine availability. This basic event will be developed further in later sections. 
Figure A-3 models the availability of the $345-\mathrm{kV}$ power. Faults are modeled for each of the five $345-\mathrm{kV}$ lines connected to the switchyard. Breakers that are required to isolate those faults are included in the modeling. Finally, the availability of the lines and breakers is modeled.

These three figures provide the information on the general structure of the original switchyard model. The modeling methods used are similar to those used in developing the nuclear plant's internal events PRA. Such a model could readily be developed for any power plant by experienced PRA modelers.

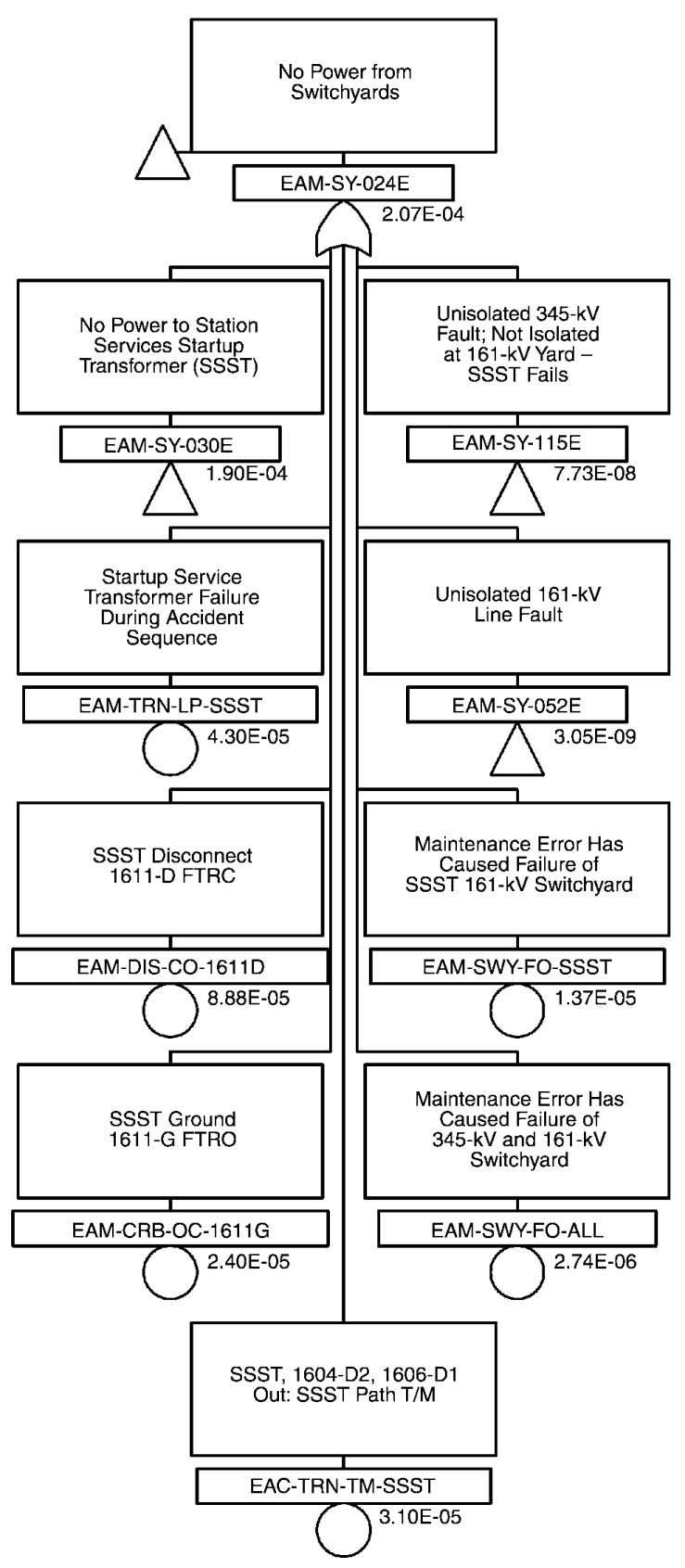

Figure A-1

Switchyard Fault Tree for Accident Mitigation 


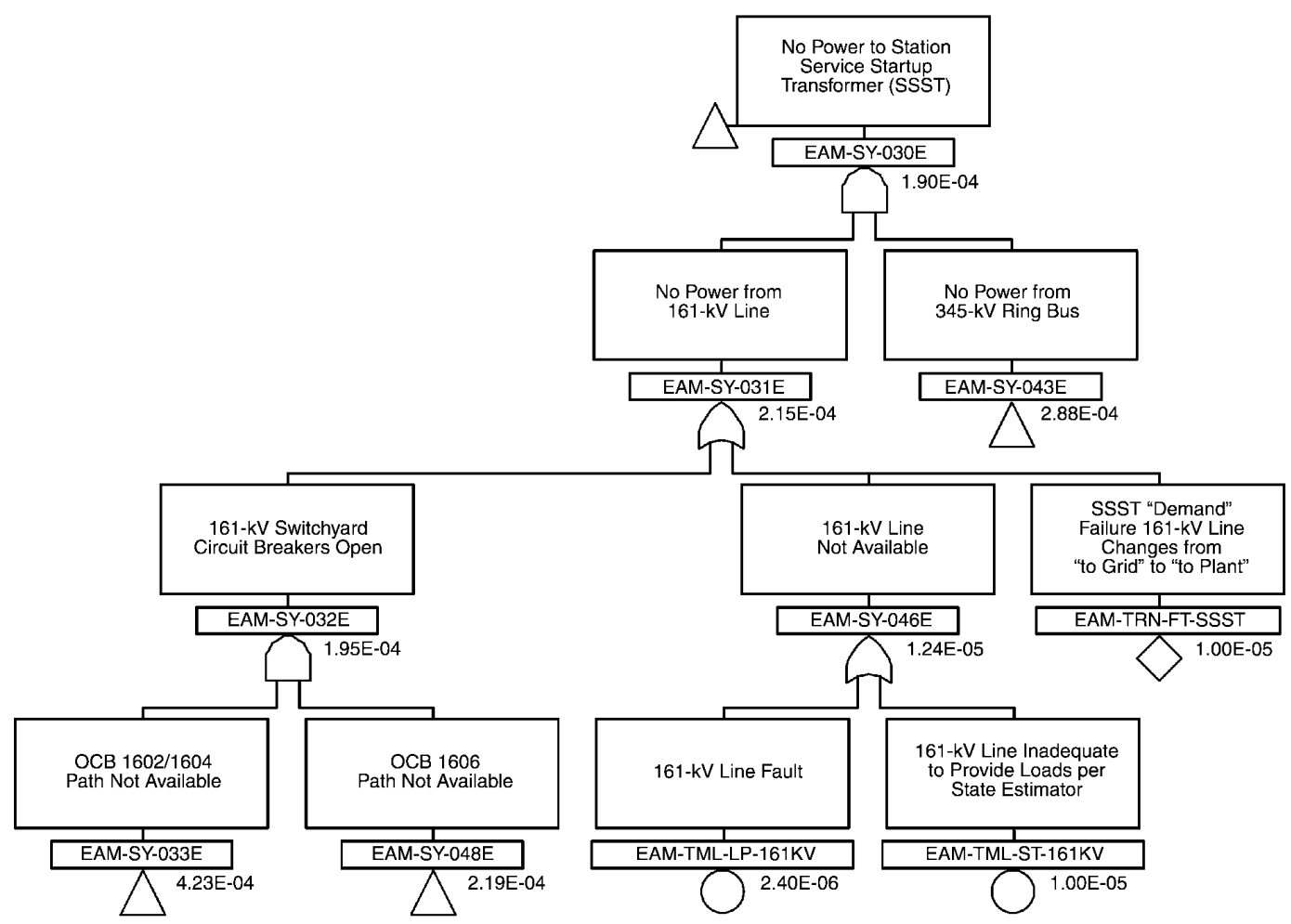

Figure A-2

Fault Tree for 161-kV Power to SSST

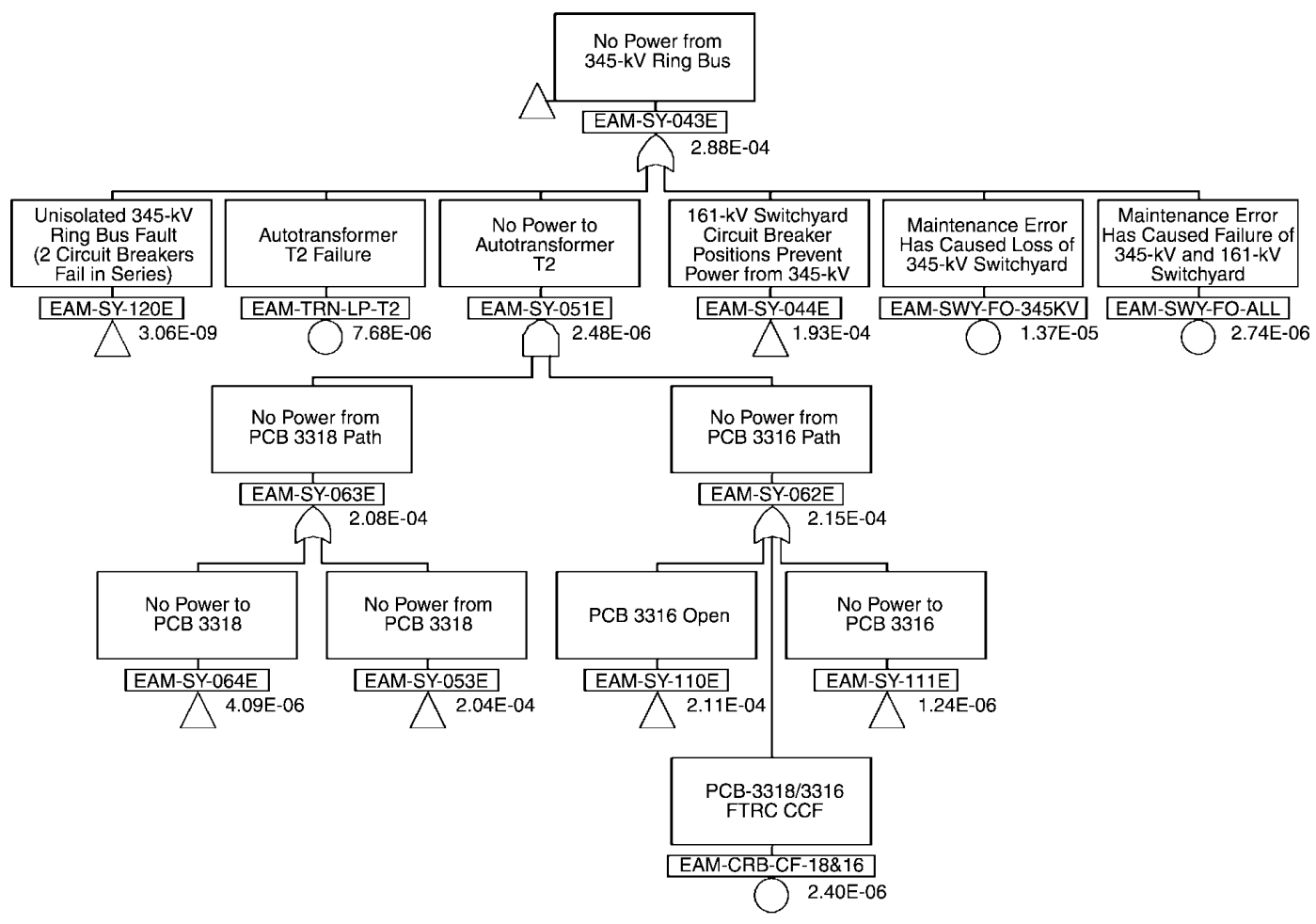

Figure A-3

Fault Tree for 345-kV Power to SSST 


\section{A.2 Review and Quantification of the Switchyard Model}

The switchyard model was reviewed for its use in a grid monitor. The model was developed primarily for the plant's use in evaluating the switchyard for potential improvements in reliability. It was necessary to determine whether any changes would be required for use in a monitor.

First, a general review of the fault tree was performed. Because of the many different pathways through which the 345-kV power can flow, a circular logic could be developed. To break this logic in the original model, the development of the pathway was simply discontinued at points where it circles back upon itself. It was found that the technique used to break the logic assumed that power was available from that pathway. This fault tree would therefore find power available even if all five lines were removed from service. This modeling method would not work with the grid monitor. The monitor requires the capability of removing lines from service when appropriate. The assumption was reversed (power not available from that pathway), which rectified that result. This change made no impact on the value of the top event but was necessary for use in the monitor. The remainder of the review identified only some minor changes and corrections.

Next, the significance indicators from the fault tree were reviewed. Cutset and risk-significance reports from this model are shown as Tables A-1 through A-3. This information was evaluated to determine whether further development of components in the power source paths from the grid was warranted.

Table A-1 lists the cutsets that contribute to risk. A cutsets is a minimal combination of components that will result in failure of the overall event-in this case, loss of power to the switchyard. A first-order cutset is a single component that results in failure, second order, combinations of two, and so forth. The report ranks them in order of contribution to risk up to a specified probability limit or percentage contribution. The table shows that the bulk of the risk is attributable to the first-order cutsets. The only transmission line that shows up with any significant probability is the $161-\mathrm{kV}$ line, and that is in a second-order cutest, indicating that failure of a second component, the autotransformer, or its path is required.

Table A-2 shows the significant components listed in order of risk achievement worth (RAW). Risk achievement worth is a multiplier of the basic risk that indicates how much risk increases if that component's failure probability is increased to one or guaranteed failure. All of the events listed in the cutset report as single order cutsets have extremely high RAWs, reflecting the overall failure with the guaranteed failure of any of these components. The 161-kV line fault then shows up as the next most significant contributor. The value of two reflects only a doubling of risk if this failure occurs. No other lines appeared as significant.

Table A-5 shows the significant components listed in order of risk reduction worth (RRW). Risk reduction worth is a divider of the basic risk that indicates how much the risk is reduced when the component never fails. Not even the $161-\mathrm{kV}$ line appeared as significant in reducing risk. 
Because there were just a few components contributing to almost all of the risk, the model was quantified again with these large contributors set to perfect (false). This was done to determine whether they were masking contributions from the lines. The 161-kV line increased in importance, but the 345-kV lines were still low.

With the exception of the SSST itself, all of the components shown in the tables are located in the $161-\mathrm{kV}$ switchyard. The only transmission line to show up in the tables is the $161-\mathrm{kV}$ line. The unavailability of this line contributes to the risk, although not significantly. This line appears in many of the second-order cutsets in combination with components that fail the $345-\mathrm{kV}$ path (the autotransformer). Failure of the autotransformer would raise the significance of this line substantially. Therefore, it was determined that additional modeling of the line was warranted. A breaker failure in the substation where this line terminates would have an equivalent effect on availability but was not included in the switchyard model. Therefore, additional components were added to reflect possible additional failures at the substation. At the substation, there are two breakers supplying this line, so another common cause failure would be required. For this reason, modeling was not extended beyond this point.

The quantification used a truncation limit of $1 \mathrm{E}-16$. That is, any cutsets with lower values were not evaluated. The $345-\mathrm{kV}$ lines do not show up in any cutsets until the E-15 probability level is reached. These cutsets are a $345-\mathrm{kV}$ line fault combined with multiple failures of switchyard breakers to isolate the fault. The $345-\mathrm{kV}$ lines did not appear at all as a single-order cutset. From these results, it was determined that detailed modeling of the $345-\mathrm{kV}$ off-site transmission components would not contribute to the model.

The final modifications to the original model were performed for completeness for use in a risk monitor. The original switchyard model did not include any modeling of the ESST line. This is because it does not connect through the plant's switchyards but runs directly to the plant's ESST from a substation several miles away. A simple model for this line was developed for inclusion in the risk monitor.

Finally, the basic events that represented the faults on the transmission lines were expanded with "OR" gates to represent the various causes. The selected causes were based on universal events as well as those to be expected in the region of the pilot plant. Other plants may desire to select different events depending on their concerns for line faults. Figure A-4 shows a typical development of the line faults. 
Detailed Development of Switchyard Fault Tree

Table A-1

Switchyard Fault Tree Model Cutsets

\begin{tabular}{|c|c|c|c|}
\hline Probability & $\begin{array}{l}\text { Cumulative } \\
\text { Percent }\end{array}$ & Basic Events & Description \\
\hline 8.88E-05 & $42.9 \%$ & EAM-DIS-CO-1611D & SSST disconnect \\
\hline 4.30E-05 & $63.7 \%$ & EAM-TRN-LP-SSST & SSST failure during accident sequence \\
\hline 3.10E-05 & $78.7 \%$ & EAC-TRN-TM-SSST & SSST transformer path fails \\
\hline 2.40E-05 & $90.3 \%$ & EAM-CRB-OC-1611G & SSST ground 1611-G FTRO \\
\hline 1.37E-05 & $96.9 \%$ & EAM-SWY-FO-SSST & Maint error SSST/161-kV switchyard \\
\hline 2.74E-06 & $98.3 \%$ & EAM-SWY-FO-ALL & Maint error 345/161-kV switchyard \\
\hline 2.40E-06 & $99.4 \%$ & EAM-CRB-CF-04\&06 & OCB 1604/OCB 1606 FTRC CCF \\
\hline $1.20 \mathrm{E}-06$ & $100.0 \%$ & EAM-CRB-CF-2\&4\&6 & OCB-1602/1604/1606 FTRC CCF \\
\hline $7.68 \mathrm{E}-10$ & $100.0 \%$ & $\begin{array}{l}\text { EAM-TML-ST-161KV } \\
\text { EAM-TRN-LP-T2 }\end{array}$ & 161-kV line test/maintenance/autotransformer \\
\hline $5.76 \mathrm{E}-10$ & $100.0 \%$ & $\begin{array}{l}\text { EAM-CRB-CO-1604 } \\
\text { EAM-CRB-CO-1606 }\end{array}$ & OCB 1604/OCB 1606 FTRC - independent \\
\hline $1.84 \mathrm{E}-10$ & $100.0 \%$ & $\begin{array}{l}\text { EAM-CRB-CF-02\&06 } \\
\text { EAM-TRN-LP-T2 }\end{array}$ & $\begin{array}{l}\text { OCB } 1602 / \mathrm{OCB} 1606 \mathrm{FTRC} \text { CCF/ } \\
\text { autotransformer }\end{array}$ \\
\hline $1.84 \mathrm{E}-10$ & $100.0 \%$ & $\begin{array}{l}\text { EAM-TML-LP-161KV } \\
\text { EAM-TRN-LP-T2 }\end{array}$ & 161-kV line fault/autotransformer \\
\hline
\end{tabular}


Table A-2

Loss of Off-Site Power to the Switchyard (Sorted by Risk Achievement Worth)

\begin{tabular}{|c|c|c|c|c|c|c|}
\hline Event Name & Probability & $\begin{array}{l}\text { Fussel- } \\
\text { Vesely }\end{array}$ & Birnbaum & $\begin{array}{c}\text { Risk } \\
\text { Reduction } \\
\text { Worth }\end{array}$ & $\begin{array}{c}\text { Risk } \\
\begin{array}{c}\text { Achievement } \\
\text { Worth }\end{array}\end{array}$ & Description \\
\hline EAC-TRN-TM-SSST & 3.10E-05 & $1.50 \mathrm{E}-01$ & $1.00 \mathrm{E}+00$ & 1.176 & 483 & SSST transformer path fails \\
\hline EAM-CRB-CF-04\&06 & 2.40E-06 & 1.16E-02 & $1.00 \mathrm{E}+00$ & 1.012 & 483 & OCB 1604/OCB 1606 FTRC CCF \\
\hline EAM-CRB-CF-2\&4\&6 & $1.20 \mathrm{E}-06$ & $5.80 \mathrm{E}-03$ & $1.00 \mathrm{E}+00$ & 1.006 & 483 & OCB-1602/1604/1606 FTRC CCF \\
\hline EAM-CRB-OC-1611G & 2.40E-05 & 1.16E-01 & $1.00 \mathrm{E}+00$ & 1.131 & 483 & SSST ground 1611-G FTRO \\
\hline EAM-DIS-CO-1611D & 8.88E-05 & 4.29E-01 & $1.00 \mathrm{E}+00$ & 1.752 & 483 & SSST disconnect 1611-D FTRC \\
\hline EAM-SWY-FO-ALL & 2.74E-06 & 1.32E-02 & $1.00 \mathrm{E}+00$ & 1.013 & 483 & Maint error 345/161-kV switchyard \\
\hline EAM-SWY-FO-SSST & 1.37E-05 & 6.62E-02 & $1.00 \mathrm{E}+00$ & 1.071 & 483 & Maint error SSST/161-kV switchyard \\
\hline EAM-TRN-LP-SSST & 4.30E-05 & 2.08E-01 & $1.00 \mathrm{E}+00$ & 1.262 & 483 & SSST failure during sequence \\
\hline EAM-TML-LP-161KV & 2.40E-06 & 2.42E-06 & 2.08E-04 & 1 & 2.01 & 161-kV line fault \\
\hline EAM-CRB-CF-02\&06 & $2.40 \mathrm{E}-06$ & $1.38 \mathrm{E}-06$ & 1.19E-04 & 1 & 1.58 & OCB 1602/OCB 1606 FTRC CCF \\
\hline EAC-TML-TM-161KV & $1.00 \mathrm{E}-07$ & 5.77E-08 & 1.19E-04 & 1 & 1.58 & 161-kV line test/maintenance \\
\hline EAM-CRB-CF-02\&04 & $2.40 \mathrm{E}-06$ & 5.67E-07 & 4.89E-05 & 1 & 1.24 & OCB-1602/OCB-1604 FTRC CCF \\
\hline EAM-CRB-CO-1604 & 2.40E-05 & 3.63E-06 & 3.13E-05 & 1 & 1.15 & OCB 1604 FTRC \\
\hline EAM-CRB-CO-1606 & 2.40E-05 & 3.07E-06 & 2.64E-05 & 1 & 1.13 & OCB 1602 FTRC \\
\hline EAM-CRB-CF-18\&16 & 2.40E-06 & 2.89E-07 & 2.49E-05 & 1 & 1.12 & PCB-3318/3316 FTRC CCF \\
\hline EAM-SWY-FO-345KV & 1.37E-05 & $1.65 \mathrm{E}-06$ & 2.49E-05 & 1 & 1.12 & Maint error loss of $345-\mathrm{kV}$ switchyard \\
\hline
\end{tabular}


Detailed Development of Switchyard Fault Tree

Table A-2 (cont.)

Loss of Off-Site Power to the Switchyard (Sorted by Risk Achievement Worth)

\begin{tabular}{|l|l|l|l|l|l|l|}
\hline \multicolumn{1}{|c|}{ Event Name } & Probability & \multicolumn{1}{|c|}{$\begin{array}{c}\text { Fussel- } \\
\text { Vesely }\end{array}$} & \multicolumn{1}{|c|}{ Birnbaum } & \multicolumn{1}{|c|}{$\begin{array}{c}\text { Risk } \\
\text { Reduction } \\
\text { Worth }\end{array}$} & $\begin{array}{c}\text { Risk } \\
\text { Achievement } \\
\text { Worth }\end{array}$ & \multicolumn{1}{|c|}{ Description } \\
\hline EAM-TRN-LP-T2 & $7.68 \mathrm{E}-05$ & $9.25 \mathrm{E}-06$ & $2.49 \mathrm{E}-05$ & 1 & 1.12 & Autotransformer T2 failure \\
\hline EAC-CRB-CC-1602 & $5.00 \mathrm{E}-06$ & $1.16 \mathrm{E}-07$ & $4.79 \mathrm{E}-06$ & 1 & 1.02 & OCB-1602 fail to open \\
\hline EAC-CRB-CC-1606 & $5.00 \mathrm{E}-06$ & $5.80 \mathrm{E}-08$ & $2.40 \mathrm{E}-06$ & 1 & 1.01 & OCB 1606 fail to open \\
\hline EAC-CRB-CF-04\&02 & $5.00 \mathrm{E}-05$ & $5.80 \mathrm{E}-07$ & $2.40 \mathrm{E}-06$ & 1 & 1.01 & $\begin{array}{l}\text { OCB } 1602 \text { and } 1604 \text { fail to open }- \\
\text { CCF }\end{array}$ \\
\hline
\end{tabular}




\section{Table A-3}

Loss of Power to the Switchyard (Sorted by Risk Reduction Worth)

\begin{tabular}{|l|l|l|l|l|l|l|}
\hline \multicolumn{1}{|c|}{ Event Name } & Probability & \multicolumn{1}{|c|}{ Fussel- } & Birnbaum & \multicolumn{1}{|c|}{$\begin{array}{c}\text { Risk } \\
\text { Reduction } \\
\text { Worth }\end{array}$} & $\begin{array}{c}\text { Risk } \\
\text { Achievement } \\
\text { Worth }\end{array}$ & \multicolumn{1}{|c|}{ Description } \\
\hline EAM-DIS-CO-1611D & $8.88 \mathrm{E}-05$ & $4.29 \mathrm{E}-01$ & $1.00 \mathrm{E}+00$ & 1.751 & 483 & SSST disconnect FTRC \\
\hline EAM-TRN-LP-SSST & $4.30 \mathrm{E}-05$ & $2.08 \mathrm{E}-01$ & $1.00 \mathrm{E}+00$ & 1.262 & 483 & $\begin{array}{l}\text { SSST failure during accident } \\
\text { sequence }\end{array}$ \\
\hline EAC-TRN-TM-SSST & $3.10 \mathrm{E}-05$ & $1.50 \mathrm{E}-01$ & $1.00 \mathrm{E}+00$ & 1.176 & 483 & SSST transformer path fails \\
\hline EAM-CRB-OC-1611G & $2.40 \mathrm{E}-05$ & $1.16 \mathrm{E}-01$ & $1.00 \mathrm{E}+00$ & 1.131 & 483 & SSST ground FTRO \\
\hline EAM-SWY-FO-SSST & $1.37 \mathrm{E}-05$ & $6.62 \mathrm{E}-02$ & $1.00 \mathrm{E}+00$ & 1.071 & 483 & $\begin{array}{l}\text { Maint error failure of SSST/161-kV } \\
\text { switchyard }\end{array}$ \\
\hline EAM-SWY-FO-ALL & $2.74 \mathrm{E}-06$ & $1.32 \mathrm{E}-02$ & $1.00 \mathrm{E}+00$ & 1.013 & 483 & $\begin{array}{l}\text { Maint error failure of 345-kV and 161- } \\
\text { kV switchyard }\end{array}$ \\
\hline EAM-CRB-CF-04\&06 & $2.40 \mathrm{E}-06$ & $1.16 \mathrm{E}-02$ & $1.00 \mathrm{E}+00$ & 1.012 & 483 & OCB 1604/OCB 1606 FTRC CCF \\
\hline EAM-CRB-CF-2\&4\&6 & $1.20 \mathrm{E}-06$ & $5.80 \mathrm{E}-03$ & $1.00 \mathrm{E}+00$ & 1.006 & 483 & OCB-1602/1604/1606 FTRC CCF \\
\hline EAM-TRN-LP-T2 & $7.68 \mathrm{E}-05$ & $2.55 \mathrm{E}-04$ & $6.88 \mathrm{E}-04$ & 1 & 4.32 & Autotransformer T2 failure \\
\hline
\end{tabular}




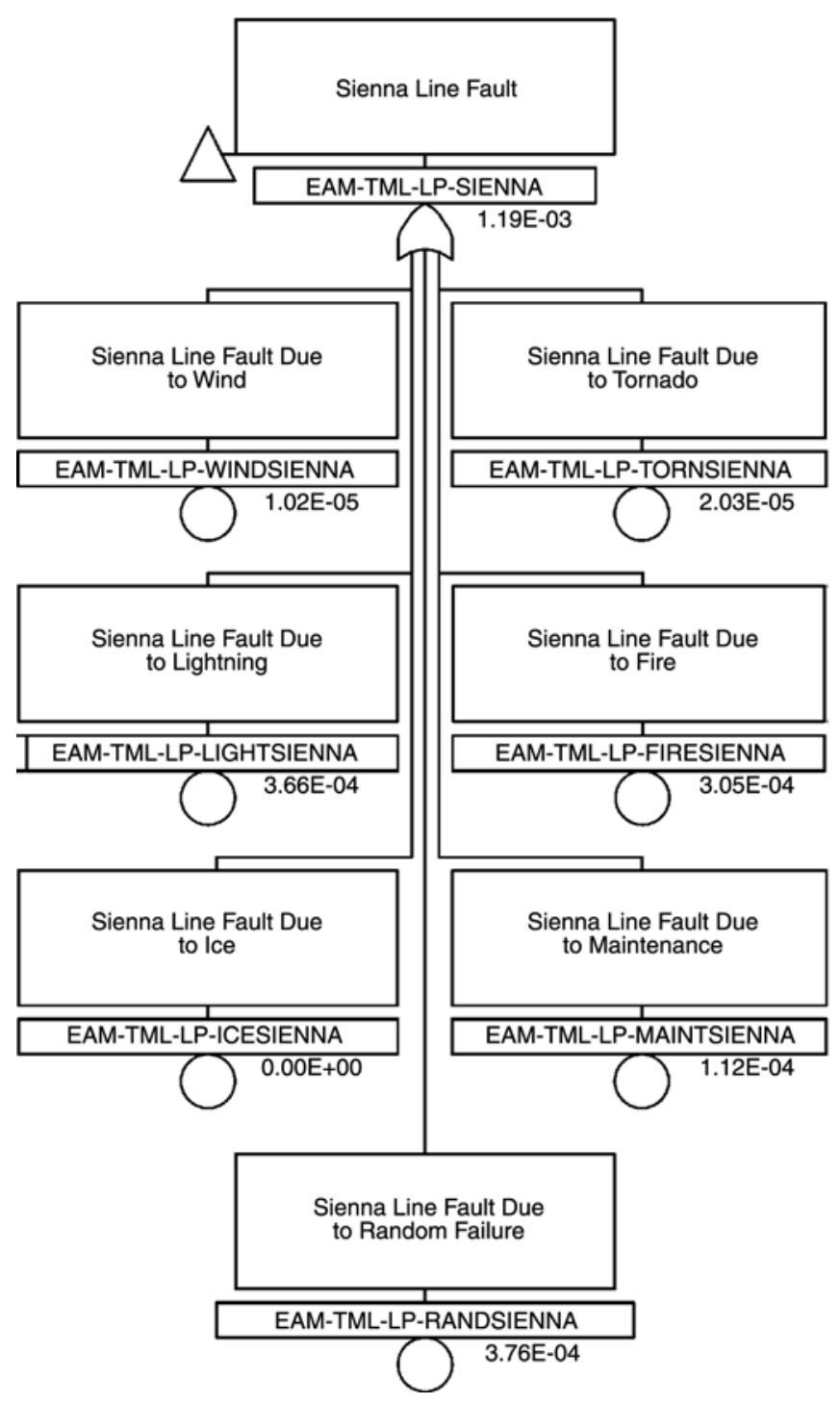

Figure A-4

Expansion of Basic Event into Fault Tree for Transmission Line Fault

\section{A.3 Development of the Grid Performance Model}

The previous section described the development of a fault tree for a switchyard model. The interface with the grid in that model shows only the probability of the connecting lines being available or faulted. It does not model the performance of the grid. The grid is a complex interconnected system that is virtually impossible to model using normal fault tree methods. The linearity of system modeling is lost as soon as the line from the plant switchyard reaches the next substation. The circular logic problem previously discussed regarding the switchyard ring bus is multiplied to an unmanageable magnitude. This is where the capability of the state estimator and contingency-analysis program is used. The state estimator is refreshing its data frequently and reevaluating contingencies every 10 minutes. It maintains a dynamic model of actual grid performance. 
It is now necessary to incorporate input from the state estimator into the fault tree model. The pilot plant switchyard model now contains three major fault tree sections in relation to the grid. There are the original sections to evaluate the $161-\mathrm{kV}$ and the $345-\mathrm{kV}$ power availability. A new section was created to model the $69-\mathrm{kV}$ availability. The $69-\mathrm{kV}$ is relatively independent because it is supplied from another utility and supplies emergency power through the ESST. The 161-kV and the $345-\mathrm{kV}$ are closely related because the autotransformer directly connects the two switchyards and both supply the SSST.

The contingencies previously identified and listed in Table 3-1 in Section 3.3 provide the basic input to the grid performance model. There are two fundamental groups of contingencies. One determines conditions at the SSST, and the other at the ESST. The ESST receives power from only the 69-kV grid and will therefore be added to that section of the model. The SSST receives power from either the $345-\mathrm{kV}$ switchyard or the $161-\mathrm{kV}$ grid. The location of this input is therefore a little more complex.

To properly incorporate the SSST contingencies, it is necessary to consider what the failed contingencies signify. Most of the SSST contingencies evaluate both the 345-kV grid and the $161-\mathrm{kV}$ grid simultaneously. As long as the autotransformer is in service, the two grids are connected at pilot plant's $161-\mathrm{kV}$ switchyard. If the contingency indicates a low voltage at this point, both sources of power are inadequate. The only exception to this is the SSST 2 contingency. This contingency assumes the loss of the autotransformer and is evaluating only the capability of the $161-\mathrm{kV}$ line. The placement of the various contingencies is illustrated in the figures that follow.

Figures A-1 through A-3 showed the original sections of the switchyard fault tree. Figures A-5, A-6, A-7, and A-8 show the modifications to the top portions of these fault trees to incorporate the new input. Figures A-5 through A-7 correspond to the previous original sections of the fault tree. Figure A-8 shows the new 69-kV tree.

The inputs from the contingencies were placed at high levels in the fault tree. They are located next to events such as failure of the SSST and ESST. The contingencies, when they solve at reduced voltages, determine that insufficient power is available at the respective transformers to maintain the required voltage. They are therefore similar to a failure of the service transformer and are placed under the same "OR" gates. SSST 2, however, because it considers only the capability of the 161-kV line, is added at that section of the tree. The figures show the following additional events.

- Two events added to the gate for "No Power at Switchyard” (Figure A-5):

- Transmission lines inadequate per state estimator

- State estimator solving at reduced voltage

- Two events added to the gate for "No Power from 161-kV Line” (Figure A-6):

- 161-kV transmission line inadequate per state estimator

- State estimator solving at reduced voltage 
- Two events included to the gate for "No Power from 69-kV Line” (Figure A-8):

- 69-kV transmission line inadequate per state estimator

- State estimator solving at reduced voltage for $69-\mathrm{kV}$ line

When the state estimator solves at voltages of $3880 \mathrm{~V}$ or less, it is predicting that voltage at the transformer will be inadequate, and a loss of off-site power will occur. When it solves at voltages from $3880 \mathrm{~V}$ to $3950 \mathrm{~V}$, it is not predicting a failure. It is, however, indicating grid degradation. Although voltage recovery is likely under this condition, there is still increased probability that further degradation and loss of off-site power could occur. The first set of gates will therefore cause the monitor to predict a certain loss of off-site power while the second set will only predict an increase in its probability.

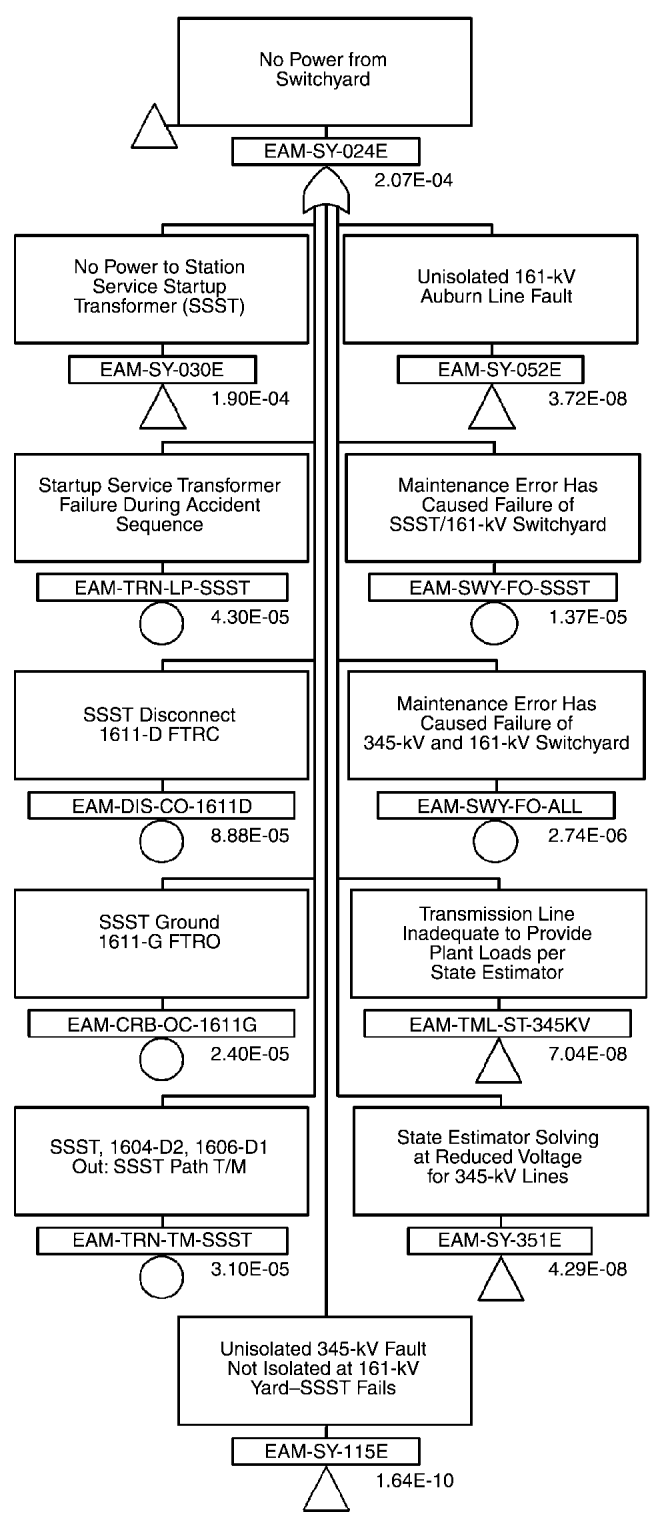

Figure A-5

Modified Switchyard Fault Tree for Accident Mitigation 


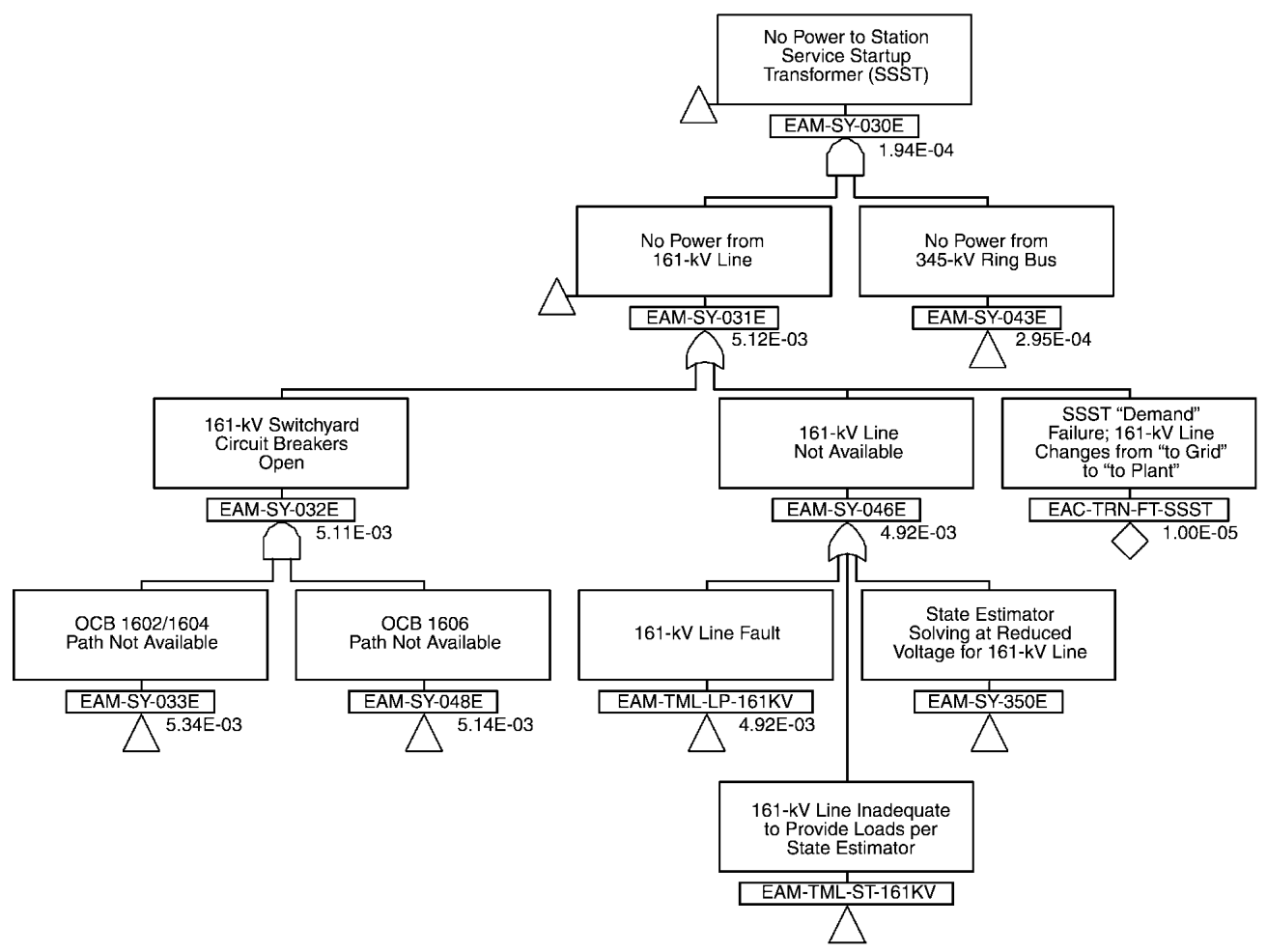

Figure A-6

Modified Fault Tree for 161-kV Power to SSST

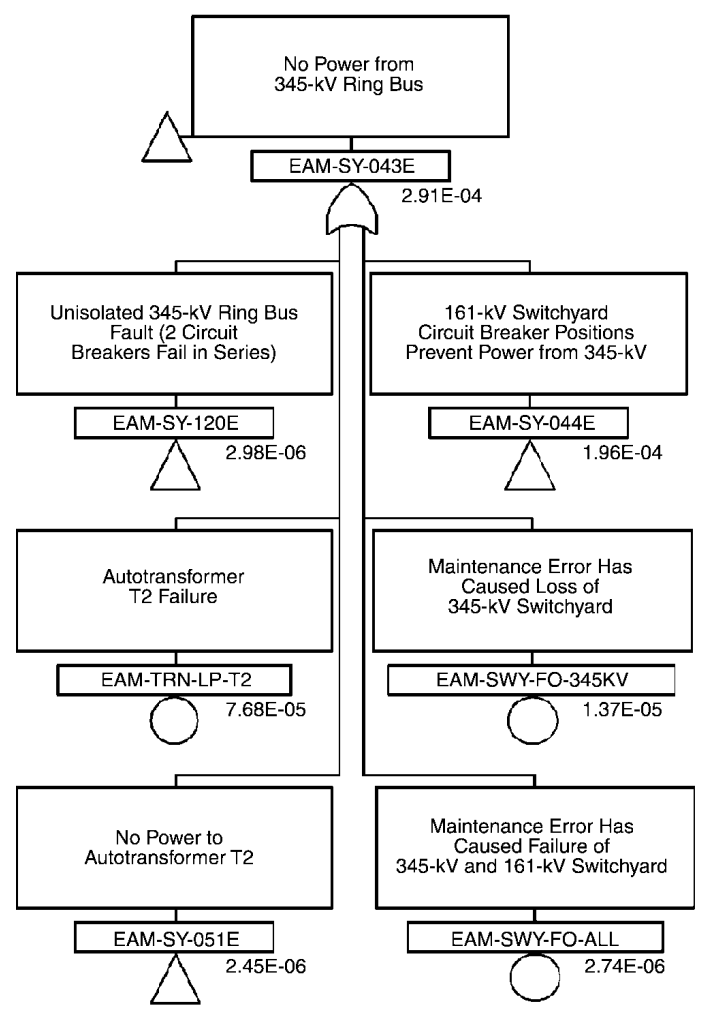

Figure A-7

Fault Tree for Availability of 345-kV Power 


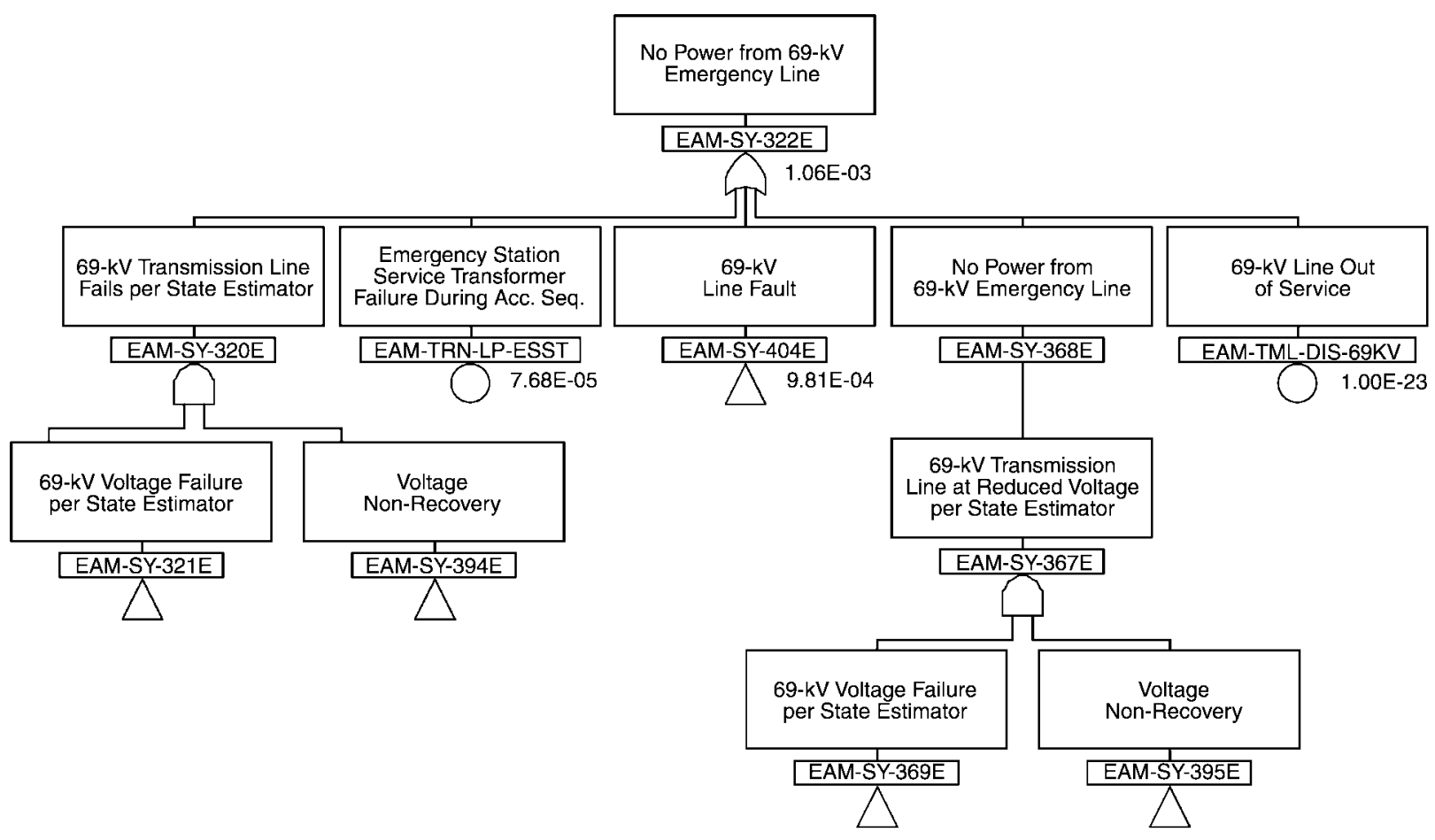

Figure A-8

New Fault Tree for Availability of 69-kV Power

In order to assign a probability when the state estimator solves at a reduced voltage, a premise was used that, during reduced-voltage conditions, the likelihood of voltage recovery decreases with the degree of voltage drop predicted. The closer to normal operating voltage, the more likely voltage-control actions will succeed. It is assumed that the failure to recover probability is near zero at $4160 \mathrm{~V}$ and near one at $3600 \mathrm{~V}$. The $3600-\mathrm{V}$ level was based on the pilot plants engineer's recommendation that this voltage level would indicate a complete loss of grid power. The non-recovery probability at the normal voltage is based on the spurious actuation of the undervoltage devices. Based on these two endpoints, an exponential curve was developed as shown in Figure A-9. The upper section of this curve, above 3880, was used to assign the voltage non-recovery probabilities used in the model. 


\begin{tabular}{|c|c|c|}
\hline \multicolumn{2}{|c|}{$P(4160)=$} & $7.20 \mathrm{E}-05$ \\
\hline & $00)=$ & 0.999979 \\
\hline 3600.0 & 0.00002 & 0.99998 \\
\hline 3620.0 & 0.00020 & 0.9998 \\
\hline 3640.0 & 0.00200 & 0.998002 \\
\hline 3660.0 & 0.02000 & 0.980199 \\
\hline 3680.0 & 0.20000 & 0.818731 \\
\hline 3700.0 & 0.58750 & 0.555715 \\
\hline 3720.0 & 0.97500 & 0.377192 \\
\hline 3740.0 & 1.36250 & 0.25602 \\
\hline 3760.0 & 1.75000 & 0.173774 \\
\hline 3780.0 & 2.13750 & 0.117949 \\
\hline 3800.0 & 2.52500 & 0.080058 \\
\hline 3820.0 & 2.91250 & 0.05434 \\
\hline 3840.0 & 3.30000 & 0.036883 \\
\hline 3860.0 & 3.68750 & 0.025035 \\
\hline 3880.0 & 4.07500 & 0.016992 \\
\hline 3900.0 & 4.46250 & 0.011533 \\
\hline 3920.0 & 4.85000 & 0.007828 \\
\hline 3940.0 & 5.23750 & 0.005314 \\
\hline 3960.0 & 5.62500 & 0.003607 \\
\hline 3980.0 & 6.01250 & 0.002448 \\
\hline 4000.0 & 6.40000 & 0.001662 \\
\hline 4020.0 & 6.78750 & 0.001128 \\
\hline 4040.0 & 7.17500 & 0.000765 \\
\hline 4060.0 & 7.56250 & 0.00052 \\
\hline 4080.0 & 7.95000 & 0.000353 \\
\hline 4100.0 & 8.33750 & 0.000239 \\
\hline 4120.0 & 8.72500 & 0.000162 \\
\hline 4140.0 & 9.11250 & 0.00011 \\
\hline 4160.0 & 9.5 & $7.49 \mathrm{E}-05$ \\
\hline
\end{tabular}

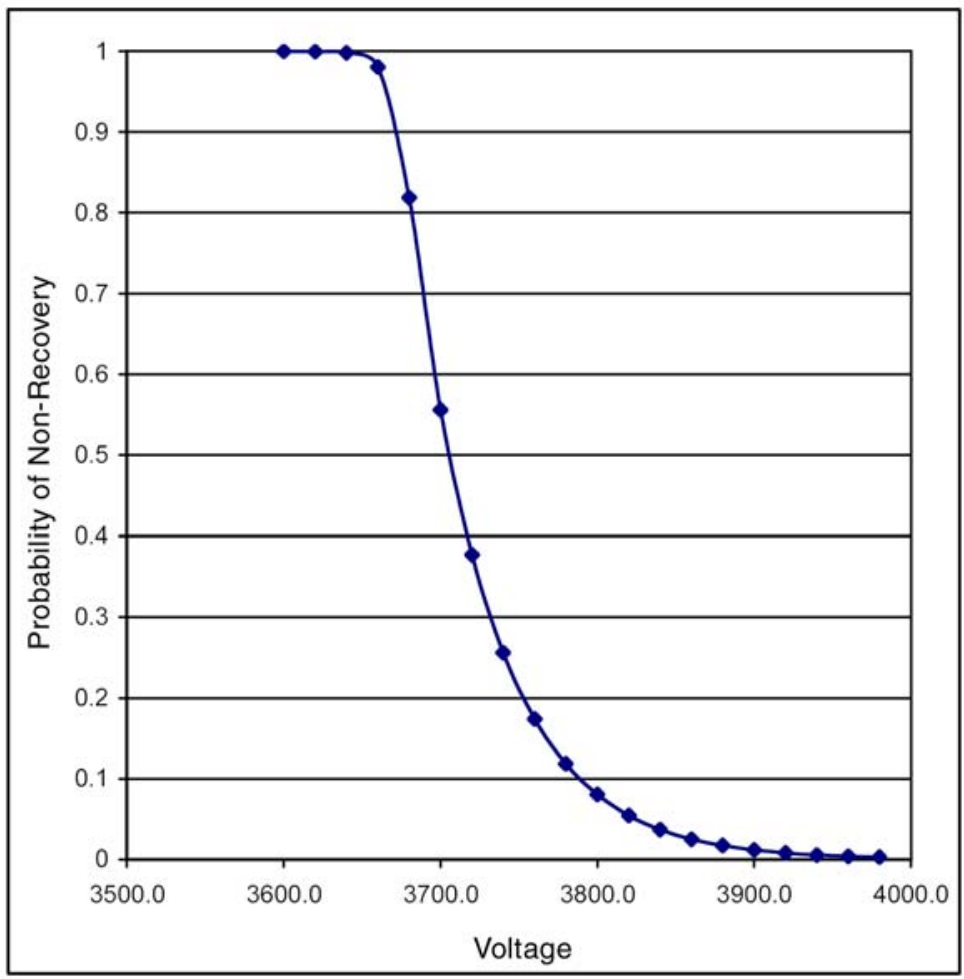

Figure A-9 Voltage Non-Recovery Probabilities

The insertion of the voltage failure and the non-recovery probabilities are shown in Figures A-10 through A-14. These figures show only the development of the SSST contingencies, but the other contingencies were developed in a similar manner.

Figure A-10 shows the input to the voltage failure "OR" gate. The input can be simply summarized as all of the contingencies except SSST 2. SSST 2 is not included in this gate because it assumes the failure of the autotransformer and is therefore evaluating only the capability of the $161-\mathrm{kV}$ line. It is therefore placed in the $161-\mathrm{kV}$ section of the fault tree. It is the only contingency that is used in the 161-kV section. All of the ESST contingencies are placed in the $69-\mathrm{kV}$ section of the model.

Figure A-11 shows how each of the contingencies is represented by a house event and is combined with a basic event that the voltage solves at 3880 or less. When both events are true, this represents a loss of off-site power. All house events are set to false for use in the grid monitor. The monitor will be used to set the events as appropriate for actual conditions. This figure shows the contingency SSST 1.

Figure A-11 shows the contingency that assumes that the system is intact. If this contingency solves at low voltage, only a plant trip would be required to cause a loss of off-site power. Therefore, only the contingency and the low voltage are input to the "AND" gate. Figure A-12 shows the development of contingency SSST 3. This contingency is the failure of the 
Monroeville line in addition to the plant trip. Therefore, another event, representing loss of power from the Monroeville line, is also input to the "AND” gate. Figure A-13 shows the modeling that represents the line's loss of power. This gate requires the additional failure prior to loss of off-site power.

Finally, Figure A-14 shows the modeling of the voltage recovery when the contingencies solve at greater than $3880 \mathrm{~V}$. At the left, the voltage failure event is the same collection of contingencies as shown in Figure A-10. The right side of the tree shows the inclusion of the voltage nonrecovery probabilities. House events represent the reduced voltage at which the contingency has solved and basic events provide the probabilities.

With the inclusion of all of the contingencies, the switchyard model is now ready for use in the grid monitor, which is described in Section 3.6 of this report.

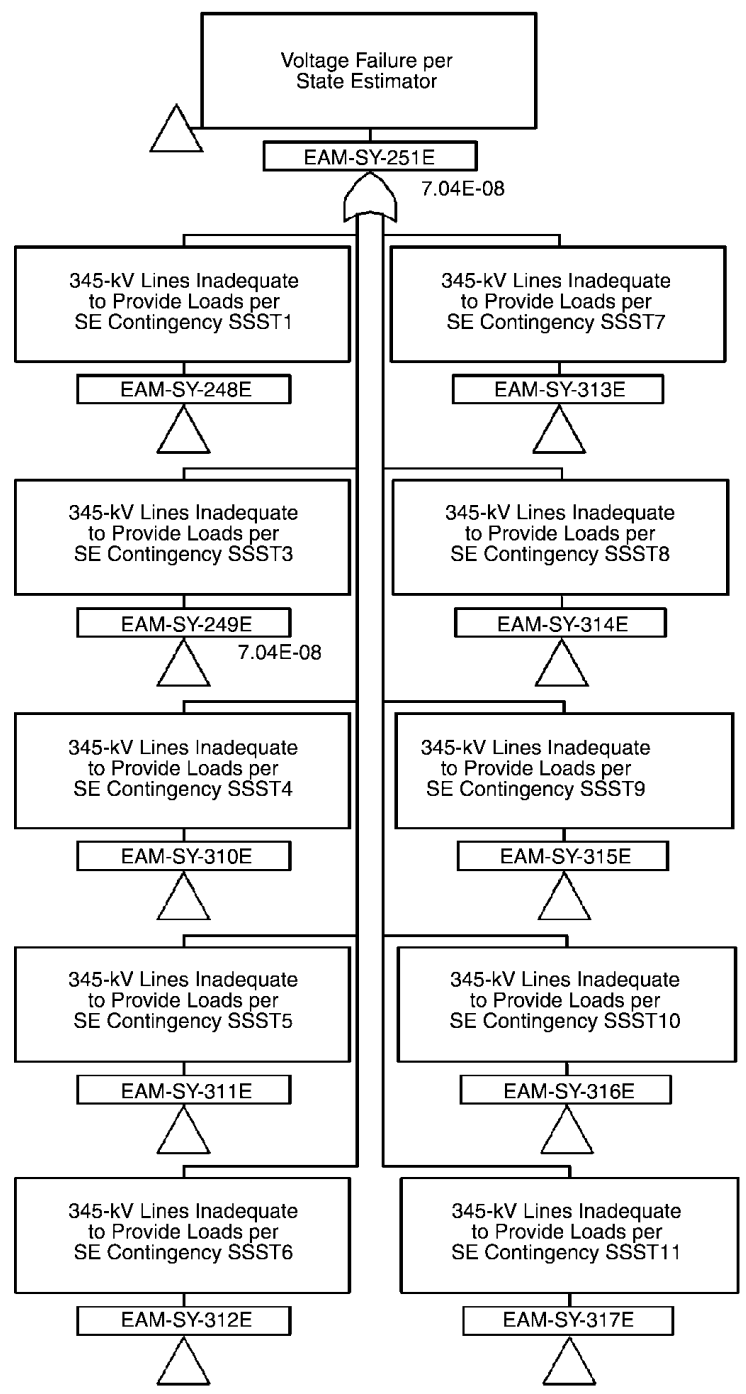

Figure A-10

Voltage Failure per State Estimator 


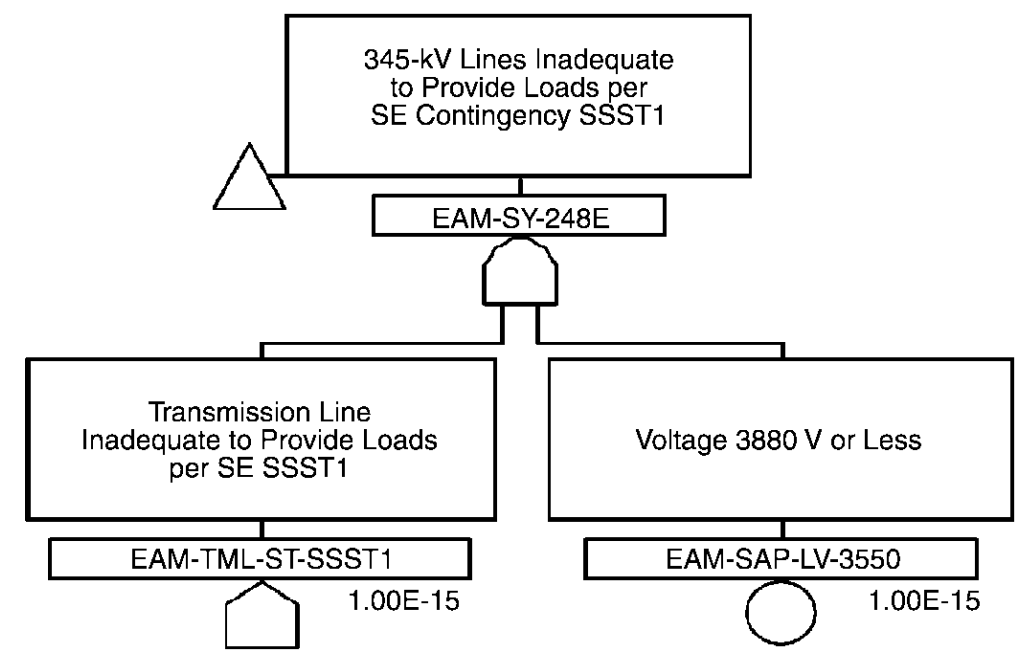

Figure A-11

Contingency SSST 1 Solves at Less Than $3880 \mathrm{~V}$

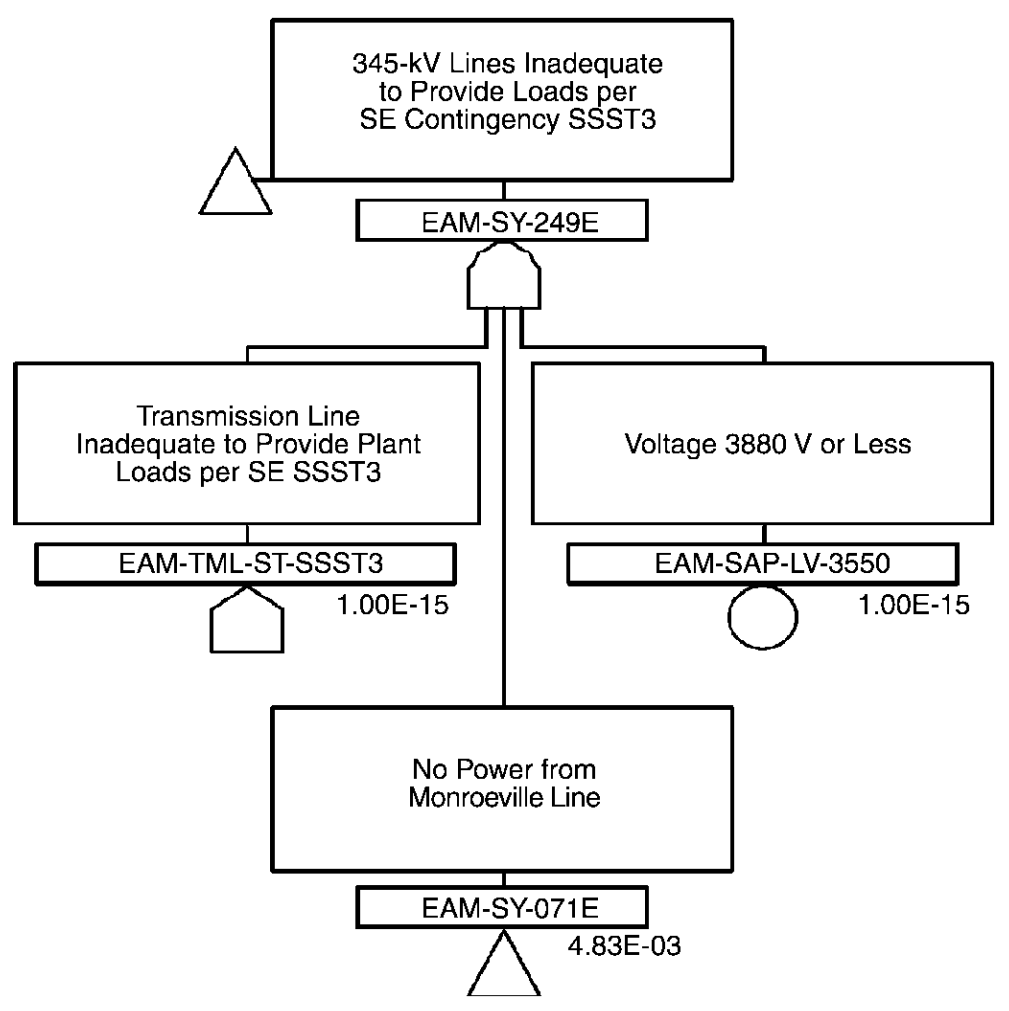

Figure A-12

Contingency SSST 3 Solves at Less Than 3880 V 
Detailed Development of Switchyard Fault Tree

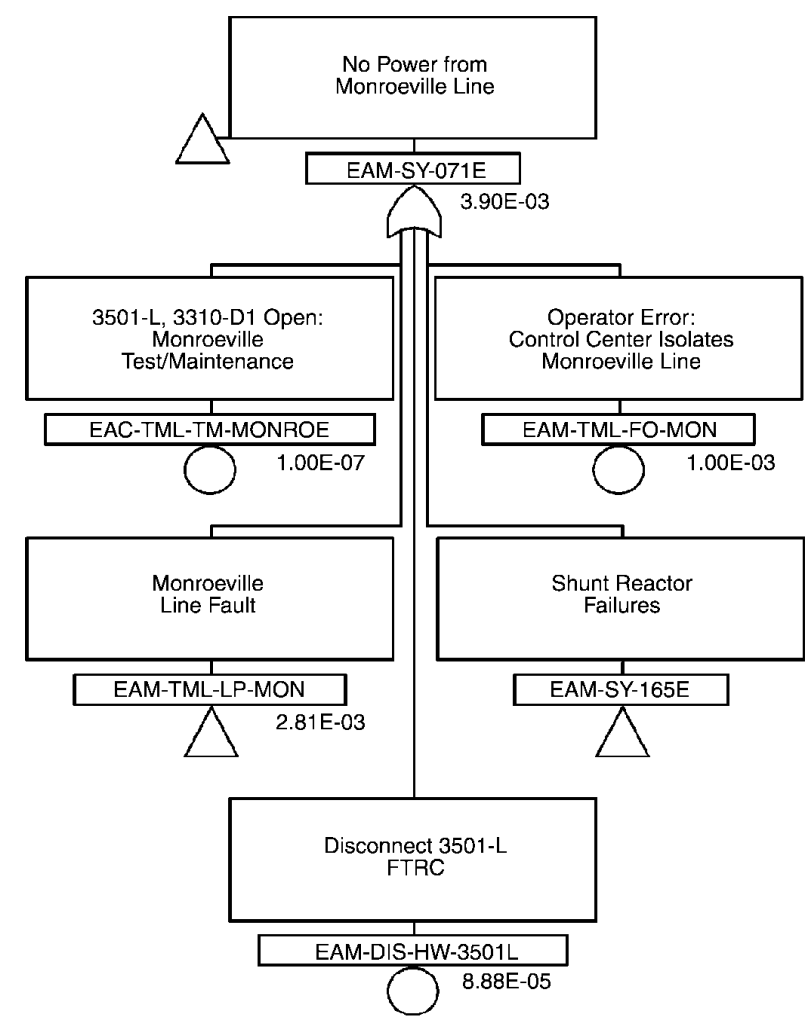

Figure A-13

No Power from Monroeville Line

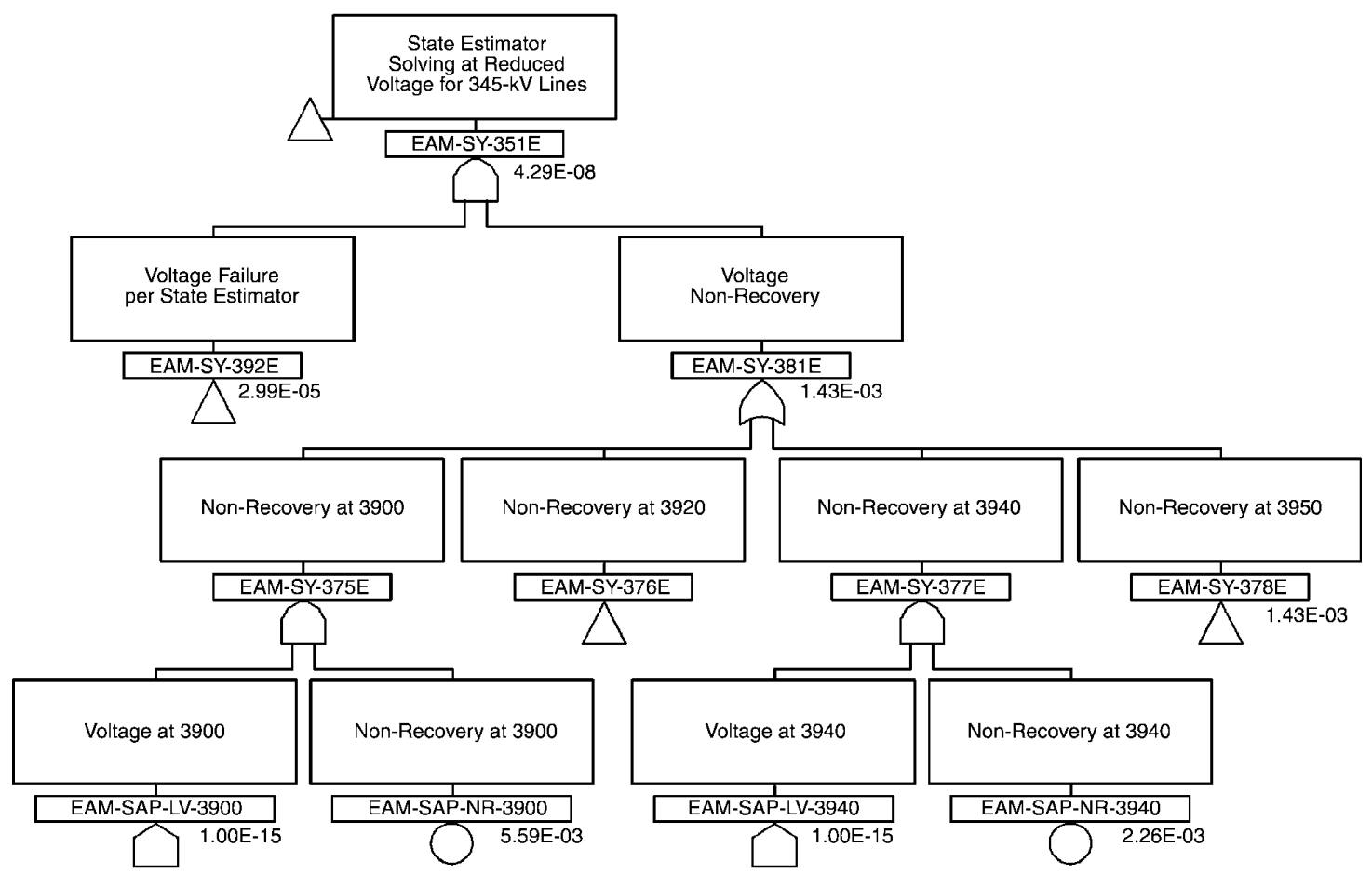

Figure A-14

Reduced Voltage per State Estimator 


\section{TRANSMISSION LINE FAILURE RATES}

In phase I of this project, generic data were used for the line failure probabilities. A search of the Internet discovered a transmission power quality project study being performed by Electrotek Concepts [5]. Preliminary data from various utilities had been gathered as part of the project. A bar graph of the data in events per hundred miles per year was presented on the Web page for transmission voltages of $69 \mathrm{kV}, 110$ to $138 \mathrm{kV}, 220$ to $230 \mathrm{kV}$, and 440 to $500 \mathrm{kV}$. The events were split into various cause groups. Although the actual values were not specified on the chart, it was possible to scale the chart and arrive at approximate values for the various failures.

Phase I used the data only for 500-kV lines. This phase required data for $69 \mathrm{kV}, 161 \mathrm{kV}$, and $345 \mathrm{kV}$. Although there are not directly applicable voltages for the $161-\mathrm{kV}$ and $345-\mathrm{kV}$ lines, it was decided to use the $110-\mathrm{kV}$ data for the $161-\mathrm{kV}$ lines and the $220-\mathrm{kV}$ data for the $345-\mathrm{kV}$ lines. Because site-specific data need to be developed later, the use of these voltages was satisfactory for development purposes. The lower voltages are slightly more conservative because the number of events per year generally decreases with increasing transmission voltage.

Following in Tables B-1 through B-4 are the summaries of the values for the various groups for each of the four transmission voltages. More general groupings were then made. The events chosen that were considered to be possibly transient-induced were the "Undesired Relay Operation," "Switching Surge,” and “Overload.” These were grouped into a new category of "Transient-Related.” "Personnel Errors," "Line Equipment,” "Customer-Owned Equipment,” "Crane," and "Contractor Damage” were combined as "Maintenance." Those that could be related to specific predictable or knowable external events such as weather (lightning, wind, and so on) were left as separate items. All other events that were generally random, "Unknown," “Trees," “Airplane," “Other,” and so on were placed in a group called "Random.” Tables A-5 through A-13 show the final group probabilities for each of the voltages. No attempt was made to assign average outage duration to the events. The grid monitor is intended to show only the probability of the loss of off-site power. Recovery from the loss must be considered elsewhere. 
Transmission Line Failure Rates

Table B-1

Generic Line Failure Probabilities for 69-kV Lines

\begin{tabular}{|c|c|c|}
\hline Cause & $\begin{array}{c}\text { Events per Year } \\
\text { per } 100 \text { Miles }\end{array}$ & $\begin{array}{c}\text { Probability per Hour } \\
\text { per } 100 \text { Miles }\end{array}$ \\
\hline Wind & 3.84E-01 & 4.39E-05 \\
\hline Vehicle & 2.88E-01 & 3.29E-05 \\
\hline Vandalism & 4.12E-02 & 4.70E-06 \\
\hline Unknown & $2.31 E+00$ & 2.63E-04 \\
\hline Undesired relay operation & 7.82E-01 & 8.93E-05 \\
\hline Trees & 7.96E-01 & 9.09E-05 \\
\hline Switching surge & $0.00 E+00$ & $0.00 E+00$ \\
\hline Personnel error & $5.90 \mathrm{E}-01$ & $6.74 \mathrm{E}-05$ \\
\hline Overload & 5.49E-01 & 6.27E-05 \\
\hline Other weather & 3.02E-01 & $3.45 E-05$ \\
\hline Other & $1.78 \mathrm{E}-01$ & $2.04 \mathrm{E}-05$ \\
\hline Line equipment & $2.94 \mathrm{E}+00$ & 3.35E-04 \\
\hline Lightning & 1.83E+00 & 2.08E-04 \\
\hline Ice or snow & $1.78 \mathrm{E}-01$ & $2.04 \mathrm{E}-05$ \\
\hline Galloping conductor & 8.24E-02 & $9.40 \mathrm{E}-06$ \\
\hline Flood & 4.12E-02 & 4.70E-06 \\
\hline Fire & 4.12E-02 & $4.70 \mathrm{E}-06$ \\
\hline Customer-owned equipment & 4.12E-02 & $4.70 \mathrm{E}-06$ \\
\hline Crane & 5.49E-02 & 6.27E-06 \\
\hline Contractor damage & 2.88E-01 & 3.29E-05 \\
\hline Contamination & $2.75 \mathrm{E}-02$ & 3.13E-06 \\
\hline Animal & 2.06E-01 & 2.35E-05 \\
\hline Airplane & $0.00 E+00$ & $0.00 E+00$ \\
\hline Total & 11.94118 & 1.36E-03 \\
\hline
\end{tabular}

B-2 
Table B-2

Generic Line Failure Probabilities for $110-k V$ to $138-k V$ Lines

\begin{tabular}{|c|c|c|}
\hline Cause & $\begin{array}{l}\text { Events per Year per } \\
100 \text { Miles }\end{array}$ & $\begin{array}{l}\text { Probability per Hour } \\
\text { per } 100 \text { Miles }\end{array}$ \\
\hline Wind & 2.33E-01 & 2.66E-05 \\
\hline Vehicle & 9.61E-02 & 1.10E-05 \\
\hline Vandalism & 1.37E-02 & 1.57E-06 \\
\hline Unknown & $1.00 \mathrm{E}+00$ & 1.14E-04 \\
\hline Undesired relay operation & 2.33E-01 & 2.66E-05 \\
\hline Trees & 2.88E-01 & 3.29E-05 \\
\hline Switching surge & $0.00 \mathrm{E}+00$ & $0.00 \mathrm{E}+00$ \\
\hline Personnel error & 8.24E-02 & $9.40 \mathrm{E}-06$ \\
\hline Overload & $0.00 \mathrm{E}+00$ & $0.00 \mathrm{E}+00$ \\
\hline Other weather & 3.71E-01 & 4.23E-05 \\
\hline Other & 2.06E-01 & 2.35E-05 \\
\hline Line equipment & 3.16E-01 & 3.60E-05 \\
\hline Lightning & $1.96 \mathrm{E}+00$ & 2.24E-04 \\
\hline Ice or snow & 6.86E-02 & 7.83E-06 \\
\hline Galloping conductor & 4.12E-02 & 4.70E-06 \\
\hline Flood & $0.00 \mathrm{E}+00$ & $0.00 \mathrm{E}+00$ \\
\hline Fire & 6.86E-02 & 7.83E-06 \\
\hline Customer-owned equipment & 4.12E-02 & 4.70E-06 \\
\hline Crane & 9.61E-02 & 1.10E-05 \\
\hline Contractor damage & 4.12E-02 & 4.70E-06 \\
\hline Contamination & 1.92E-01 & 2.19E-05 \\
\hline Animal & 6.86E-02 & 7.83E-06 \\
\hline Airplane & $0.00 \mathrm{E}+00$ & $0.00 \mathrm{E}+00$ \\
\hline Total & 5.42 & 6.19E-04 \\
\hline
\end{tabular}


Table B-3

Generic Line Failure Probabilities for 220-kV to 230-kV Lines

\begin{tabular}{|c|c|c|}
\hline Cause & $\begin{array}{c}\text { Events per Year } \\
\text { per } 100 \text { Miles }\end{array}$ & $\begin{array}{l}\text { Probability per Hour } \\
\text { per } 100 \text { Miles }\end{array}$ \\
\hline Wind & 2.75E-02 & 3.13E-06 \\
\hline Vehicle & $0.00 \mathrm{E}+00$ & $0.00 \mathrm{E}+00$ \\
\hline Vandalism & $0.00 E+00$ & $0.00 E+00$ \\
\hline Unknown & 6.04E-01 & 6.89E-05 \\
\hline Undesired relay operation & 1.10E-01 & $1.25 \mathrm{E}-05$ \\
\hline Trees & $1.24 \mathrm{E}-01$ & 1.41E-05 \\
\hline Switching surge & 2.75E-02 & 3.13E-06 \\
\hline Personnel error & 4.12E-02 & 4.70E-06 \\
\hline Overload & 1.37E-02 & 1.57E-06 \\
\hline Other weather & 8.24E-02 & 9.40E-06 \\
\hline Other & 9.61E-02 & 1.10E-05 \\
\hline Line equipment & 4.12E-02 & 4.70E-06 \\
\hline Lightning & $1.02 \mathrm{E}+00$ & 1.16E-04 \\
\hline Ice or snow & $0.00 \mathrm{E}+00$ & $0.00 \mathrm{E}+00$ \\
\hline Galloping conductor & 5.49E-02 & 6.27E-06 \\
\hline Flood & $0.00 \mathrm{E}+00$ & $0.00 \mathrm{E}+00$ \\
\hline Fire & 9.61E-02 & 1.10E-05 \\
\hline Customer-owned equipment & 1.37E-02 & 1.57E-06 \\
\hline Crane & $0.00 \mathrm{E}+00$ & $0.00 \mathrm{E}+00$ \\
\hline Contractor damage & $0.00 \mathrm{E}+00$ & $0.00 \mathrm{E}+00$ \\
\hline Contamination & 4.12E-02 & 4.70E-06 \\
\hline Animal & 2.75E-02 & 3.13E-06 \\
\hline Airplane & 8.24E-02 & 9.40E-06 \\
\hline Total & 2.5 & 2.85E-04 \\
\hline
\end{tabular}

B-4 
Table B-4

Generic Line Failure Probabilities for $440-k V$ to $500-k V$ Lines

\begin{tabular}{|c|c|c|}
\hline Cause & $\begin{array}{c}\text { Events per Year } \\
\text { per } 100 \text { Miles }\end{array}$ & $\begin{array}{c}\text { Probability per Hour } \\
\text { per } 100 \text { Miles }\end{array}$ \\
\hline Wind & 1.37E-02 & 1.57E-06 \\
\hline Vehicle & 0.00E+00 & $0.00 \mathrm{E}+00$ \\
\hline Vandalism & $0.00 E+00$ & $0.00 E+00$ \\
\hline Unknown & $2.20 \mathrm{E}-01$ & 2.51E-05 \\
\hline Undesired relay operation & $4.12 \mathrm{E}-02$ & 4.70E-06 \\
\hline Trees & 6.86E-02 & 7.83E-06 \\
\hline Switching surge & 4.12E-02 & $4.70 \mathrm{E}-06$ \\
\hline Personnel error & 9.61E-02 & $1.10 \mathrm{E}-05$ \\
\hline Overload & $2.75 \mathrm{E}-02$ & $3.13 E-06$ \\
\hline Other weather & $2.75 \mathrm{E}-02$ & 3.13E-06 \\
\hline Other & 1.65E-01 & 1.88E-05 \\
\hline Line equipment & 5.49E-02 & $6.27 E-06$ \\
\hline Lightning & 4.94E-01 & 5.64E-05 \\
\hline Ice or snow & $0.00 E+00$ & $0.00 E+00$ \\
\hline Galloping conductor & $0.00 E+00$ & $0.00 E+00$ \\
\hline Flood & $0.00 E+00$ & $0.00 E+00$ \\
\hline Fire & 4.12E-01 & 4.70E-05 \\
\hline Customer-owned equipment & $0.00 E+00$ & $0.00 E+00$ \\
\hline Crane & $0.00 E+00$ & $0.00 E+00$ \\
\hline Contractor damage & $0.00 E+00$ & $0.00 E+00$ \\
\hline Contamination & 2.75E-02 & 3.13E-06 \\
\hline Animal & $0.00 E+00$ & $0.00 E+00$ \\
\hline Airplane & 5.49E-02 & $6.27 E-06$ \\
\hline Total & 1.74 & 1.99E-04 \\
\hline
\end{tabular}


Table B-5

Grouped Generic Line Failure Probabilities for 69-kV Lines

\begin{tabular}{|l|l|l|}
\hline \multicolumn{1}{|c|}{ Cause } & \multicolumn{1}{|c|}{$\begin{array}{c}\text { Events per Year } \\
\text { per 100 Miles }\end{array}$} & \multicolumn{1}{|c|}{$\begin{array}{c}\text { Probability per Hour } \\
\text { per 100 Miles }\end{array}$} \\
\hline Transient-related & $1.33 \mathrm{E}+00$ & $1.52 \mathrm{E}-04$ \\
\hline Wind & $3.84 \mathrm{E}-01$ & $4.39 \mathrm{E}-05$ \\
\hline Maintenance & $3.91 \mathrm{E}+00$ & $4.47 \mathrm{E}-04$ \\
\hline Other weather & $3.02 \mathrm{E}-01$ & $3.45 \mathrm{E}-05$ \\
\hline Lightning & $1.83 \mathrm{E}+00$ & $2.08 \mathrm{E}-04$ \\
\hline Ice & $1.78 \mathrm{E}-01$ & $2.04 \mathrm{E}-05$ \\
\hline Fire & $4.12 \mathrm{E}-02$ & $4.70 \mathrm{E}-06$ \\
\hline Contamination & $2.75 \mathrm{E}-02$ & $3.13 \mathrm{E}-06$ \\
\hline Random & $3.94 \mathrm{E}+00$ & $4.50 \mathrm{E}-04$ \\
\hline Total & 11.9 & $1.36 \mathrm{E}-03$ \\
\hline
\end{tabular}

Table B-6

Grouped Generic Line Failure Probabilities for 110-kV to 138-kV Lines

\begin{tabular}{|c|c|c|}
\hline Cause & $\begin{array}{c}\text { Events per Year per } \\
100 \text { Miles }\end{array}$ & $\begin{array}{c}\text { Probability per Hour per } \\
100 \text { Miles }\end{array}$ \\
\hline Transient-related & 2.33E-01 & 2.66E-05 \\
\hline Wind & 2.33E-01 & 2.66E-05 \\
\hline Maintenance & 5.76E-01 & $6.58 \mathrm{E}-05$ \\
\hline Other weather & 3.71E-01 & 4.23E-05 \\
\hline Lightning & $1.96 \mathrm{E}+00$ & 2.24E-04 \\
\hline Ice & 6.86E-02 & 7.83E-06 \\
\hline Fire & 6.86E-02 & 7.83E-06 \\
\hline Contamination & 1.92E-01 & 2.19E-05 \\
\hline Random & $1.72 \mathrm{E}+00$ & $1.96 \mathrm{E}-04$ \\
\hline Total & 5.42 & 6.19E-04 \\
\hline
\end{tabular}

B-6 
Table B-7

Grouped Generic Line Failure Probabilities for 220-kV to 230-kV Lines

\begin{tabular}{|l|l|l|}
\hline \multicolumn{1}{|c|}{ Cause } & \multicolumn{1}{|c|}{$\begin{array}{c}\text { Events per Year } \\
\text { per 100 Miles }\end{array}$} & \multicolumn{1}{|c|}{$\begin{array}{c}\text { Probability per Hour } \\
\text { per 100 Miles }\end{array}$} \\
\hline Transient-related & $1.51 \mathrm{E}-01$ & $1.72 \mathrm{E}-05$ \\
\hline Wind & $2.75 \mathrm{E}-02$ & $3.13 \mathrm{E}-06$ \\
\hline Maintenance & $9.61 \mathrm{E}-02$ & $1.10 \mathrm{E}-05$ \\
\hline Other weather & $8.24 \mathrm{E}-02$ & $9.40 \mathrm{E}-06$ \\
\hline Lightning & $1.02 \mathrm{E}+00$ & $1.16 \mathrm{E}-04$ \\
\hline Ice & $0.00 \mathrm{E}+00$ & $0.00 \mathrm{E}+00$ \\
\hline Fire & $9.61 \mathrm{E}-02$ & $1.10 \mathrm{E}-05$ \\
\hline Contamination & $4.12 \mathrm{E}-02$ & $4.70 \mathrm{E}-06$ \\
\hline Random & $9.88 \mathrm{E}-01$ & $1.13 \mathrm{E}-04$ \\
\hline Total & 2.50 & $2.85 \mathrm{E}-04$ \\
\hline
\end{tabular}

Table B-8

Grouped Generic Line Failure Probabilities for 440-kV to 500-kV Lines

\begin{tabular}{|l|l|l|}
\hline \multicolumn{1}{|c|}{ Cause } & \multicolumn{1}{|c|}{$\begin{array}{c}\text { Events per Year } \\
\text { per 100 Miles }\end{array}$} & \multicolumn{1}{|c|}{$\begin{array}{c}\text { Probability per Hour } \\
\text { per 100 Miles }\end{array}$} \\
\hline Transient-related & $1.10 \mathrm{E}-01$ & $1.25 \mathrm{E}-05$ \\
\hline Wind & $1.37 \mathrm{E}-02$ & $1.57 \mathrm{E}-06$ \\
\hline Maintenance & $1.51 \mathrm{E}-01$ & $1.72 \mathrm{E}-05$ \\
\hline Other weather & $2.75 \mathrm{E}-02$ & $3.13 \mathrm{E}-06$ \\
\hline Lightning & $4.94 \mathrm{E}-01$ & $5.64 \mathrm{E}-05$ \\
\hline Ice & $0.00 \mathrm{E}+00$ & $0.00 \mathrm{E}+00$ \\
\hline Fire & $4.12 \mathrm{E}-01$ & $4.70 \mathrm{E}-05$ \\
\hline Contamination & $2.75 \mathrm{E}-02$ & $3.13 \mathrm{E}-06$ \\
\hline Random & $5.08 \mathrm{E}-01$ & $5.80 \mathrm{E}-05$ \\
\hline Total & 1.74 & $1.99 \mathrm{E}-04$ \\
\hline
\end{tabular}




Export Control Restrictions

Access to and use of EPRI Intellectual Property is granted with the specific understanding and requirement that responsibility for ensuring full compliance with all applicable U.S. and foreign export laws and regulations is being undertaken by you and your company. This includes an obligation to ensure that any individual receiving access hereunder who is not a U.S. citizen or permanent U.S. resident is permitted access under applicable U.S. and foreign export laws and regulations. In the event you are uncertain whether you or your company may lawfully obtain access to this EPRI Intellectual Property, you acknowledge that it is your obligation to consult with your company's legal counsel to determine whether this access is lawful. Although EPRI may make available on a case by case basis an informal assessment of the applicable U.S. export classification for specific EPRI Intellectual Property, you and your company acknowledge that this assessment is solely for informational purposes and not for reliance purposes. You and your company acknowledge that it is still the obligation of you and your company to make your own assessment of the applicable U.S. export classification and ensure compliance accordingly. You and your company understand and acknowledge your obligations to make a prompt report to EPRI and the appropriate authorities regarding any access to or use of EPRI Intellectual Property hereunder that may be in violation of applicable U.S. or foreign export laws or regulations.

\section{About EPRI}

EPRI creates science and technology solutions for the global energy and energy services industry. U.S. electric utilities established the Electric Power Research Institute in 1973 as a nonprofit research consortium for the benefit of utility members, their customers, and society. Now known simply as EPRI, the company provides a wide range of innovative products and services to more than 1000 energyrelated organizations in 40 countries. EPRI's multidisciplinary team of scientists and engineers draws on a worldwide network of technical and business expertise to help solve today's toughest energy and environmental problems.

EPRI. Electrify the World
Program: 1009662

Nuclear Power

(C) 2004 Electric Power Research Institute (EPRI), Inc. All rights reserved. Electric Power Research Institute and EPRI are registered service marks of the Electric Power Research Institute, Inc. EPRI. ELECTRIFY THE WORLD is a service mark of the Electric Power Research Institute, Inc. 